\title{
Renewable Diesel from Algal Lipids: An Integrated Baseline for Cost, Emissions, and Resource Potential from a Harmonized Model
}

Coordinating Authors: Ryan Davis, ${ }^{3}$ Daniel Fishman, ${ }^{2}$ Edward D. Frank, ${ }^{1}$ Mark S. Wigmosta ${ }^{4}$

Contributing Authors: Andy Aden, ${ }^{3}$ Andre M. Coleman, ${ }^{4}$ Philip T. Pienkos, ${ }^{3}$ Richard J. Skaggs, ${ }^{4}$ Erik R. Venteris, ${ }^{4}$ Michael Q. Wang ${ }^{1}$

${ }^{1}$ Argonne National Laboratory, Argonne, Illinois

${ }^{2}$ BCS, Incorporated, Laurel, Maryland

${ }^{3}$ National Renewable Energy Laboratory, Golden, Colorado

${ }^{4}$ Pacific Northwest National Laboratory, Richland, Washington

Argonne is a U.S. Department of Energy laboratory managed by UChicago Argonne, LLC under contract DE-AC02-06CH11357.

NREL is a national laboratory of the U.S. Department of Energy, Office of Energy Efficiency \& Renewable Energy, operated by the Alliance for Sustainable Energy, LLC, under contract DE-AC36-08G028308.

Pacific Northwest National Laboratory is operated by Battelle for the United States Department of Energy under contract DE-AC05-76RL01830.

Technical Report

ANL/ESD/12-4

NREL/TP-5100-55431

PNNL-21437

June 2012

Prepared for the U.S. Department of Energy Biomass Program 


\section{Recommended Citation:}

ANL; NREL; PNNL. (June 2012). Renewable Diesel from Algal Lipids: An Integrated Baseline for Cost, Emissions, and Resource Potential from a Harmonized Model. ANL/ESD/12-4; NREL/TP-5100-55431; PNNL-21437. Argonne, IL: Argonne National Laboratory; Golden, CO: National Renewable Energy Laboratory; Richland, WA: Pacific Northwest National Laboratory.

\section{NOTICE}

This report was prepared as an account of work sponsored by an agency of the United States government. Neither the United States government nor any agency thereof, nor the Alliance for Sustainable Energy, LLC, nor UChicago Argonne, LLC, nor Battelle Memorial Institute, nor any of their employees, makes any warranty, express or implied, or assumes any legal liability or responsibility for the accuracy, completeness, or usefulness of any information, apparatus, product, or process disclosed, or represents that its use would not infringe privately owned rights. Reference herein to any specific commercial product, process, or service by trade name, trademark, manufacturer, or otherwise does not necessarily constitute or imply its endorsement, recommendation, or favoring by the United States government or any agency thereof. The views and opinions of authors expressed herein do not necessarily state or reflect those of the United States government or any agency thereof, or UChicago Argonne, LLC, or the Alliance for Sustainable Energy, LLC, or Battelle Memorial Institute.

Available electronically at http://www.osti.gov/bridge

Available for a processing fee to U.S. Department of Energy and its contractors, in paper, from:

U.S. Department of Energy

Office of Scientific and Technical Information

P.O. Box 62

Oak Ridge, TN 37831-0062

phone: 865.576.8401

fax: 865.576 .5728

email: mailto:reports@adonis.osti.gov

Available for sale to the public, in paper, from:

U.S. Department of Commerce National Technical Information Service 5285 Port Royal Road Springfield, VA 22161 phone: 800.553.6847 fax: 703.605.6900

email: orders@ntis.fedworld.gov online ordering: http://www.ntis.gov/help/ordermethods.aspx 


\section{Table of Contents}

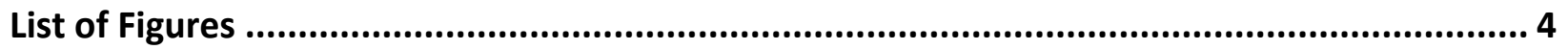

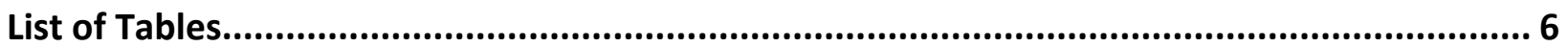

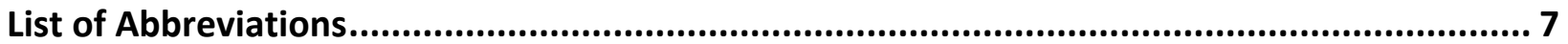

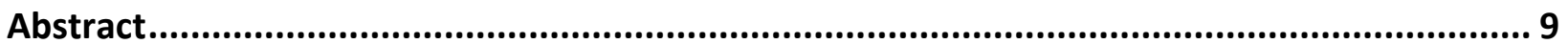

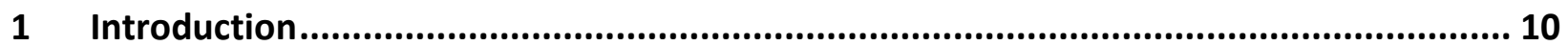

$1.1 \quad$ Algal Biofuels Technology Development ........................................................................... 10

$1.2 \quad$ Integrated Baseline vs. State of Technology and Design Case......................................... 11

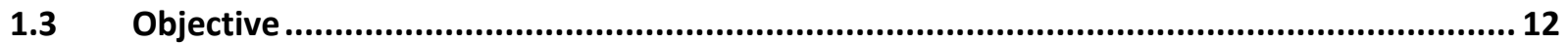

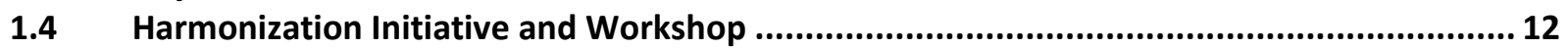

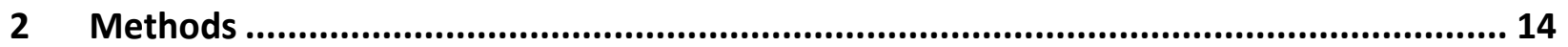

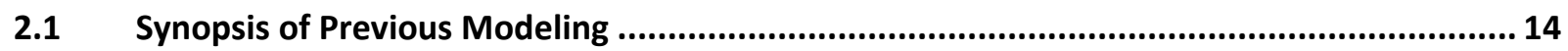

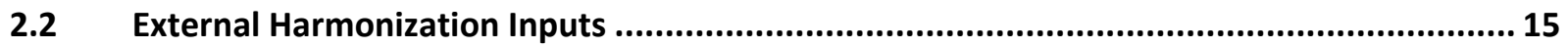

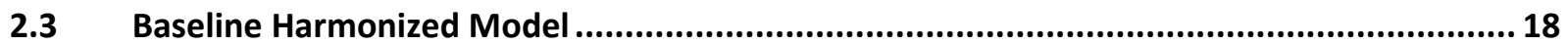

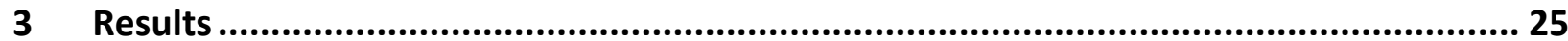

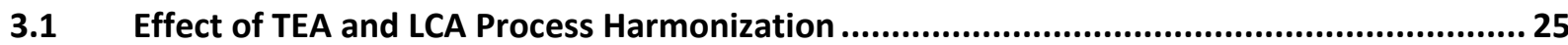

3.2 Definition of the 5 BGY Resource Assessment Scenario................................................... 29

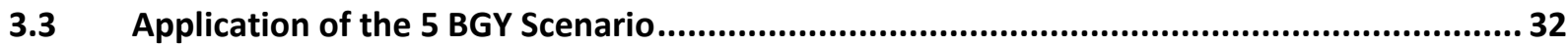

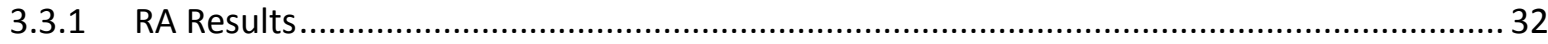

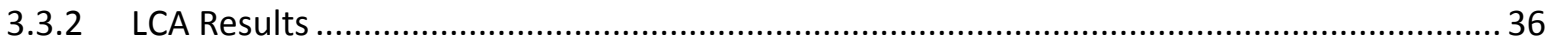

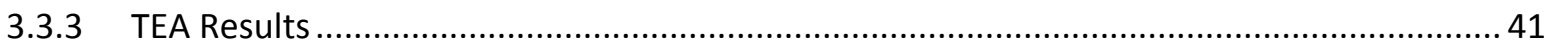

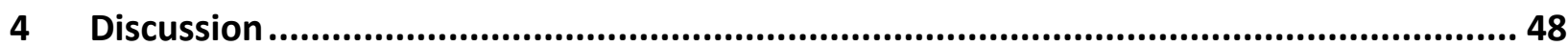

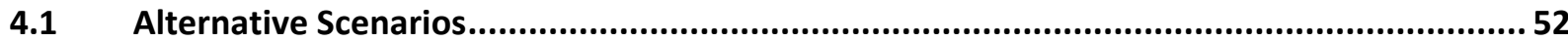

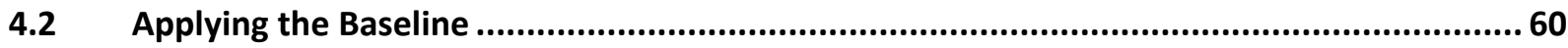

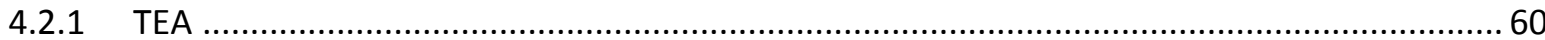

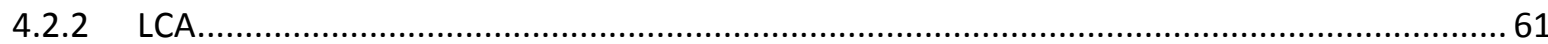

5 Conclusions and Research Opportunities ............................................................. 63

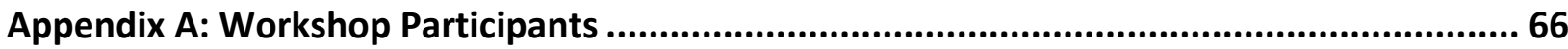

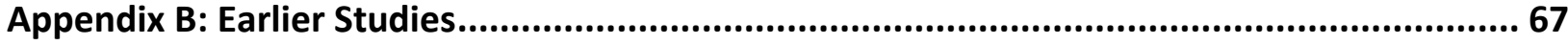

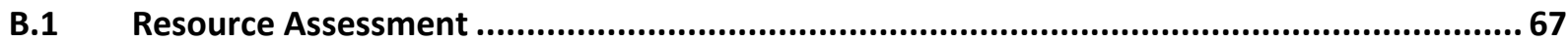

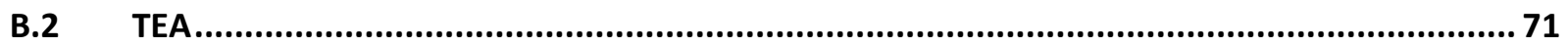

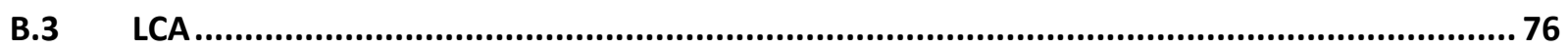

Appendix C: TEA Cost Details for Harmonized Model (5BGY, year-average case) .................. 80

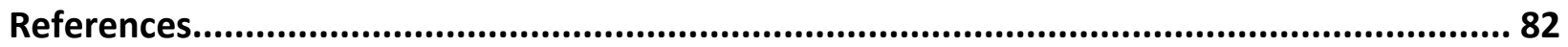




\section{List of Figures}

Figure 2.1a: Schematic of baseline process used in FY 2011 TEA analysis. ............................................. 15

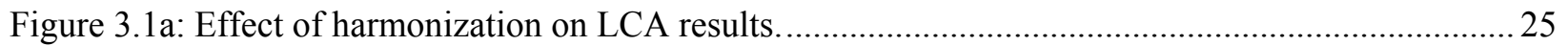

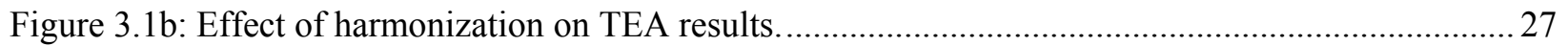

Figure 3.1c: Effect of lipid fraction and productivity on GHG emissions..............................................2 28

Figure 3.1d: Effect of lipid fraction and productivity on diesel selling price ........................................28

Figure 3.2a: Original RA modeling output: mean annual biofuel production (L/ha-year) under current technology plotted at the centroid of each pond facility. 29

Figure 3.2b: Determination of sufficient freshwater availability through comparison of unit farm consumptive water demand with available mean annual freshwater water supply (plotted at the centroid of each pond facility).

Figure 3.3.1a: Map showing the annual flow through each 6 digit HUC watershed, the water consumption rate for sites with freshwater supply, and the location of farm sites that cannot be supplied with freshwater under the existing constraints 33

Figure 3.3.1b: Map showing the annual production per 10 unit farms in gallons per year.

Figure 3.3.1c: Cumulative site prioritization in 10\% intervals based on production, lipid transport, and freshwater pumping cost. 35

Figure 3.3.2a: Distribution of WTW GHG emissions in the 5 BGY scenario 38

Figure 3.3.2b: Expanded view of Figure 3.4a for spring, summer, and fall. .38

Figure 3.3.2c: Site distribution of WTW GHG emissions after averaging over spring, summer, and fall

Figure 3.3.2d: The geographic distribution of sites with fall GHG emissions exceeding (red) or below (green) $68,000 \mathrm{gCO}_{2} \mathrm{e} / \mathrm{mmBTU}$.

Figure 3.3.2e: WTW GHG emissions as a function of location after averaging spring, summer, and fall.

Figure 3.3.2f: WTW LCA results for (A) fossil energy, (B) petroleum energy , (C) total energy including renewable, and (D) GHG emissions for algal renewable diesel in the 5 BGY scenario

Figure 3.3.3a: Grouping of RA 5 BGY unit farms into representative sites for TEA modeling.

Figure 3.3.3b: Year-average and season-dependent cost results based on 5 BGY scenario.

Figure 3.3.3c: Capital and operating cost contributions to the $\$ 18.63 /$ gal diesel price associated with the year-average output of the 5 BGY scenario.

Figure 3.3.3d: Capital and operating expenses associated with the year-average output of the 5 BGY scenario ( $\$ 18.63 /$ gal diesel).

Figure 3.3.3e: Diesel selling price and seasonal productivity range for each representative site group.

Figure 3.3.3f: Diesel selling price for year-round versus winter shut-down operating modes for the $5 \mathrm{BGY}$ scenario. 
Figure 4a. Seasonal biomass productivity for selected water temperature and solar intensity model input parameter sets.

Figure 4b: Cost sensitivity tornado plot for process changes, excluding lipid content and algal

productivity.

Figure 4.1a: Locations of unit farms required to meet the 5 BG biofuel production target under:

(a) the baseline scenario (upper left), (b) a doubling of production at each site (upper right), and

(c), a tripling of production at each site (lower left).

Figure 4.1b: Life-cycle GHG emissions for four alternative scenarios.

Figure 4.1c: Life-cycle GHG emissions as a function of lipid fraction and productivity when several emission-reducing options are considered. .56

Figure 4.1d: Diesel selling price for four alternative scenarios.

Figure 4.1e: Diesel selling price as a function of lipid fraction when several cost-reducing options are considered.

Figure B.1: Mean annual biofuel production (L/ha-year) under current technology plotted at the centroid of each pond facility.....

Figure B.2: Mean annual water requirements (L/ha-year) for microalgae biofuels production using current technology plotted at the centroid of each pond facility.

Figure B.3: Mean annual microalgae biofuel water requirements per liter of biofuel produced

(L water/L biofuel) plotted at the centroid of each pond facility..... 70

Figure B.4: Annual cumulative biofuel production as a function of (a) cumulative water use and (b) cumulative land use. .71

Figure B.5: Schematic of baseline process used in FY 2011 TEA analysis. .73

Figure B.6: FY 2011 TEA baseline economics for TAG and diesel production. .75

Figure B.7: FY 2011 TEA sensitivity analysis; baseline MSP = \$9.28/gal TAG. .76

Figure B.8: System boundary defining the LCA. 78

Figure B.9: Schematic of the algae and lipid production model. 78

Figure B.10: LCA sensitivity analysis. .79 


\section{List of Tables}

Table 2.2a: Relevant High-Level Pre-Harmonization Parameters Presented in the Workshop................. 17

Table 2.3a: TEA and LCA Harmonization Details............................................................................ 24

Table 3.3.1a: Mean Biomass, Oil Production, and Water Demand for Selected Sites ............................. 36

Table 3.3.2a: WTW Results for RD Production in the 5 BGY Scenario Averaged Over Spring,

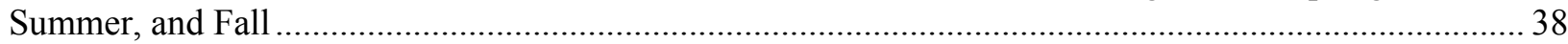

Table 3.3.3a: Average Productivity and Water Consumption Per Season for Each Site Group................ 42

Table 4a: Land and Water Demand Associated With Increased Productivity ........................................ 53

Table 4.2a: Total Burdened Cost Contributions of Each Major Unit Operation, Associated with the Year-Average Output of the 5 BGY Scenario (\$18.63/gal diesel)................................................... 61

Table B.1: Summary of FY 2011 TEA Baseline Design Assumptions .................................................... 73

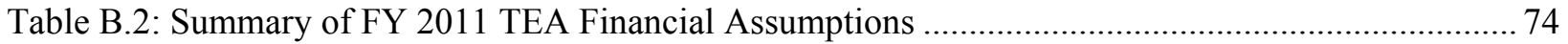




\section{List of Abbreviations}

$\mathrm{AD}$

ANL

APD

ASP

ASU/SABC

BAT

$\mathrm{BD}$

BGY

$\mathrm{CH}_{4}$

CHP

$\mathrm{CO}_{2}$

CONUS

COP

DAF

DAP

DDGS

DOE

EC

EERE

EISA

FCI

$\mathrm{g} / \mathrm{L}$

$\mathrm{gCO}_{2} \mathrm{e}$

GHG

GREET

ha

HDPE

$\mathrm{H}_{2} \mathrm{~S}$

HUC

IBR

IC

INL

ISBL
Anaerobic Digestion

Argonne National Laboratory

Algae Process Description Tool

Aquatic Species Program

Arizona State University/Sustainable Algal Biofuels Consortium

Biomass Assessment Tool

Biodiesel

Billion Gallons per Year

Methane

Combined Heat and Power

Carbon Dioxide

Contiguous United States

Cost of Production

Dissolved Air Flotation

Diammonium Phosphate

Distiller's Dried Grains with Solubles

U.S. Department of Energy

Electrocoagulation

Energy Efficiency and Renewable Energy

Energy Independence and Security Act of 2007

Fixed Capital Investment

Grams per Liter

Grams $\mathrm{CO}_{2}$ Equivalent

Greenhouse Gas

Greenhouse Gases, Regulated Emissions, and Energy Use in Transportation Model

Hectare

High-Density Polyethylene

Hydrogen Sulfide

Hydrological Unit Code

Integrated Biorefineries

Indirect Capital Costs

Idaho National Laboratory

Inside Boundary Limit 
List of Abbreviations

\begin{tabular}{|c|c|}
\hline KW & Kilowatts \\
\hline $\mathrm{kWh}$ & Kilowatt Hours \\
\hline LCA & Life-Cycle Analysis \\
\hline LEA & Lipid Extracted Algae \\
\hline LHV & Lower Heating Value \\
\hline LLE & Liquid-Liquid Extraction \\
\hline Ls & Light Saturation Constant \\
\hline LS & Low Sulfur Diesel \\
\hline MEA & Monoethanolamine \\
\hline MGY & Million Gallons per Year \\
\hline MMBTU & Million British Thermal Units \\
\hline mmol & Millimole \\
\hline MSP & Minimum Selling Price \\
\hline $\mathrm{N}_{2} \mathrm{O}$ & Nitrous Oxide \\
\hline NAABB & National Alliance for Advanced Biofuels and Bioproducts \\
\hline NATCARB & National Carbon Sequestration Database and Geographic Information System \\
\hline NREL & National Renewable Energy Laboratory \\
\hline ORNL & Oak Ridge National Laboratory \\
\hline PBRs & Photobioreactors \\
\hline PNNL & Pacific Northwest National Laboratory \\
\hline psi & Pounds per Square Inch \\
\hline PTW & Pump-to-Wheels \\
\hline $\mathrm{R} \& \mathrm{D}$ & Research and Development \\
\hline RA & Resource Assessment \\
\hline $\mathrm{RD}$ & Renewable Diesel \\
\hline RDD\&D & Research, Development, Demonstration \& Deployment \\
\hline RFS & Renewable Fuel Standard \\
\hline SNL & Sandia National Laboratory \\
\hline TAG & Triacylglycerides \\
\hline TDC & Total Direct Costs \\
\hline TEA & Techno-Economic Analysis \\
\hline USGS & U.S. Geological Survey \\
\hline WTP & Well-to-Pump \\
\hline WTW & Well-to-Wheel \\
\hline
\end{tabular}




\section{Abstract}

The U.S. Department of Energy's Biomass Program has begun an initiative to obtain consistent quantitative metrics for algal biofuel production in order to establish an "integrated baseline" by harmonizing and combining the Program's national resource assessment (RA), techno-economic analysis (TEA), and life-cycle analysis (LCA) models. The baseline attempts to represent a plausible near-term production scenario with freshwater microalgae growth, extraction of lipids, and conversion via hydroprocessing to produce a renewable diesel (RD) blendstock. Energy and nutrients are recycled from the residual biomass using onsite anaerobic digestion.

Differences in the prior TEA and LCA models were reconciled (harmonized) and the RA model was used to prioritize and select the most favorable consortium of sites that supports production of 5 billion gallons per year (BGY) of RD. Aligning the TEA and LCA models produced slightly higher costs and emissions compared to the pre-harmonized results. However, after then applying the productivities predicted by the RA model $\left(13 \mathrm{~g} / \mathrm{m}^{2} / \mathrm{d}\right.$ on annual average vs. $25 \mathrm{~g} /$ $\mathrm{m}^{2} / \mathrm{d}$ in the original models), the integrated baseline resulted in markedly higher costs and emissions. This may represent a conservative baseline given the resulting lipid productivity of roughly $1,000 \mathrm{gal} / \mathrm{acre} / \mathrm{year}$ compared to some claims on the order of 1,500-2,000 gal/acre/year for near-term potential. Given such uncertainties, in conjunction with process uncertainties associated with a dearth of data on downstream operations (e.g., harvesting, extraction, spent biomass utilization, and nutrient recycling performance), the results of this harmonization effort are more appropriately viewed as a quantitative, explicit performance baseline rather than a "state of technology."

The relationship between performance (cost and emissions) and either productivity or lipid fraction was found to be non-linear, especially at lower values. This made the performance season-dependent and caused over-sizing of the facility capacity for portions of the year, increasing costs. Increasing productivity and lipid fraction alone was insufficient to achieve cost and emission targets; however, combined with lower energy, less expensive alternative technology scenarios, emissions and costs were substantially reduced. The baseline shows that performance estimates based on annual average productivity are inaccurate and suggest temporally and spatially explicit computations allow for more rigorous analysis of these dynamic systems.

The integrated baseline reported here, and the associated modeling tools, establish a vehicle for quantifying the cost, emissions, and resource potential consequences of emerging data from algal biofuel research and development activities. It is envisioned that this initiative will be ongoing with opportunities for data validation and parameter/process improvements based upon shared community data. 


\section{Introduction}

\subsection{Algal Biofuels Technology Development}

Algal biofuels may offer great potential in contributing to the nation's renewable energy future, as well as helping to meet the Renewable Fuel Standard (RFS) in the Energy Independence and Security Act of 2007 (EISA). Algae oils can be a suitable feedstock for high-energy density renewable biofuels to power both light- and heavy-duty vehicles, as well as jet and marine engines. However, the conclusions of the 2010 National Algal Biofuels Technology Roadmap indicate that a great deal of research, development, deployment, and demonstration must still take place to both improve performance and reduce the risk and uncertainty in deploying any given algal biofuel process (DOE, 2010).

In order to meet that need, the Department of Energy (DOE) funds a diverse portfolio of research, development, demonstration, and deployment (RDD\&D) and supporting analyses to accelerate the deployment of commercially viable algal biofuels. DOE's Office of Energy Efficiency and Renewable Energy (EERE) Biomass Program works with industry, academia, and national laboratory partners on a portfolio of activities that span the biofuels supply chain and technology readiness scale. Through research, development, and demonstration efforts geared toward the development of integrated biorefineries, the Biomass Program is helping transform the nation's renewable and abundant biomass resources into commercially viable, highperformance biofuels, bioproducts, and biopower.

The Department's efforts, and the efforts of other federal agencies, private entrepreneurs, and established industry, build on the foundation established by the Aquatic Species Program (ASP). In the 20-year history of the ASP, many proof-of-concept designs for algal biofuels were developed, implemented, and validated. In the time from the 1996 close-out of the ASP to the initiation of a new Algae Platform within the Department's Biomass Program, new technologies were developed. In 2008, the Biomass Program began scoping activities to understand the critical technical barriers to affordable and scalable algae-based biofuels with the National Algal Biofuels Technology Roadmap Workshop. The resulting Roadmap identified technology challenges to overcome in accelerating the development of a scalable, affordable, and sustainable national algal biofuels industry. These challenges fall into three main areas: algae feedstock production and supply, algae feedstock processing and conversion, and supporting infrastructure for siting and distribution. A key conclusion of the Workshop was that the integration of these three rather separate disciplines into a rigorous systems modeling framework would be "crucial in guiding research efforts along select pathways that offer the most opportunity to practically enable a viable and sustainable algae-based biofuels and co-products industry." The Roadmap specifically identified a number of purposes and goals that can be accomplished with algal biofuels techno-economic based models, including tradeoffs among different systems, economic and sustainability impacts of research and development (R\&D), consequences and constraints of different systems, informing R\&D and business development decisions, and providing insight to accelerate scale-up. These goals closely align with those already in place at the Biomass Program, which has a long history of using techno-economic based models in support of developing cellulosic biofuels.

Subsequent to the Roadmap, four research consortia were selected to begin a national applied research program (see DE-FOA-0000123) to address many of the technical challenges for 
successful large-scale algae biomass production. Due to various constraints on appropriations, one consortium was selected for full funding, with \$48 million in federal government money and additional cost share of more than $\$ 15$ million. Three additional consortia were selected at a reduced scope, with a federal government award size of \$6-\$9 million and additional cost share from \$1.5-\$4 million. The goal of the consortia initiative is to foster a multi-institutional and multi-disciplinary approach to accelerate algal biofuels technology development by creating public/private partnerships between universities, national laboratories, and industry. Each consortium addresses many facets of the algae biofuels supply chain and is constructed to facilitate technology transfer between researchers and commercial partners using pre-negotiated intellectual property arrangements.

As the consortia initiative was started, the core bioenergy modeling capabilities of the national labs were identified as being necessary to address the key role of integration identified in the Roadmap. Projects were initiated at Argonne National Laboratory (ANL), the National Renewable Energy Laboratory (NREL), and the Pacific Northwest National Laboratory (PNNL) to extend traditional cellulosic biofuels analysis capabilities to algal biofuels. These projects seek to understand the state of specific biofuel pathways and focus appropriate resources to better understand and identify ways to advance the environmental, economic, and social sustainability of algal biofuels. Additional demonstration and deployment activities are being conducted with industrial partners through the Biomass Program's Integrated Biorefineries (IBR) Platform. These activities will construct integrated algae biorefinery facilities to cultivate algae and produce fuels and products at the pilot (nominally 1 ton of $\mathrm{CO}_{2}$ feedstock per day) and demonstration (nominally 50 tons of $\mathrm{CO}_{2}$ feedstock per day) scale.

\subsection{Integrated Baseline vs. State of Technology and Design Case}

The Biomass Program utilizes design case and state of technology analyses to assess and guide Program activities. A design case analyzes a biofuel technology by integrating well-developed experimental data with detailed process engineering models. The design case identifies technical barriers for the specific technology under consideration to determine where R\&D could improve production costs and scale. State of technology analysis surveys a spectrum of design cases to predict cost and scale achievable with the "best" technology and data currently available at the time of the analysis. The results can be compared with Program objectives for cost and scale.

This report discusses a baseline analysis. Insufficient data exist to support an end to end experimentally-verified process engineering model of algal biofuel production without resorting to theoretical processes, so the present algal biofuel analysis is not yet a fully rigorous design analysis. Also, many claims are made in the algae R\&D community about processes that would revolutionize algal biofuel production - including proprietary high-yield organisms to low-cost, high-throughput dewatering systems, to efficient extraction systems - but data required to simulate those processes are proprietary. While every effort is made in the present analysis to select technology and performance assumptions representative of currently-available technologies and supporting data, it is important to caution that the modeling efforts are still largely theoretical, thus representing a baseline or benchmark scenario rather than a state of algal biofuel technology. Nevertheless the integrated baseline reported here, formed from a synthesis of resource assessment (RA), techno-economic analysis (TEA), and life-cycle analysis (LCA) models using available public knowledge does provide a quantitative framework for assessing progress and gaps in algal biofuel development. 
Introduction

\subsection{Objective}

The Biomass Program believes that to achieve its goal of accelerating the deployment of commercially viable algal biofuels, a concerted effort toward harmonizing the treatment of disparate technology developments in its strategic plans is needed. This "Harmonization Initiative" will take what is known about engineering algal cultivation systems and leverage the core competencies of the national laboratories in strategic biofuels analysis with input from innovative algal R\&D and industrial pilot and demonstration practitioners to develop an integrated baseline that can focus RDD\&D efforts towards the critical technical targets necessary to achieve scalable algal biofuel technologies. The Algae Model Harmonization Initiative seeks to define a baseline algal biofuel production scenario with model-based quantitative metrics for cost, scale-up potential, and sustainability. The primary goal of the Initiative is to harmonize the three DOE modeling efforts in TEA, LCA, and RA around consistent, well-understood, and reasonable assumptions that are publically available. The objective is not harmonization per se; however, through the process of harmonizing, it will become possible to study tensions and tradeoffs between environmental, economic, and social implications of algal biofuels. Furthermore, comparing differences in the independently developed models will suggest where the major uncertainties are in the integrated model set.

Another objective of the Harmonization Initiative is to gather feedback, information, insights, and new ideas from algae production and processing experts and stakeholders to iteratively refine an integrated algae baseline definition, reduce uncertainty, and to explore alternatives for process improvements. The Initiative will identify key information and direction needed to develop technical performance targets that can be used in the Biomass Program Multi-Year Program Plan. The work also seeks to quantify the consequences of alternate performance and cost assumptions. This is more of a system approach, relating inputs and outputs, than a comprehensive survey of emerging technology; however, some emerging technologies are discussed to illustrate how the study results may be used to assess alternative scenarios. Additionally, this work can inform the larger global debate on bioenergy analysis. The suite of analyses being discussed and undertaken in algal biofuels, as well as those in bioenergy in general, fit within the field of industrial ecology, where an active debate on the tools, challenges, and frameworks available and needed to move the community forward is taking place (see Davis et al., 2010 for discussion). The conclusions from the Harmonization Initiative will be relevant to both the immediate algal biofuel practitioners, as well as the larger industrial ecology community.

\subsection{Harmonization Initiative and Workshop}

The Harmonization Initiative was launched with a Program-sponsored workshop at the University of Arizona, Tucson, from November 30-December 1, 2011. The Workshop participants included Biomass Program staff, the modeling teams from ANL, NREL, and PNNL (i.e., Harmonization Working Group), representatives from the algae consortia, including the National Alliance for Advanced Biofuels and Bioproducts (NAABB), the Arizona State University (ASU)/Sustainable Algal Biofuels Consortium (SABC), and Cellana/Cornell, independent university researchers, integrated algae biorefinery developers, waste-water and algal biofuel industry representatives, and additional national lab modeling teams from Idaho National Laboratory (INL), Oak Ridge National Laboratory (ORNL), and Sandia National Laboratory (SNL). 
The Workshop format included in-depth presentations of RA, TEA, and LCA models. The assumptions, sensitivities, caveats, and unknowns were discussed. Significant time was spent in small group discussions about the current assumptions in the baseline models, possible new technologies, alternate pathways to consider, and barriers requiring further R\&D (i.e. the key parameters and sensitivities). The model presentations provided a framework for engaging the algae developers attending the Workshop and in critiquing the model approach. Round-table discussions were held, major issues were identified, and Workshop findings were recorded and partially vetted before adjourning.

The Workshop was divided into four modules: resource assessment, techno-economics, lifecycle analysis, and harmonization across the three disciplines. Discussions were focused on:

- Establishing a common understanding of each discipline and offering perspectives to improve specific parameters, process assumptions, and systems integration

- Identifying areas where harmonization needs to occur

- Proposing process improvements and emerging technologies that could offer performance targets for an integrated design case.

A fourth supplementary module included presentations on additional relevant topics.

An important caveat is that for this initiative, the modeling efforts supported by the Program can only use available (disclosed) data. Many companies and researchers claim performances substantially better than those assumed in the models, but detailed descriptions required to include them in a model are generally not available, nor are data supporting the claims. The scenario developed in harmonization, then, should be deemed conservative and likely underestimates the potential for algae; however, the framework will be useful to assess the implications for improved technologies when data are made available. The intention is that developers will see this framework as an aid for promoting their technologies and will choose to contribute data in the future. 


\section{Methods}

Following the Workshop, the Initiative proceeded by first harmonizing the analysis scenarios and parameters in the original TEA, LCA, and RA models to define a baseline scenario. The harmonized models were then used to determine steady-state cost, life-cycle energy consumption, life-cycle greenhouse gas (GHG) emissions, and resource utilization as a function of several key variables - namely productivity, lipid fraction, and nutrient recycle. Next, the RA model was used to estimate seasonal and spatial distributions of biomass production and water demand for the most optimal sites with sufficient freshwater supply that sum to a net production of 5 billion gallons per year (BGY) of renewable diesel. Five BGY was chosen as a minimum volume of algal biofuels that would contribute significantly to national goals. These distributions were then used to assess seasonal and annual TEA and LCA results.

\subsection{Synopsis of Previous Modeling}

This section briefly summarizes the algae pathway models as published prior to the current harmonization effort. Additional details are shown in Appendix B and in the original publications (Davis 2011, Frank 2011a, Wigmosta 2011). In brief, the TEA and LCA were originally based on a notional facility design that was sized to produce 10 million gallons per year (MGY) and contained an integrated system for algae cultivation, processing, and upgrading. Figure 2.1a displays the baseline algae production and processing pathway analyzed by the TEA. Algae are grown in open ponds, dewatered from 0.5 grams per liter $(\mathrm{g} / \mathrm{L})$ to $200 \mathrm{~g} / \mathrm{L}$ by settling, dissolved air flotation (DAF), and centrifugation. Cellular disruption by high-pressure homogenization is followed by a wet extraction process. Remnants, including lost solvent and unrecovered lipids, are sent to anaerobic digestion (AD) for energy and nutrient recycling. Energy recycling was accomplished by biogas combustion in a combined heat and power (CHP) system that was heat-integrated with the solvent recycle loop. Waste heat was sent to a steam turbine combined cycle to raise additional power. Extracted lipids were converted to renewable diesel (RD) by hydrotreating. AD solids (digestate) were disposed as waste. Brackish makeup water replaced losses to evaporation and blowdown. The pond design and cost $[\$ 34,000 /$ hectare (ha) in 2009-dollars] was based on analysis presented in Lundquist et al., 2011, namely unlined ponds sized at $4 \mathrm{ha} /$ pond and paddle-wheel mixing stations consuming an average of 2.0 kilowatts per hectare (KW/ha) (Lundquist 2011); this pond cost supersedes the original cost of $\$ 11,000 /$ ha (1996-dollars), as assumed in the Davis et al., 2011 publication noted above.

The LCA pathway was similar, but included a biogas cleanup step between the digester and CHP. The LCA considered both conversion to biodiesel (BD) by transesterification and conversion to $\mathrm{RD}$, but emphasized results for $\mathrm{BD}$. While TEA returned the algae in the DAF supernatant to the pond, LCA sent them to the digester. LCA considered freshwater rather than brackish water and did not consider blowdown. Also, the LCA utilized the AD digestate as fertilizer rather than disposal as waste. Although the TEA and LCA pathways were nearly identical, the power demands, performances, and flows for the unit operations were assessed independently. 


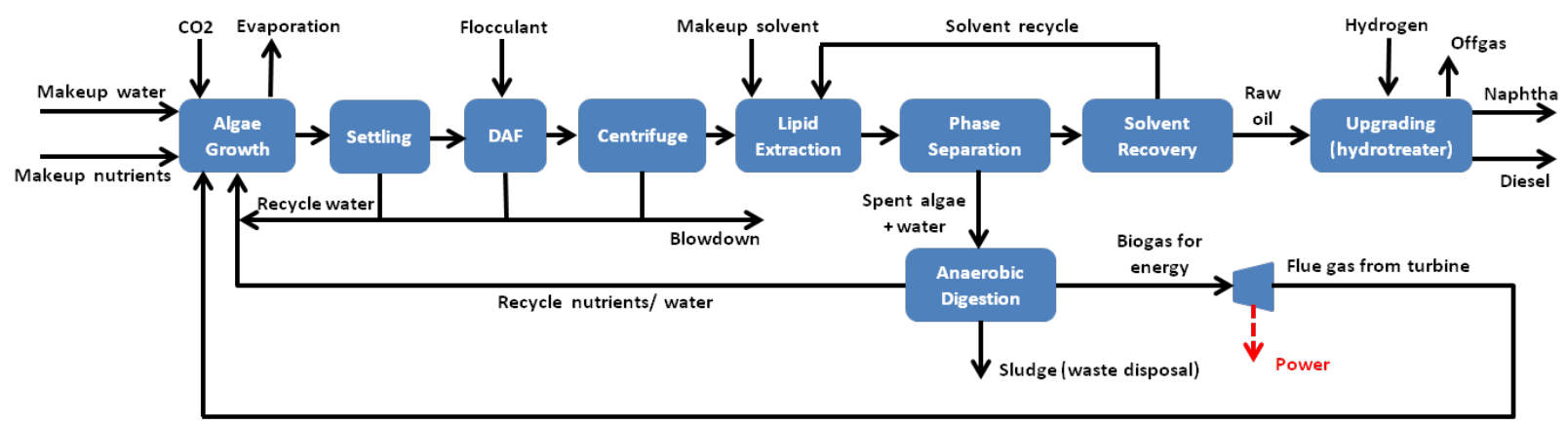

Figure 2.1a: Schematic of baseline process used in FY 2011 TEA analysis. The 2011 LCA model was similar with differences as noted in the text. See also, Appendix B. (Davis et al. 2011).

The RA entailed a high-resolution national-scale resource and production assessment for algal biofuels produced from open pond facilities. Potential oil production, land resources, and water requirements were estimated using a series of coupled model components developed at a high spatiotemporal scale, based on the dominant physical processes affecting algal growth. Land suitable for open pond microalgae production was identified using topography and existing land cover data. Ponds and associated infrastructure are situated on potentially non-sensitive flat land to avoid conflicts with existing land use and to minimize soil excavation and water pumping costs. From the suitable slope areas, only non-agricultural, undeveloped or low-density developed, non-sensitive, generally non-competitive land was considered for microalgal culture facilities. Specifically, this excludes open water, urban areas, airports, cultivated cropland and orchards, federal and state protected areas such as national and state parks, wilderness areas, wildlife refuges, wetlands, and other areas that are deemed environmentally sensitive.

The RA identified 11,588 non-competitive areas totaling approximately $430,830 \mathrm{~km}^{2}$, or $5.5 \%$ of the conterminous United States, that are potentially suitable for large-scale open pond microalgae production. A simplified biophysical microalgae growth model was used to estimate productivity based on site specific incoming solar radiation and pond water temperature. Lipid fractions were assumed to be $20 \%$ of the accumulated biomass. Water temperature, evaporative losses, solar radiation, and rainfall were estimated from 30 years of hourly meteorological data. Cumulative biofuel production as a function of cumulative land and water was then studied. Options for controlling water use through site selection were also evaluated. This assessment demonstrated the potential for algal-based biofuels to meet the EISA advanced biofuel target of 21 BGY. However, the volume of water required was significant - equal to $25 \%$ of the water consumed in irrigated agriculture (350 gallons of water per 1 gallon of biofuel). Work is ongoing to connect these results for spatially explicit resource demand with nutrient resources, including computation of energy and economic costs for transportation.

\subsection{External Harmonization Inputs}

Table 2.2a tabulates high-level parameters and modeling assumptions used in each independent model prior to harmonization. The table guided detailed harmonization, described in Section 2.3. To initiate considerations for reworking the models, several key issues were identified in discussions at the Harmonization Workshop, summarized below. A number of these issues 
(namely items 4-8 on the list below) pertain to specific technology choices, a point which reiterates the difficulty in establishing a single "best" design case at the time being.

1. The combination of both algal productivity $\left(25 \mathrm{~g} / \mathrm{m}^{2} /\right.$ day $)$ and lipid content $(25 \%)$ assumed in TEA and LCA resulted in higher oil yields compared to what developers attending the meeting felt were justified at this time. Moreover, it appears easier to increase lipid fraction than productivity.

2. The TEA and LCA analyses did not include a detailed treatment of the lipid profile and simply assumed that the stated lipid content was the product fraction, namely triacylglycerides (TAG), sent downstream for subsequent upgrading. Researchers expressed concern that phospholipids and other non-TAGs can account for sizeable portions of the lipid fraction. The modelers felt the uncertainties in measuring and characterizing the lipid fraction were so large and process-dependent that more specificity would be hard to analyze and justify, particularly in a strain-agnostic analysis.

3. A number of questions were raised regarding how the TEA and LCA results might change due to seasonal variability and whether facility operations might have to adjust to changing seasonal variables.

4. Some developers pump water to ponds and then flow back (without pumping) to discharge or settling, thus reducing energy demand compared to the LCA and TEA models that pump in both directions. However, a flow-back approach depends on a detailed analysis of water circulation logistics that may not scale.

5. The modelers expressed concern that only limited data exist demonstrating that natural settling ("autoflocculation") works for initial dewatering. Workshop participants engaged in large-scale culturing commented that they select their strains on this basis (among other constraints) and it is not a concern. Regarding the use of flocculant-aided dewatering, one participant commented that careful control of water chemistry and careful dosing of flocculants allows a range of flocculants to be used and subsequently removed from the media via the settled flocs, so that downstream processes are unaffected by flocculant use.

6. Concerns were raised about the possibility of permitting for ponds without a liner and, even with a liner, whether permitting would be possible for marine or brackish water.

7. A discussion was raised regarding the possibility for alternative dewatering options, including the use of belt filters or agricultural-based operations. These options would likely reduce the final dewatered solids content, which may be acceptable depending on the downstream extraction process. For the baseline analysis, given the lack of first-hand process and cost data for such options, as well as the cost and energetic penalty incurred for the assumed extraction process at lower solids loadings, the stipulation for $20 \%$ solids and associated three-step dewatering basis was maintained.

8. A number of comments were made as to the value of anaerobic digestion versus alternatives (primarily animal or fish feed) for spent biomass utilization. While these are important and legitimate topics for consideration, anaerobic digestion was selected to be maintained for baseline harmonization, given the completeness of the associated economic and process data for TEA and LCA modeling, in addition to the proven LCA benefits in carbon and nutrient recycling. However, this alternative is explored in the TEA sensitivity analysis presented later in the report. 
Methods

Table 2.2a: Relevant High-Level Pre-Harmonization Parameters Presented in the Workshop

\begin{tabular}{|c|c|c|c|}
\hline $\begin{array}{l}\text { Parameter or } \\
\text { Assumption }\end{array}$ & LCA & TEA & RA \\
\hline \multicolumn{4}{|l|}{ Cultivation } \\
\hline Algal productivity, $\mathrm{g} / \mathrm{m}^{2} / \mathrm{d}$ & 25 & 25 & $\begin{array}{c}\text { 8-15 } \\
\text { (30-year national mean } \\
\text { annual biomass } \\
\text { production of } 8.7 \mathrm{~g} / \mathrm{m}^{2} / \mathrm{d} \\
\text { with maximum site mean } \\
\text { annual of } 15.8 \mathrm{~g} / \mathrm{m}^{2} / \mathrm{d} \text { ) }\end{array}$ \\
\hline Lipid content & $25 \%$ & $25 \%$ & $20 \%$ \\
\hline $\begin{array}{l}\text { Scale of production (pond } \\
\text { size) }\end{array}$ & 4712 ha & $\begin{array}{c}1955 \text { ha (set by } 10 \text { MGY } \\
\text { algal oil basis) }\end{array}$ & $\begin{array}{l}405 \text { ha of pond, facility } \\
485 \text { ha }\end{array}$ \\
\hline Land use/cost & $\begin{array}{l}\text { Land-use change not } \\
\text { considered. }\end{array}$ & $\begin{array}{l}\$ 3000 / \text { acre (low-value } \\
\text { land) }\end{array}$ & $\begin{array}{c}\text { Model of relative } \\
\text { availability and cost } \\
\text { model based on real } \\
\text { estate and income }\end{array}$ \\
\hline Liners for ponds? & $\begin{array}{c}\text { Infrastructure } \\
\text { materials not included } \\
\text { in LCA }\end{array}$ & No plastic liners & $\begin{array}{l}\text { Yes - assume liner with } \\
\text { no infiltration loss. }\end{array}$ \\
\hline Days of operation & N/A. Steady state & 330. Steady state & 365 days/year. Dynamic \\
\hline $\mathrm{C}: \mathrm{N}: \mathrm{P}$ molar ratio & 103:10:1 & 106:15:1 & Not Applicable \\
\hline $\begin{array}{l}\text { Gross nitrogen as N, } \\
\text { g/dry-g algae }\end{array}$ & 0.0555 & 0.087 & Not Applicable \\
\hline $\begin{array}{l}\text { Gross phosphorous as } \mathrm{P}, \\
\text { g/dry-g algae }\end{array}$ & 0.0125 & 0.013 & Not Applicable \\
\hline Net $N$ demand, g/g-algae & 0.014 & 0.026 & Not Applicable \\
\hline Net $P$ demand, g/g-algae & 0.0063 & 0.0064 & Not Applicable \\
\hline $\mathrm{N}$ nutrient & Urea & Ammonia $\left(\mathrm{NH}_{3}\right)$ & Not Applicable \\
\hline$P$ nutrient & $\begin{array}{l}\text { DAP (diammonium } \\
\text { phosphate) }\end{array}$ & DAP & Not Applicable \\
\hline $\mathrm{CO}_{2}$ source & $\begin{array}{l}\text { Flue gas, } 20 \text { weight } \\
\text { percent }(w t \%) \mathrm{CO}_{2}\end{array}$ & Captured/purified $\mathrm{CO}_{2}$ & Not Applicable \\
\hline \multicolumn{4}{|l|}{ Water } \\
\hline Blow down & Zero & $5 \%$ of recycle rate & Zero \\
\hline Water supply & $38 \mathrm{ft}$ head & $\begin{array}{l}\text { Brackish water, pumped } \\
\text { from saline aquifer per } \\
\text { Benemann } 1996\end{array}$ & $\begin{array}{c}\text { Freshwater supply } \\
\text { based on watershed } \\
\text { capacity, costing based } \\
\text { on } 30 \text { m of pumping } \\
\text { head } \\
\end{array}$ \\
\hline $\begin{array}{l}\text { Water on-site pumping } \\
\text { circulation power demand }\end{array}$ & $38 \mathrm{ft}$ head & $20 \mathrm{ft}$ head & Not Applicable \\
\hline Evaporation loss & $0.6 \mathrm{~cm} / \mathrm{d}$ & $0.3 \mathrm{~cm} / \mathrm{d}$ & $\begin{array}{c}\text { Fully explicit spatial } \\
\text { model }\end{array}$ \\
\hline Precipitation & Zero & Zero & Included in spatial model \\
\hline
\end{tabular}


Methods

\begin{tabular}{|c|c|c|c|}
\hline $\begin{array}{l}\text { Parameter or } \\
\text { Assumption }\end{array}$ & LCA & TEA & $\mathbf{R A}$ \\
\hline \multicolumn{4}{|l|}{ Harvesting } \\
\hline $\begin{array}{l}\text { Dewatered algal biomass } \\
\text { concentration, g/L }\end{array}$ & 200 & 200 & Not Applicable \\
\hline Harvesting efficiency & $\begin{array}{l}85.5 \%(90 \% \text { at } \mathrm{DAF} \\
95 \% \text { at centrifuge. All } \\
\text { lost algae sent to AD.) }\end{array}$ & $\begin{array}{c}90 \% \text { (with } 95 \% \\
\text { subsequent recovery of } \\
\text { lost algae, } 5 \% \text { loss to } \\
\text { blowdown) }\end{array}$ & $\begin{array}{l}\text { Combined harvesting } \\
\text { and conversion } \\
\text { efficiency of } 80 \%\end{array}$ \\
\hline \multicolumn{4}{|l|}{ Extraction } \\
\hline Solvent system & Hexane & Butanol & Not Applicable \\
\hline Heat supply & From CHP & From CHP & Not Applicable \\
\hline Extraction efficiency & $\begin{array}{c}85.5 \%(90 \% \text { at } \\
\text { homogenizer, } 95 \% \text { at } \\
\text { recovery. Lost } \\
\text { materials sent to } A D)\end{array}$ & $\begin{array}{c}85.5 \%(90 \% \text { at } \\
\text { homogenizer, } 95 \% \text { at } \\
\text { recovery. Lost materials } \\
\text { sent to } A D)\end{array}$ & $\begin{array}{l}\text { Combined harvesting } \\
\text { and conversion } \\
\text { efficiency of } 80 \%\end{array}$ \\
\hline \multicolumn{4}{|l|}{ Spent Biomass Usage } \\
\hline Fate of spent biomass & $A D$ & $A D$ & Not Applicable \\
\hline$A D$ residue handling & $\begin{array}{l}\text { Digestate applied to } \\
\text { soil. Supernatant } \\
\text { returned to pond }\end{array}$ & $\begin{array}{l}\text { Digestate is a cost } \\
\text { (waste); supernatant } \\
\text { returned back to pond. }\end{array}$ & Not Applicable \\
\hline $\begin{array}{l}\text { Electrical efficiency of gas } \\
\text { turbine }\end{array}$ & $\begin{array}{l}33 \% \text { (lower heating } \\
\text { value-LHV) }\end{array}$ & $33.7 \%(\mathrm{LHV})$ & Not Applicable \\
\hline $\begin{array}{l}\text { Total CHP efficiency } \\
\text { (Total electrical energy } \\
\text { plus recovered heat } \\
\text { divided by fuel energy) }\end{array}$ & $76 \%(\mathrm{LHV})$ & $\begin{array}{l}83 \% \text { (LHV); includes } \\
\text { steam turbine combined } \\
\text { cycle to recover excess } \\
\text { heat as additional power }\end{array}$ & Not Applicable \\
\hline \multicolumn{4}{|l|}{ Fuel Upgrading } \\
\hline Algal oil conversion & $\begin{array}{c}\text { Biodiesel } \\
\text { (transesterification) } \\
\text { and renewable diesel } \\
\text { (hydrotreating) }\end{array}$ & $\begin{array}{l}\text { Renewable diesel } \\
\text { (hydrotreating) }\end{array}$ & $\begin{array}{c}\text { Harvesting and } \\
\text { conversion efficiency of } \\
\text { biomass to biofuel of } \\
80 \%\end{array}$ \\
\hline
\end{tabular}

\subsection{Baseline Harmonized Model}

The harmonization goal was to make the independent models consistent enough that the results established by the TEA, LCA, and RA models all carry the same implications by using consistent inputs as relevant to each model. Since the simulation methods and models are different, exact replication was neither possible nor attempted; however, the final harmonized TEA and LCA are close to identical for electricity balance, nutrient demand, and water demand, indicating a high degree convergence in the two models. See Table 2.3a (for a comparison of values before \& after harmonization). One area that was not harmonized in detail was the conversion of algal lipids to fuel. The harmonized TEA and LCA now convert to RD, but each uses their original models, e.g., LCA uses its previous UOP-based model, while TEA uses its previous model based on a literature survey of RD hydrotreating studies. This choice was made because all operations upstream of conversion are specific to algae, but if the conversion step were changed in LCA, for example, it would become difficult to compare the harmonized algae 
LCA results with LCA results for other bio-based RD fuels, because the conversion steps would then be (arbitrarily) different. Similar remarks apply if the TEA conversion model were to be changed. Aside from the conversion step, nearly all process assumptions were revisited in detail and harmonized as appropriate between the TEA, LCA, and RA models. The relevant modifications made as a result of the harmonization efforts are summarized below.

Prior to harmonization, the TEA, LCA, and RA models all assumed different facility scales. LCA assumed 4700 ha of ponds, while RA assumed 405 ha of ponds in a single minimal unit farm. TEA was based on a set algal oil production rate of $10 \mathrm{MGY}$, corresponding to 1955 ha of ponds in the Fiscal Year (FY) 2011 base case. The harmonized model was set based upon a grouping of 10 RA-based 405 ha unit farms, i.e., 4050 hectares of total pond area (4850 ha total facility footprint, including all processing operations), assumed universally for all models. Where relevant, each individual pond was based on the design presented by Lundquist 2011, namely 4 ha per pond (Lundquist 2011). This facility size, under the assumptions described below (most notably $25 \mathrm{~g} / \mathrm{m}^{2} /$ day productivity and $25 \mathrm{wt} \%$ lipids), produces $20 \mathrm{MGY}$ lipids vs. the $10 \mathrm{MGY}$ analysis scale selected for the original TEA study. It is comparable to the 4700 ha scale assumed in the original LCA. Aside from this change, the only other modification to the pond assumptions was to add a pond liner as part of the base case. In the previous TEA model, the base assumption was that the facility location would be constrained to areas with sufficiently high clay content in the soil, such that a pond liner would not be needed. However, after receiving feedback from the Workshop on concerns of the practicality of this assumption, as well as questions on regulatory policy restrictions, the decision was made to add liners. This decision was also supported by the fact that a large number of sites associated with the RA 5 BGY screening analysis were found to be located in areas where soil characteristics would demand liners to avoid excessive pond drainage and percolation. Thus, liners were added to the ponds at an installed cost of $\$ 0.47 / \mathrm{ft}^{2}$ after updating to 2007-dollars (Stone, 1999), a price which was verified with a third-party industry partner and corresponds well to several online vendor quotations. This price is associated with fairly heavy duty (40-mil) high-density polyethylene (HDPE) material, with typical lifetime warranties of 20 years or more, and thus was not assumed to require replacement in the 30-year facility lifetime; however, it is still a critically important assumption to the TEA model, as shown by the cost sensitivities discussed further below.

The algae composition was set according to the medium lipid scenario in Williams and Laurens (2010), selected based upon the comprehensiveness of that work. This corresponds to a C:N:P molar ratio of 175:21:1, increasing the nitrogen demand for LCA, while decreasing it for TEA. Also from Williams and Laurens, the macromolecular composition was assumed to be $47 \%$ protein, $28 \%$ polysaccharides, and $25 \%$ lipids on a dry weight basis. Given the large uncertainty in the lipid fraction at this time and its sensitivity to specific growth conditions, the lipids were treated as $100 \%$ TAG - e.g., all discussions of "lipid content" throughout this report refer to an assumption of useable lipids as a precursor to RD conversion. Future analysis should consider lipid impurities and subsequent cleanup requirements prior to RD upgrading or developments in conversion processes that are more robust in the presence of impurities.

Nutrients are supplied by anhydrous ammonia and diammonium phosphate (DAP), thus changing the LCA from urea to ammonia. This change was made after surveying the commodity fertilizer market, recognizing that urea and ammonia are similar in price, and have similarly sized markets. Ammonia was chosen, then, to simplify mass balance computations. Nutrient recycle rates were almost identical in the original LCA and TEA models. 
A number of assumptions around water supply and circulation were revised. First, the study considered only freshwater sources. This is a conservative choice that avoids environmental concerns associated with the use of saltwater in land-based open ponds and concerns about largescale saline disposal. As sufficient freshwater resources were located to satisfy the $5 \mathrm{BGY}$ approach, the freshwater requirement did not limit the production target. Expansion to brackish and marine water can be considered in future work, but is beyond the scope of the current study. Thus, the TEA model was revised from assuming brackish water pumped from underground (based on analysis by Benemann and Oswald 1996) to instead transporting freshwater from local sources. For costing purposes, the TEA model assumes a fixed water transport distance of one mile from source to facility, transported by pipeline and fed into a header system for delivery to the ponds; water costs include capital for pipelines and pumps, as well as power for pumping. The TEA and LCA models were revised to assume a pumping power of $30 \mathrm{~m}$ total head for freshwater delivery from off-site between source and ponds. The head required for on-site water circulation was also reconsidered. The LCA value, taken from EPA's Computer Assisted Procedure for the Design and Evaluation of Wastewater Treatment Systems (CAPDET) wastewater simulation documentation, was determined to be too high. Instead, 20 feet of head was estimated to be sufficient based upon $2 \mathrm{~m}$ to $5 \mathrm{~m}$ assumed clarifier depth. The analyses conservatively assumed pumping to this pressure would occur both ways, as there was no conceptual design that showed how to avoid pumping both to and from settling. All pumping occurs with total efficiency of $67 \%$, arising from $75 \%$ pump efficiency and $90 \%$ motor efficiency. For an example, see U.S. Department of Agriculture (USDA) (1984). Finally, the assumption around blowdown was revised. Given the harmonized basis of utilizing exclusively freshwater, a blowdown stream was deemed unnecessary for the RA analysis, and the TEA and LCA models followed suit to remove blowdown. Therefore, the vast majority of the water consumption in the harmonized models is associated only with making up for evaporative losses from the ponds, with a small amount of water lost with the AD digestate (sludge).

When mass flows for solids and water were compared, the LCA model had higher flows to AD because it sent the DAF supernatant to AD, while the TEA returned this stream to the pond. As a result, the LCA model was shown to have too much water flowing to AD and was changed to match the TEA assumption. The algae returned to the growth ponds from settling and from DAF are considered to be viable algae that will grow and later be harvested. In reality, a comment was raised during the Workshop that this may have an unintended consequence of selecting for unharvestable algal cells and not be practicable; however, given the lack of data to support or negate this theory, and since the solution might be to occasionally filter the flow (e.g., via sand filter), which would not affect the LCA or TEA results significantly, this issue was neglected for the time being.

Secondary dewatering was changed in two regards. The DAF output was $10 \mathrm{wt} \%$ in the original analyses. This was reduced to $6 \mathrm{wt} \%$ as a more realistic basis for what has been achieved in the context of algal dewatering (Uduman 2010). Also, the power consumption for DAF, obtained from the CAPDET wastewater treatment simulator, was adopted in the TEA. Additionally, the previous "lump sum" overall harvesting efficiency basis of $90 \%$ assumed for TEA and LCA was revised to explicitly consider harvesting efficiency of each unit — now assumed as $90 \%$ efficiency in primary dewatering (settling), 90\% in DAF, and 95\% in centrifugation . The clarified supernatant streams from settling and DAF are returned to the ponds, while the centrifuge supernatant is routed to anaerobic digestion to provide for a reasonable AD solids content of roughly $5 \%$, when combined with the spent algal residue stream. The original LCA 
centrifuge power was revised to a lower value used in the TEA model, as the latter appears to represent a more typical value for a decanter bowl centrifuge (Leung 1998).

The homogenizer power was considerably lower in TEA than LCA based upon contrasting vendor information. Other references (GEA, Greenwell 2009) were higher, similar to the LCA values. The data from GEA were chosen because they are public; however, the TEA analysis identified a potential cooling requirement for the homogenizer that was missed in the LCA. The GEA data revealed that by operating at higher pressure, a single pass might be achieved, thereby avoiding excessive heat generation and subsequent inter-stage cooling. Both analyses adopted these data, namely $96 \%$ homogenization in one pass at 1400 bar with a $20 \mathrm{wt} \%$ feed, although the homogenization efficiency was reduced for modeling to $90 \%$ to be conservative, especially considering the single-pass assumption.

The original LCA lipid extraction model was a lumped model adopted from the literature, while the TEA model was based on an explicit Aspen simulation, including heat integration with the CHP system. Subsequent to cell disruption via homogenization, the original TEA model used nbutanol for lipid extraction, based on limited experimental data from the ASP (Nagle 1989), while the LCA used hexane. In practice, there continues to be little experimental data to support either choice; however, hexane offers a number of process advantages due to a lower boiling point (thus less heat demands for solvent stripping and recovery), lower water miscibility (thus less loss of solvent into the water phase during separation), and lower cost, and consequently the TEA model was changed to hexane. The original TEA and LCA models assumed sufficient mixing during lipid extraction without explicitly considering the extraction operation itself; in the refined analysis, an explicit liquid-liquid extraction (LLE) column was added to the configuration. The addition of this unit did not considerably impact the TEA or LCA results, but nonetheless is important to include for completeness. Both the LCA and TEA models assume a gross solvent to biomass ratio of 5:1 to ensure adequate mixing (e.g., at 20\% solids, the assumed solvent ratio is 1:1 solvent to total slurry feed rate). After the LLE column, the water and spent biomass phases are separated from the solvent and oil phase in a disk stack centrifuge, assuming a $5 \%$ carryover loss of oil into the water phase (resulting in a combined $85.5 \%$ overall extraction efficiency between cell disruption and oil retention). Finally, the solvent is recovered from the oil phase and recycled via a stripping column. Given the process-specific heat and power balances for the lipid extraction section (LLE unit, centrifuge, and solvent stripping/recycle), the LCA analysis used the heat and electricity demands computed by the rigorous TEA Aspen simulation.

The LCA anaerobic digestion model produced less methane than did the TEA AD model per unit of feed. The LCA values were based on a survey of current algae specific literature. In the original TEA model, the methane yield was based on a somewhat dated report from Weissman and Goebel (1987) evaluating AD of algal residues, while the AD power demand was scaled from a vendor-supplied estimate in NREL's Humbird et al., 2011 ethanol design report, according to total solids loading rate. For harmonization, the biogas yield and composition were adopted from the LCA analysis but the AD heat and power demand were reconsidered because the LCA values (Collet 2011) were so much higher than those in other sources. Heat demand was estimated from data in CAPDET (Harris 1982) for the largest AD cylindrical tank and from data in Metcalf \& Eddy (Tchobanoglous 2003) for the largest typical tank. In CAPDET, the tank was $34 \mathrm{~m}$ diameter and $11 \mathrm{~m}$ high, while in Metcalf \& Eddy, the diameter was $38 \mathrm{~m}$. The operations being modeled would require multiple tanks this size. For Metcalf \& Eddy, the tank was assumed to be mounded with earth $2 / 3$ its height so that all surfaces had a heat transfer 
coefficient of roughly $2 \mathrm{~W} / \mathrm{m}^{2} / \mathrm{C}$. In CAPDET, heat loss for the southern United States was assumed. The two calculations gave 0.46 and $0.31 \mathrm{KWh}$ thermal $/ \mathrm{kg}$-total solids (TS) while Wang (2007) gave $0.16 \mathrm{KWh}$ thermal $/ \mathrm{kg}$-TS for the southern United States. The average, 0.22 KWh_thermal/kg-TS was used. Electricity demand was computed from Metcalf \& Eddy after adding a sludge dewatering centrifuge identical to the dewatering centrifuge discussed previously. This results in a total AD power demand of $0.085 \mathrm{KWh} / \mathrm{kg}$-TS. These numbers assume 20-day retention in AD.

The AD nutrient recycle flows and digestate composition were recomputed to reflect the new algae $\mathrm{C}: \mathrm{N}: \mathrm{P}$ ratio. Similar to the AD biogas yields, the nitrogen and phosphorous splits differed slightly between the LCA and TEA models. The TEA, previously assuming $75 \%$ capture of nitrogen and $50 \%$ capture of phosphorous in the supernatant, was revised to the LCA basis of $80 \%$ nitrogen and $50 \%$ phosphorous, with a subsequent $5 \%$ loss of nitrogen to volatilization during recycle. Additionally, the TEA analysis modified the assumed handling of the AD digestate (sludge) to take a credit for the material to be sold as a fertilizer, as is assumed in the LCA model, rather than the previous assumption of treating the material as a waste which would incur disposal costs. The digestate is sold on a nitrogen basis at a rate of $\$ 500 /$ tonne $\mathrm{N}$ (Lundquist 2011), assuming that $40 \%$ of the total nitrogen is bioavailable as per the LCA model.

Finally, the biogas evolved from AD is combusted in a gas turbine, with heat raised from the flue gas in a CHP system. The TEA and LCA harmonized models differ in their CHP treatment. The TEA uses an explicit Aspen simulation of the CHP system including gas compression, combustion, turbine, heat exchangers, and pressure drops. This allows the TEA to explicitly evaluate the heat integration between the CHP and solvent recovery, while also considering the penalty in decreased power generation associated with elevating the turbine exhaust pressure to allow for pressure losses in the flue gas recycle line (namely the CHP heat exchanger, pressure drop across the sparger in the ponds, and the $1.5 \mathrm{~m}$ head of the pond sump). The LCA uses a rolled up model from EPA (2008) in terms of overall CHP efficiency and electrical efficiency. The LCA model electrical efficiency (33\%) is higher than the TEA electrical efficiency (25\%), due to the TEA model modifying the turbine outlet pressure relative to a standard gas turbine, as described above, but the LCA adds a blower to move the flue gas into the pond, which partly compensates. Due to a decrease in biogas yields from AD in the TEA model after harmonization, the steam turbine combined cycle was deemed to be too small to be cost-effective and was removed, given the marginal amount of waste heat remaining in the flue gas after the CHP heat exchange.

The differences in CHP modeling approach (Aspen vs. Excel model) make further CHP harmonization difficult, but the differences do not jeopardize the objectives of this work. First, most changes in design do not significantly affect TEA cost estimates once the overall nature of the system is set (turbine, steam generation for the reboiler, no bottom cycle for power), but those same changes affect the CHP efficiency and thereby have a significant effect on LCA. Using a rolled up CHP efficiency on the LCA side, then, allowed better control of that variable, but further work is needed in this area.

Last, the assumptions pertaining to off-site $\mathrm{CO}_{2}$ delivery were revisited. In the harmonized model, $\mathrm{CO}_{2}$ is supplied by flue gas transported by low-pressure pipeline. Other options include bottled $\mathrm{CO}_{2}$, pressurized pipelines, and supercritical pipelines. Bottled $\mathrm{CO}_{2}$ is not consistent with large-scale production. Campbell et al., (2009) determined that pressurized pipelines required excessive energy consumption-30\% of the algal energy in their computations. Supercritical 
$\mathrm{CO}_{2}$ pipelines require careful consideration. Kadam (2001) determined that $\mathrm{CO}_{2}$ concentration can reduce costs; however, the steam required for monoethanolamine (MEA) regeneration significantly reduced GHG benefits and energy recovery in his model. Further investigation is warranted, but this analysis chose to use low-pressure pipeline transport, similar to Benemann and Oswald 1996 and Campbell et al. 2009.

The low-pressure $\mathrm{CO}_{2}$ transport incurs many questions because it invokes tradeoffs between site location, $\mathrm{CO}_{2}$ source location, $\mathrm{CO}_{2}$ demand, and pipeline economics. For example, there is a tradeoff between capital cost, pipeline diameter, number of pipelines, and pipeline power consumption. For purposes of initial harmonization reported here, the TEA was changed from pure $\mathrm{CO}_{2}$ (captured via amine scrubbing and delivered at $\$ 40 /$ tonne) to pipeline delivery based upon an Aspen pipeline model which assumes: (a) cooling the flue gas in an air cooler to $60{ }^{\circ} \mathrm{C}$ and knocking out condensed water, (b) splitting the flue gas into four 1-mile pipelines that transport flue gas to the farms from a central source in a "pinwheel" fashion, as in Frank et al. (2011a) (c) adding a main blower to each 1-mile pipeline, and (d) recompressing the flue gas to roughly 3 pounds per square inch (psi) at the end of the main pipeline for distribution into a header system and subsequent transfer into the ponds. Thus, the $\mathrm{CO}_{2}$ cost was modified from a raw material operating cost to a capital expense for the above equipment, plus power for transfer and distribution.

The LCA uses an independent model of pipeline power demand. That model was missing the pressure drop for diffusers that disperse the flue gas into the pond, so one psi was added to the pressure requirement (in addition to the $1.5 \mathrm{~m}$ sump depth). The LCA model was further corrected because the recycled flue gas (from on-site CHP) in the TEA model has high enough temperatures to degrade blower efficiency substantially. As noted above, it should be emphasized that any flue gas pipeline model depends on a number of factors that must be optimized - a task which realistically requires a detailed design of the pond facility, layout, and flue gas distribution system. Such an analysis is beyond the scope or intention of the present harmonization effort, thus the assumptions pertaining to flue gas transfer and delivery should be classified here as preliminary. One issue not harmonized was biogas cleanup prior to combustion in the CHP gas turbine. Biogas cleanup is assumed to be necessary in the LCA because hydrogen sulfide $\left(\mathrm{H}_{2} \mathrm{~S}\right)$ and other contaminants are common in many types of biogas. A biogas clean-up operation was not deemed to affect the TEA cost estimation significantly and was not added. 
Table 2.3a: TEA and LCA Harmonization Details

\begin{tabular}{|c|c|c|c|c|}
\hline Metric & \multicolumn{2}{|c|}{ Before Harmonization } & \multicolumn{2}{|c|}{ After Harmonization } \\
\hline & LCA & TEA & LCA & TEA \\
\hline Productivity, $\mathrm{g} / \mathrm{m}^{2} / \mathrm{d}$ & 25 & 25 & \multicolumn{2}{|c|}{ per site from RA } \\
\hline Water demand & $0.6 \mathrm{~cm} / \mathrm{d}$ & $0.3 \mathrm{~cm} / \mathrm{d}$ & \multicolumn{2}{|c|}{ per site from RA } \\
\hline Lipid fraction, wt $\%$ & $25 \%$ & $25 \%$ & $25 \%$ & $25 \%$ \\
\hline Net harvesting efficiency ${ }^{1}$ & $85.5 \%$ & $99 \%$ & $95 \%$ & $95 \%$ \\
\hline Net extraction efficiency ${ }^{2}$ & $85.5 \%$ & $85.5 \%$ & $85.5 \%$ & $85.5 \%$ \\
\hline $\mathrm{RD}$ yield from raw oil, wt $\%^{3}$ & $85 \%$ & $78 \%$ & $85 \%$ & $78 \%$ \\
\hline Nitrogen recovery to culture, net & 0.76 & 0.75 & 0.76 & 0.76 \\
\hline$P$ recovery to culture, net & 0.5 & 0.5 & 0.5 & 0.5 \\
\hline Net $\mathrm{N}$ demand, mg/g-algae & 14 & 32 & 19.5 & 20.0 \\
\hline Net $\mathrm{P}$ demand, $\mathrm{mg} / \mathrm{g}$-algae & 6.3 & 6.4 & 4.1 & 4.1 \\
\hline Pond mixing, KWh/ha/d & 48 & 48 & 48 & 48 \\
\hline Recycle pump, KWh/L & 4.80E-05 & 1.95E-05 & $2.5 \mathrm{E}-05$ & $2.5 \mathrm{E}-05$ \\
\hline Water pump from off-site, $\mathrm{KWh} / \mathrm{L}$ & 4.80E-05 & $3.00 \mathrm{E}-04$ & 1.23E-04 & $1.23 \mathrm{E}-04$ \\
\hline DAF, output solids content & $10 \mathrm{wt} \%$ & $10 \mathrm{wt} \%$ & $6 \mathrm{wt} \%$ & $6 \mathrm{wt} \%$ \\
\hline Centrifuge power, $\mathrm{KWh} / \mathrm{g}$-out & 5.77E-05 & 1.01E-05 & 1.93E-05 & 1.94E-05 \\
\hline $\begin{array}{l}\text { Homogenizer power, KWh/g- } \\
\text { homogenized }\end{array}$ & 2.04E-04 & $1.10 \mathrm{E}-04$ & 2.04E-04 & 2.03E-04 \\
\hline Solvent extraction heat, KWh/kg-oil & 1.38 & 4.48 & 3.09 & 3.15 \\
\hline $\begin{array}{l}\text { Solvent extraction electricity, } \\
\text { KWh/kg-oil }\end{array}$ & 0.54 & 0.05 & 0.069 & 0.069 \\
\hline AD heat demand, $\mathrm{KWh} / \mathrm{kg}-\mathrm{TS}$ & 0.54 & NA & 0.22 & 0.22 \\
\hline AD electricity demand, $\mathrm{KWh} / \mathrm{kg}-\mathrm{TS}$ & 0.136 & 0.027 & 0.085 & 0.085 \\
\hline AD yield, L-CH4/g-TS & 0.3 & 0.333 & 0.3 & 0.3 \\
\hline $\begin{array}{l}\text { Gross electricity demand (including } \\
\left.\text { all } \mathrm{CO}_{2}\right), \mathrm{KWh} / \mathrm{kg} \text {-oil }{ }^{4}\end{array}$ & 5.7 & 3.7 & 5.1 & 4.9 \\
\hline Net electricity imported, $\mathrm{KWh} / \mathrm{kg}^{-\mathrm{oil}^{5}}$ & 1.4 & -1.8 & 1.32 & 1.16 \\
\hline
\end{tabular}

\footnotetext{
${ }^{1}$ Algae that are not retained during dewatering, but are ultimately returned to the pond with the supernatant are not counted as loss.

2 Product of disruption efficiency $(90 \%)$ and lipid recovery efficiency $(95 \%)$.

${ }^{3}$ Not harmonized to facilitate comparison with previous LCA and TEA studies of other biofuels, as explained above.

${ }^{4}$ Gross facility power demand, including off-site and recycle $\mathrm{CO}_{2}$ considerations, for $25 \mathrm{~g} / \mathrm{m}^{2} /$ day, $25 \mathrm{wt} \%$ lipids. CHP power generation is excluded.

${ }^{5}$ Net facility power balance, including CHP power generation. Positive value denotes net power import; negative value denotes net power export.
} 


\section{Results}

\subsection{Effect of TEA and LCA Process Harmonization}

Before changing the productivity and water demand to match those for the sites selected by the RA, the harmonized TEA and LCA analyses were first rerun with the original basis of $25 \mathrm{~g} / \mathrm{m}^{2} / \mathrm{d}$ productivity and $25 \%$ lipids to examine the consequences of the process changes resulting from the harmonization of the LCA and TEA models independently from the site-dependent productivity changes computed by the RA model.

Figure 3.1a shows the change in well-to-wheel (WTW) GHG emissions resulting from each step in the harmonization process. The largest effect is from reducing on-site water pumping energy. The next largest change was a reduction in emissions by switching to the NREL Aspen model for hexane extraction. This occurs because the electricity demand in that model arising from the LLE unit, phase separation centrifuge, and solvent recycle stripping column is less than in the lumped model from the literature; much of the literature around the extraction process is based on traditional vegetable oil extraction, which may translate poorly to algal lipid extraction. Returning the DAF supernatant to the culture redirects algae from AD to the pond. Even though these algae are viable in the model and effectively increase the net yield from the process, the loss of electricity (less biomass goes to AD) is the larger effect, and a net increase in GHGs occurs. Future work needs to evaluate electricity for extraction, on-site pumping, and AD in more detail.

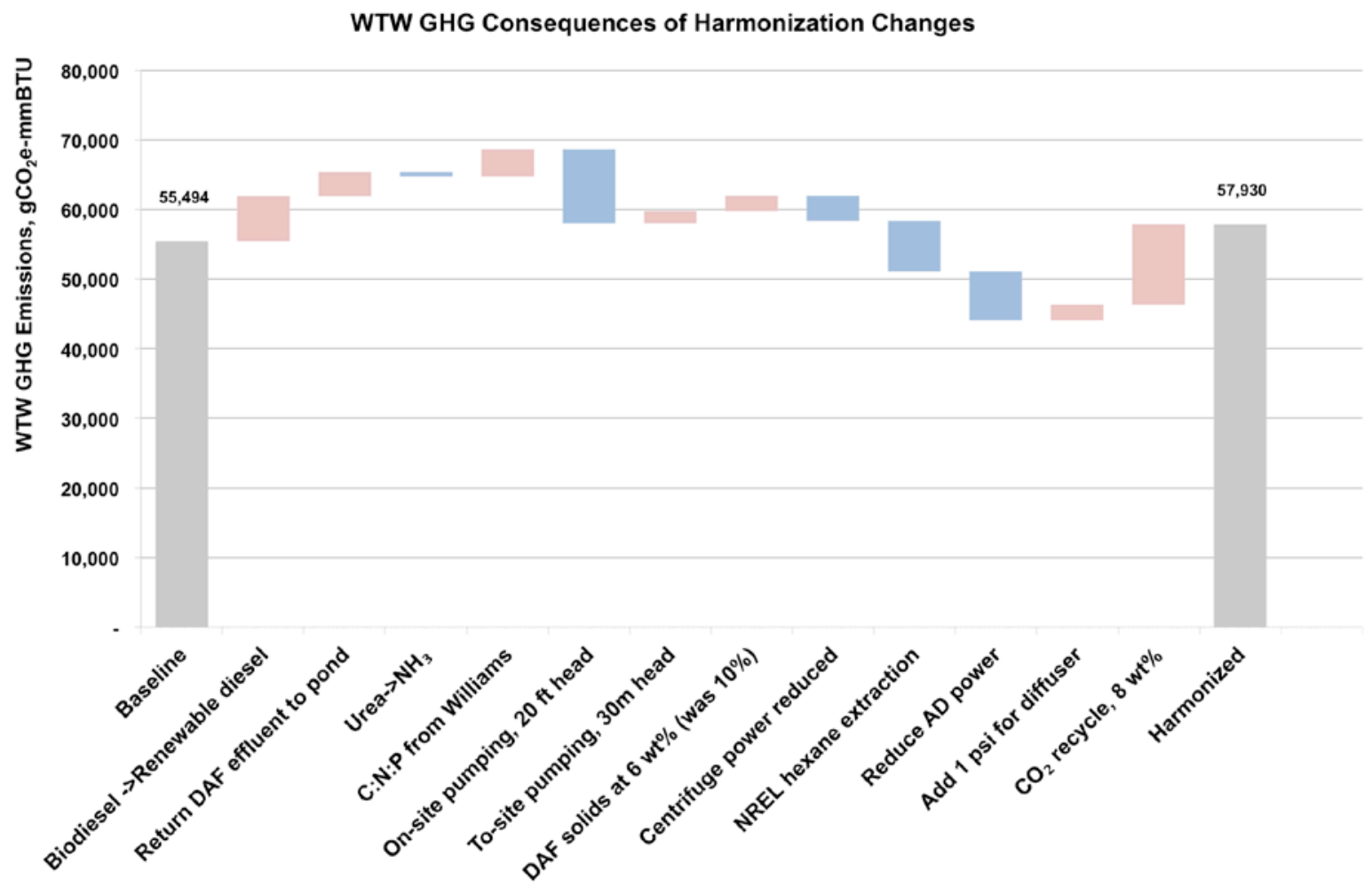

Figure 3.1a: Effect of harmonization on LCA results. Each bar shows the effect on WTW GHG emissions for the harmonization change listed—red for increases and blue for decreases. 
Figure $3.1 \mathrm{~b}$ presents a similar waterfall plot to quantify the impact of each respective process change on the TEA results. In addition to the process modifications that were implemented as part of the harmonization between the TEA, LCA, and RA models as documented above, a number of additional modifications were made on the cost side of the TEA model that do not effect harmonization with the other analyses. These additional TEA modifications were made in many cases as a result of relevant feedback from the Workshop and are intended to further refine the TEA model, reduce uncertainty, and improve practicality. The relevant cost modifications are summarized as follows:

- Updated nutrient costs with recent USDA numbers (USDA 2012), namely ammonia at \$643/ton and DAP at \$616/ton (average price between 2009-2011)

- Removed AD nutrients: this was already done in the LCA model, and was deemed appropriate in the TEA model as well, given the high nutrient $(\mathrm{N}, \mathrm{P})$ content of the incoming algal material

- Revised total facility footprint to $120 \%$ of pond footprint, per RA model basis of 485 ha facility $=405$ ha ponds (impacts land costs)

- Re-costed settling tank based on explicit sizing calculations: previous cost was based on cost factor equation from EPA. Revised to cost individual units using Aspen Capital Cost Estimator assuming 2-hour settling time, based on Workshop feedback

- Revised AD sizing and costing calculations: increased AD hydraulic residence time from 10 to 20 days for more practical operation. Re-costed based on updated AD costs provided in 2011 NREL biochemical ethanol design report (Humbird 2011)

- Replaced "outside boundary limit" and "general machinery" costs in previous model with explicit costs for water delivery pipelines, facility pumps, and heat exchangers

- Decoupled hydrotreating facility from algal oil facility (no longer integrated), revised scale such that four algal facilities (4,050 ha each) feed into a single hydrotreating facility to ensure that adequate minimum hydrotreating scale is achieved (5,700 bbl/day feed rate at $25 \mathrm{~g} / \mathrm{m}^{2} /$ day productivity $+25 \%$ lipid case), per Workshop feedback

- Revised factors for indirect capital (IC) costs to be more reasonable and appropriate for algal production: previous IC factors were based on NREL ethanol model (Humbird 2011), however some factors were deemed to be too high for algal production, where costs are dominated by simple items such as ponds and liners, which may be more appropriately viewed in the context of agricultural economics. The revised IC factors are summarized as follows (refer to Humbird 2011 for a description of cost items):

- Site development: $9 \%$ of inside boundary limit (ISBL) capex costs, unchanged from Humbird 2011 basis in previous model

- Warehouse: $1 \%$ of ISBL, reduced from $4 \%$ given high capex costs in revised model

- Prorateable costs: 10\% of TDC (total direct costs), unchanged from 2011 model

○ Field expenses: 10\% of TDC, unchanged from 2011 model

○ Home office and construction: 10\% of TDC, reduced from 20\% per Workshop feedback

- Contingency: $20 \%$ of TDC, reduced from $30 \%$ per Workshop feedback and given reduced cost uncertainty in revised cost estimates

○ Other costs: $5 \%$ of TDC, reduced from $10 \%$ given costs included elsewhere

$\circ$ Working capital: 5\% of FCI (fixed capital investment), unchanged from 2011 model. 
As shown in Figure 3.1b, a number of changes to the TEA model had a substantial impact to overall diesel selling price of roughly $\$ 1 /$ gal or more. The largest drivers behind increasing the selling price were found to be adding liners, reducing DAF concentration to $6 \%$, and harmonizing unit-level power demands with the LCA model. It should be noted that the addition of pond liners accounts for the single largest cost impact to the harmonized model (roughly $\$ 3 /$ gal at the $25 \mathrm{~g} / \mathrm{m}^{2} /$ day basis); this is further discussed below in the cost sensitivity analysis. The cost increases were offset to some extent by a number of cost decreases, the largest of which were revising the indirect cost factors, replacing butanol solvent with hexane, removing the water blowdown, and re-costing the primary settler tank. After considering all process changes to the TEA model, the diesel selling price was found to increase by $14 \%$, from $\$ 10.66 /$ gal in the FY 2011 model to $\$ 12.15 /$ gal in the revised model. Again, note these changes only reflect the impacts to the TEA model prior to incorporating the RA model output (algal productivity and water footprint), thus showing changes to the model itself after harmonizing with the LCA model. Final results, including incorporation of the RA model output, are described in section 3.3 .

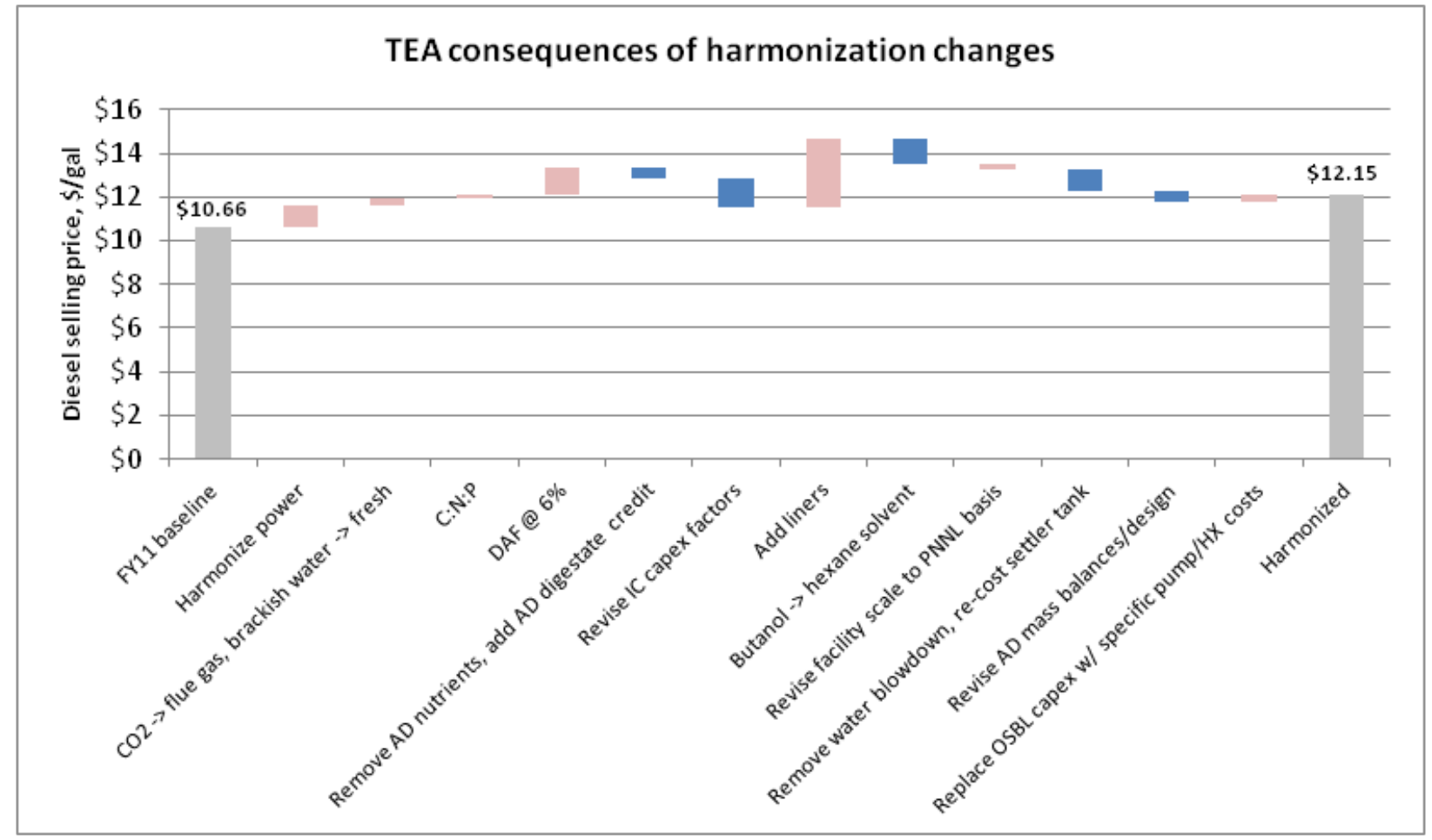

Figure 3.1b: Effect of harmonization on TEA results. Each bar shows the effect on diesel selling price for the harmonization change listed-red for increases and blue for decreases.

Upon establishing a harmonized LCA and TEA model to incorporate the process and operational changes described above, the next area warranting consideration of feedback from the Workshop is the assumed lipid content and algal productivity. These variables are uncertain and profoundly affect both LCA and TEA. Figure 3.1c shows GHG emissions in the harmonized model as a function of productivity and lipid fraction, while Figure 3.1d shows similar results for diesel selling price in the TEA model. The productivity will vary from site to site in the RA study described below, so in these plots, the effects of these variables are displayed when changed 
independently. The key messages presented in Figures 3.1c-d are that (a) the LCA and TEA results are strongly dependent on both lipid fraction and growth rate, and (b) the GHG and cost sensitivities are non-linear and change rapidly at lower values, so that even small changes in these values in the non-linear region can translate to a significant effect on the results. The location of the non-linear region (here, below roughly $20 \mathrm{~g} / \mathrm{m}^{2} / \mathrm{d}$ and $20 \mathrm{wt} \%$ lipids) is not absolute and depends upon details of the process. Section 4.1 will show examples of changing the location of the non-linear region by simple changes in the model.

Nutrient recycling is also important, but does not couple strongly to other process choices. For example, the effect of changes in net nitrogen demand can be estimated via 3,200 $\mathrm{gCO}_{2}-\mathrm{e} / \mathrm{kg} \mathrm{N}$ and $\$ 0.75 / \mathrm{kg} \mathrm{N}$, when supplied by ammonia.
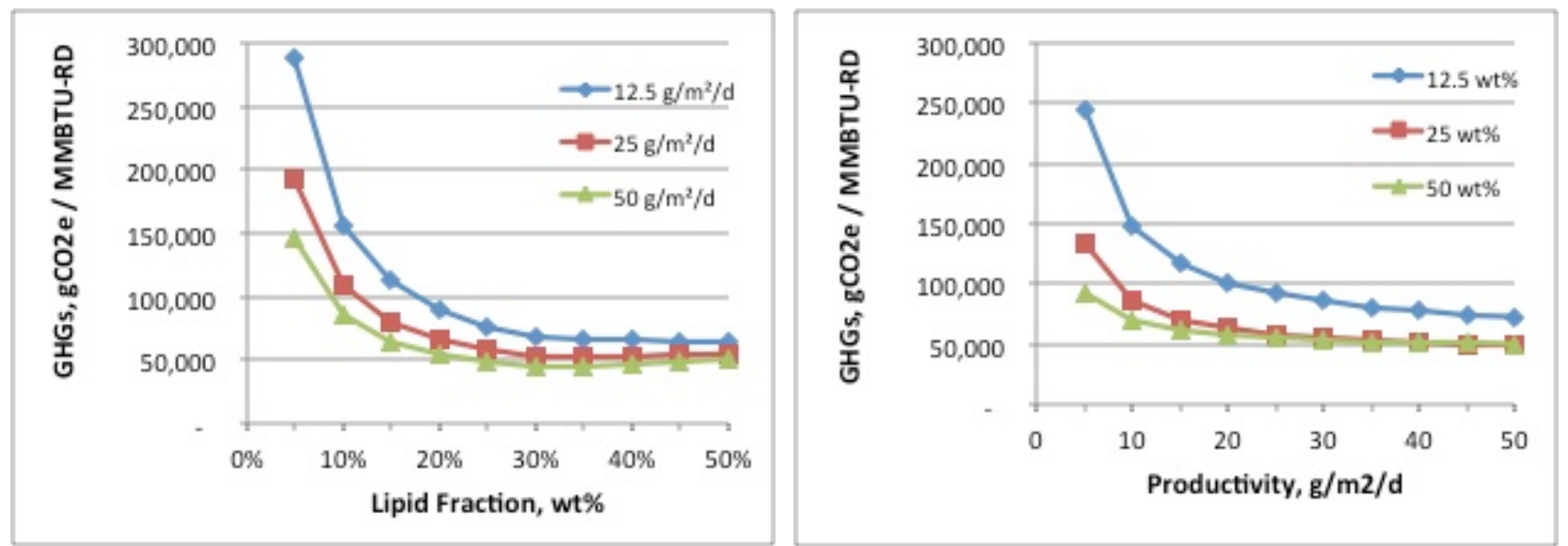

Figure 3.1c: Effect of lipid fraction and productivity on GHG emissions. Although lipid fraction and productivity are not independent variables, the plots display the system sensitivity to both parameters.
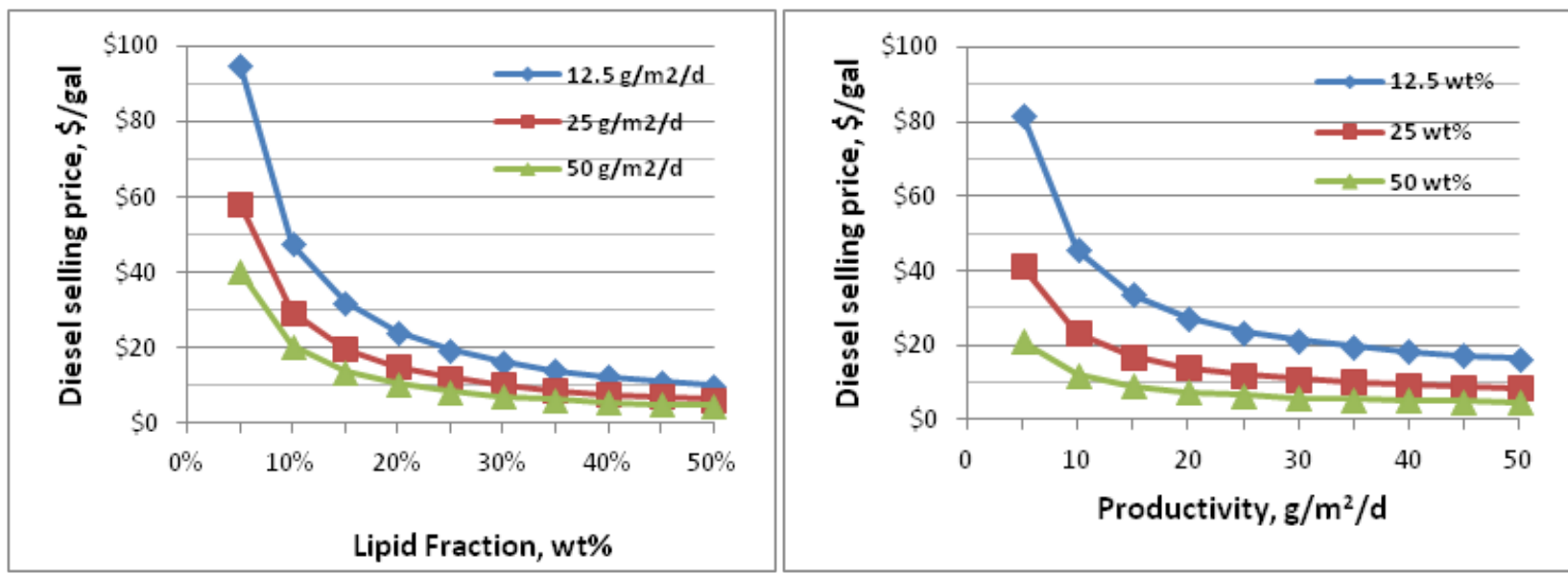

Figure 3.1d: Effect of lipid fraction and productivity on diesel selling price. Although lipid fraction and productivity are not independent variables, the plots display the system sensitivity to both parameters. 


\subsection{Definition of the 5 BGY Resource Assessment Scenario}

EISA calls for 21 billion gallons of advanced biofuels by the year 2022. The Harmonization Working Group determined that a minimum of 5 BGY of microalgae-based biofuels would be required for this feedstock to provide a meaningful contribution to the EISA advanced biofuel target. PNNL's Biomass Assessment Tool (BAT) was employed previously to identify suitable land areas within the conterminous United States and to calculate biomass and oil production, as well as freshwater consumption, in an open pond system.

The previous study (Wigmosta et al., 2011), identified $430,830 \mathrm{~km}^{2}$ of suitable (i.e., nonagricultural, non-competitive, non-sensitive) land that produced an estimated 58 billion gallons, assuming no resource constraints. National patterns of microalgae biofuel production show an expected strong linkage to climate, which in turn is tied to patterns of time, elevation, topography, and latitude (Figure 3.2a). Evaluating annual patterns at the national scale, the lowelevation southern portions of the United States exhibit the highest production rates ranging from 6,000-8,000 L/ha-year of potential biofuel production. These areas (portions of California, Arizona, the Texas-gulf coast region, and the southeastern seaboard) are characterized by relatively warm year-round temperatures and additional hours of solar insolation over more northerly locales.

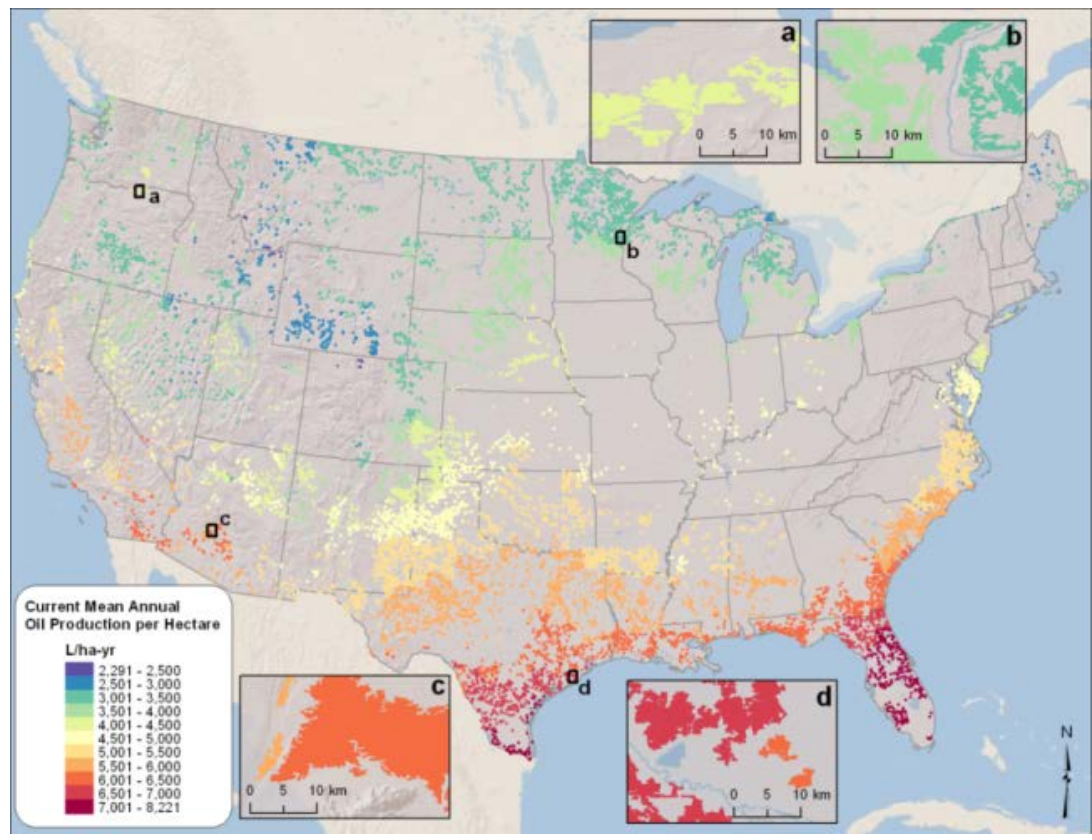

Figure 3.2a: Original RA modeling output: mean annual biofuel production (L/ha-year) under current technology plotted at the centroid of each pond facility. (Wigmosta et al. 2011). ${ }^{\mathrm{ii}}$

Freshwater is the only water source considered in the baseline 5 BGY scenario. BAT calculates freshwater demand for each site as hourly pond evaporation minus precipitation, with limited dynamic storage in the pond. Currently, water consumed by onsite processes and rates of water recycling are not accounted for. The availability of freshwater was based on mean annual volume estimated from U.S. Geological Survey (USGS) streamflow measurements for each USGS 6digit Hydrologic Unit Code (HUC_6) watershed. These data reflect current upstream water use 
and represent a reasonable estimate of the maximum sustainable supply of combined surface and groundwater. Only a small fraction of this resource will be available for biofuel feedstock production due to environmental constraints and other local, state, and federal regulations, as well as future competition for water. We assume that $5 \%$ of the mean annual flow for each watershed is available for algae ponds; this number is based on the amount of water that the EPA allows power plants to withdraw (EPA, 2001). It should be noted that this baseline analysis does not consider water rights or other compacts.

Freshwater supplies were appropriated to site locations previously determined as suitable by BAT (Figure 3.2a). Each potential farm site from BAT was flagged as having water available or unavailable based on the capacity of their respective watersheds. Sites were prioritized within each watershed by water use rate (lowest first) until the capacity of the watershed (5\% of mean annual flow) was exhausted (Figure 3.2b). The baseline scenario requirement of freshwater only eliminates most of the potentially high production sites in the southwestern United States and portions of Texas; saline or other alternative water sources may be more appropriate in this region.

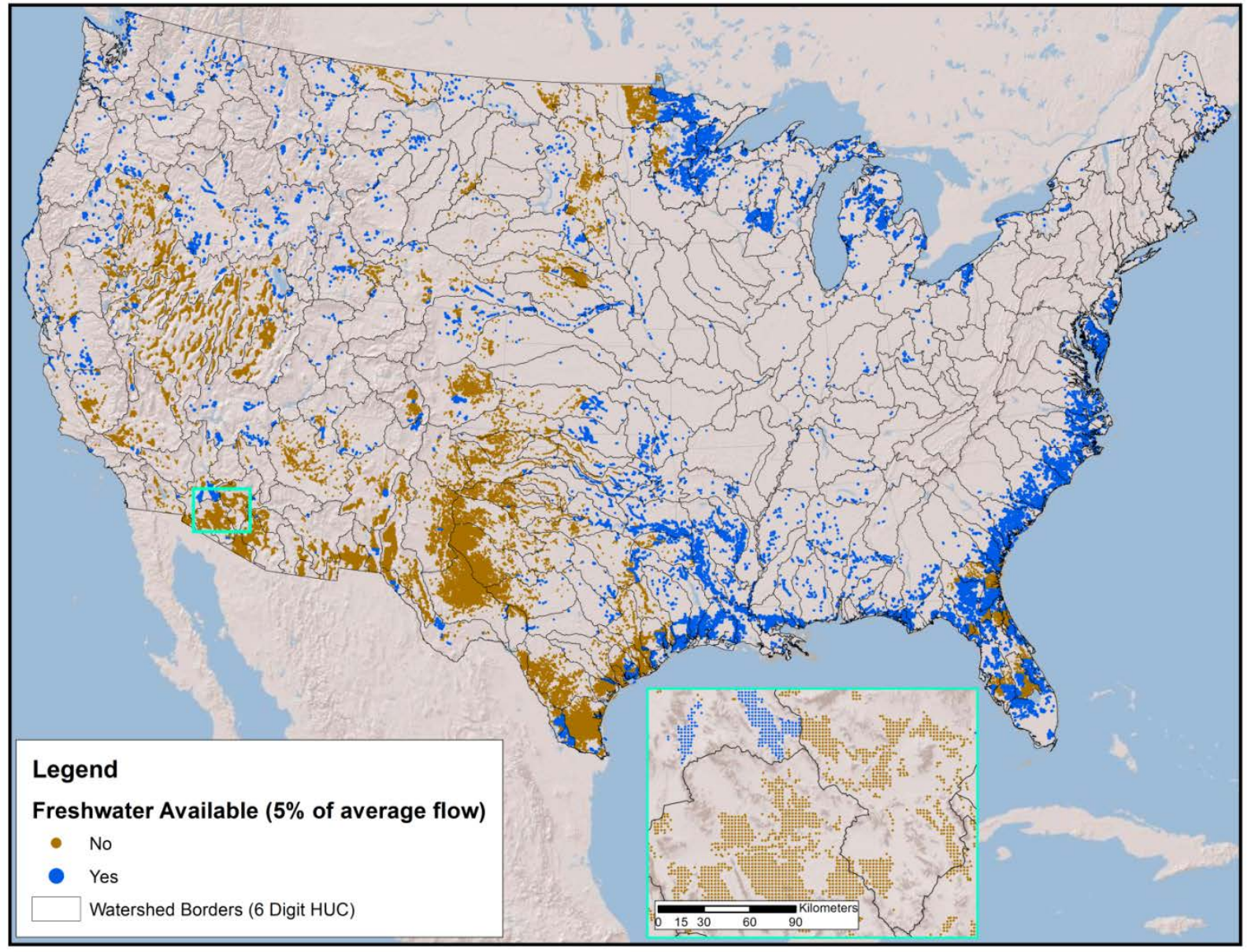

Figure 3.2b: Determination of sufficient freshwater availability through comparison of unit farm consumptive water demand with available mean annual freshwater water supply (plotted at the centroid of each pond facility). 
We selected sites from the national dataset to meet a 5 BGY production target based on an initial consideration of resource costs and constraints. The down select analysis is based on biomass and biofuel production calculated from BAT, an assessment of freshwater demand and supply, and the cost to transport extracted lipids to existing refineries. It is recognized that a variety of resources are needed to grow algal biomass and that constraints on supply and transport costs for each resource vary in space. For this baseline study, we developed a site selection model based on preliminary estimates of the economic value of biofuel production relative to a limited set of resource supply constraints and costs. The approach presented below was used to determine the order of site selection and is not intended to be a full economic assessment. ${ }^{1}$

The primary site selection variable for the RA model is the production rate of algal biomass and attendant lipid production. Annual biomass production is calculated from the generalized growth model contained in the BAT. Although lipid content in microalgae can reach up to $75 \%$ by weight of dry biomass, most common algae have oil levels between 20 and 50\% (Manta, 2010). As noted during feedback from the Harmonization Workshop, the critical element is the combination of productivity and lipid content; e.g. lipid productivity (gal/acre/year). In the 2011 Algal Biomass Summit, a plenary panel of leaders in algae consortia partnerships spoke on where the industry currently stands with respect to this metric and how far it may be improved in the future. The general consensus was in agreement with a baseline range of 1,500-2,000 gallons per acre per year for today's benchmark, as described by Jose Olivares of the NAABB consortium (ABS 2011). This would roughly translate to a lipid content of $25 \%$ at an algal productivity value of $20 \mathrm{~g} / \mathrm{m}^{2} /$ day, or $32 \%$ at $15 \mathrm{~g} / \mathrm{m}^{2} /$ day. This corresponds closely to a comprehensive survey of growth performance in outdoor ponds published by Griffiths (2009), which projects roughly 2,300 gal/acre/year at an average $26 \%$ lipid content and a thorough analysis stipulating 2,000 gal/acre/year at 25\% lipid content, projected to be plausible in the near term (Lundquist 2011). After careful consideration of this and other published data, a lipid content of $25 \%$ was assumed for all models under the baseline harmonization for the 5 BGY scenario; given the RA output of $13.2 \mathrm{~g} / \mathrm{m}^{2} /$ day on average (Section 3.3 .1 below), this would represent a potential lipid productivity (before harvesting) of roughly 1,400 gal/acre/year and thus may well represent a conservative assumption. However, the Harmonization Team felt uncomfortable increasing the lipid content above $25 \%$ without supporting operational data, given the feedback and concerns raised at the Workshop as described previously. Therefore, the RA model assumes a lipid content of $25 \%$, an extraction and conversion efficiency of $80 \%$ (Chisti, 2007), and an oil density of $920 \mathrm{~kg} \mathrm{~m}^{-3}$.

Consistent with the LCA and TEA, each point on the maps presented below represents 10 unit farms or a total facility area of 4,850 ha, with 4,050 ha in production ponds. The RA modeling cost of providing freshwater is based on a pumping head of $30 \mathrm{~m}$ from either a shallow well or frictional head loss from transporting water from a reservoir. The electricity cost for operating the pumps is set at $\$ 0.068 \mathrm{kWh}$ (EIA, 2012b). The current model is based on an average well depth for relatively humid regions (as appropriate for the down selected locations); it is expected that for the arid regions of the western United States wells are likely to be deeper and more saline.

\footnotetext{
${ }^{1}$ As ongoing enhancements to the BAT progress, additional resource supply constraints and costs will be explicitly considered in the site selection process including alternative water sources, $\mathrm{CO} 2$ sources, nutrient sources, and related transportation costs.
} 
The financial benefit of proximity to refineries was also assessed assuming that produced lipids will be transported to existing refineries (Demorro, 2012), so algal farms proximal to these facilities will benefit from decreased transport costs. Existing refinery locations were taken from the National Carbon Sequestration Database and Geographic Information System (NATCARB) database (NETL, 2010). Costs were assessed based on trucking costs and Euclidian distances.

The information above was incorporated into a contiguous United States, or CONUS GIS-based site selection model. The first step of the selection was based on water availability. Each potential farm site from BAT was flagged as having water available or unavailable based on the capacity of their respective watersheds. Sites were prioritized within each watershed by water use rate (lowest first), until the capacity of the watershed (5\% of mean annual flow) was exhausted. All ordering is done on the basis of spatial benefit rather than absolute cost. This was done to facilitate clearer comparative assessment between parameters that may have widely differing absolute magnitudes, but similar spatial variability statistics. Each site was then evaluated as to the financial benefit of selecting it over the worst site in the lower 48 states in terms of oil production, lipid transport to refinery costs, and water pumping costs. This analysis was used to prioritize the farm sites sequentially until the 5 billion gallon goal was reached. All potential pond sites in watersheds that supported less than five 4,850 ha sites were excluded from the selection to avoid excessive dispersion of the sites.

\subsection{Application of the 5 BGY Scenario}

\subsubsection{RA Results}

As noted above, the baseline scenario requirement of freshwater only eliminates most of the potentially high production sites in the southwestern United States and portions of Texas (Figure 3.2a). While every potential site in CONUS was modeled, the most suitable sites for the $5 \mathrm{BGY}$ baseline study are located in the general vicinity of the Gulf of Mexico. Many sites in the Gulf region were also eliminated due to the lack of available freshwater (Figure 3.3.1a). The majority of watersheds in the area have large surface water flows, generally exceeding one billion cubic meters per year. Therefore, the main factor affecting the geography of supply is the water consumption rate due to local climate. Water consumption for sites in south Texas is an order of magnitude greater than for those in the northern Gulf coast and Florida. Despite the large amount of water available, far fewer farms are supported per watershed in south Texas (Figure 3.3.1a) because of consumption. South Texas and Florida have the highest potential production rates in the United States, and a significant portion of this production capacity cannot be realistically met using freshwater. It is noted that considering the availability of alternative water sources, such as seawater, could potentially increase the productivity of the region significantly. This incorporation of alternative water sources could result in important differences in TEA and LCA results over those presented here, as the sites would shift towards inclusion of additional highproductivity sites, thus increasing overall average productivity.

Meeting the 5 BGY target requires 446 farms of 4,850 ha units (Figure 3.3.1b) — a total land area equal to approximately $0.3 \%$ of the conterminous United States. These farms are located along the coast of the Gulf of Mexico and the Atlantic coast of Florida. Total oil production per 4,850 ha location ranges from 9.9-12.8 MGY, with the largest production rate occurring on the Florida peninsula. The associated water demand is equivalent to approximately $3.3 \%$ of the current 
consumptive water use for irrigated agriculture. Freshwater costs are not a significant factor in this model, the main geographic influence of water is site elimination due to lack of supply.

The priority map (Figure 3.3.1c) shows that for the limited set of constraints and costs considered, the Florida peninsula is a favorable location due to high production and low water consumption. This benefit is tempered somewhat by the cost of transport to the nearest refineries in Mobile, Alabama; however, these sites still have a high priority in selection. The area around the Rio Grande River in south Texas is also of interest as it has high production, but also very high water consumption. The lowest priority sites are in the central Gulf coast but are still included because of the freshwater limitations in Texas.

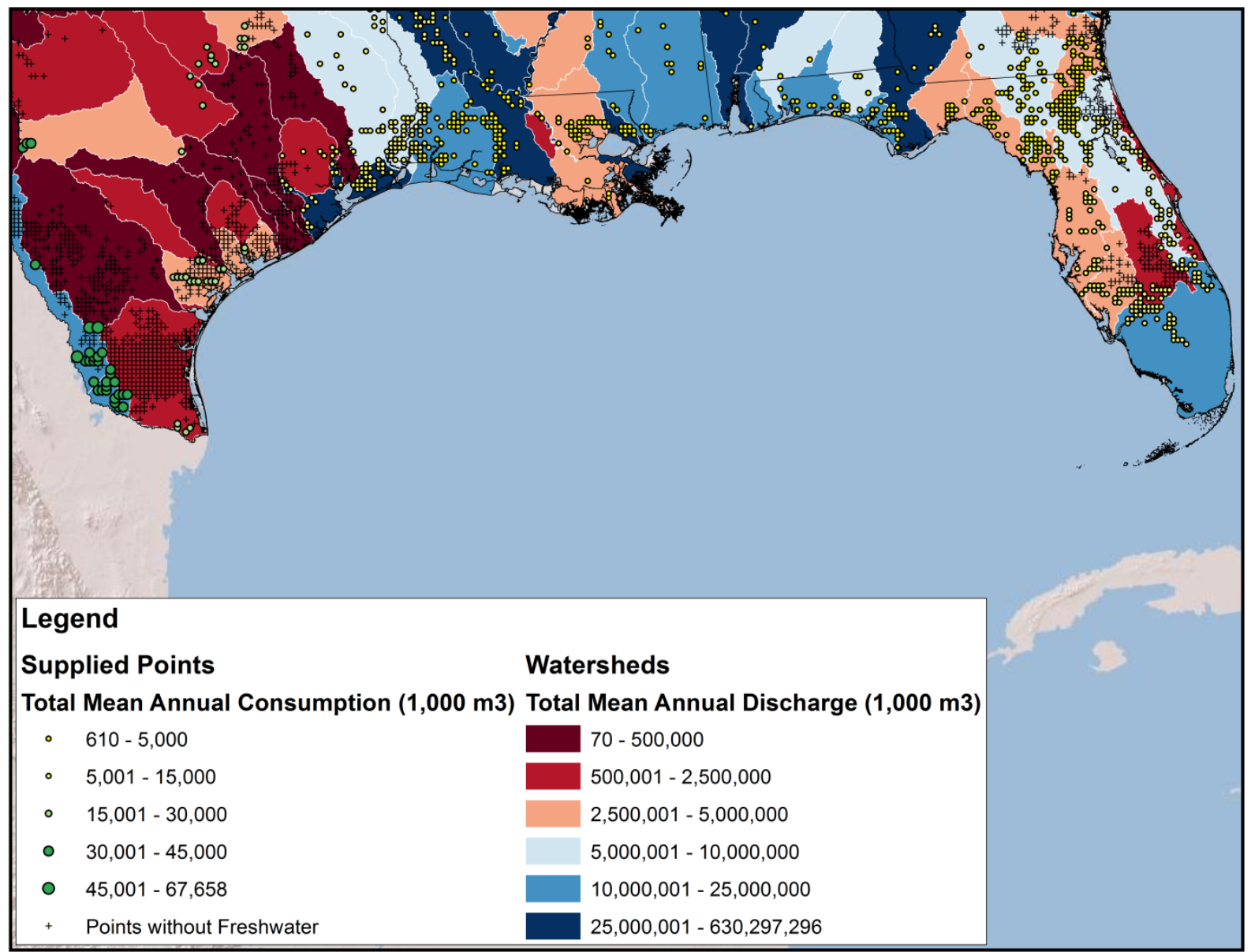

Figure 3.3.1a: Map showing the annual flow through each 6 digit HUC watershed, the water consumption rate for sites with freshwater supply, and the location of farm sites that cannot be supplied with freshwater under the existing constraints. Each point represents ten 485 ha unit farms. Water consumption is much higher in south Texas and some of the watersheds in this location have significantly less flow than others in the region. 


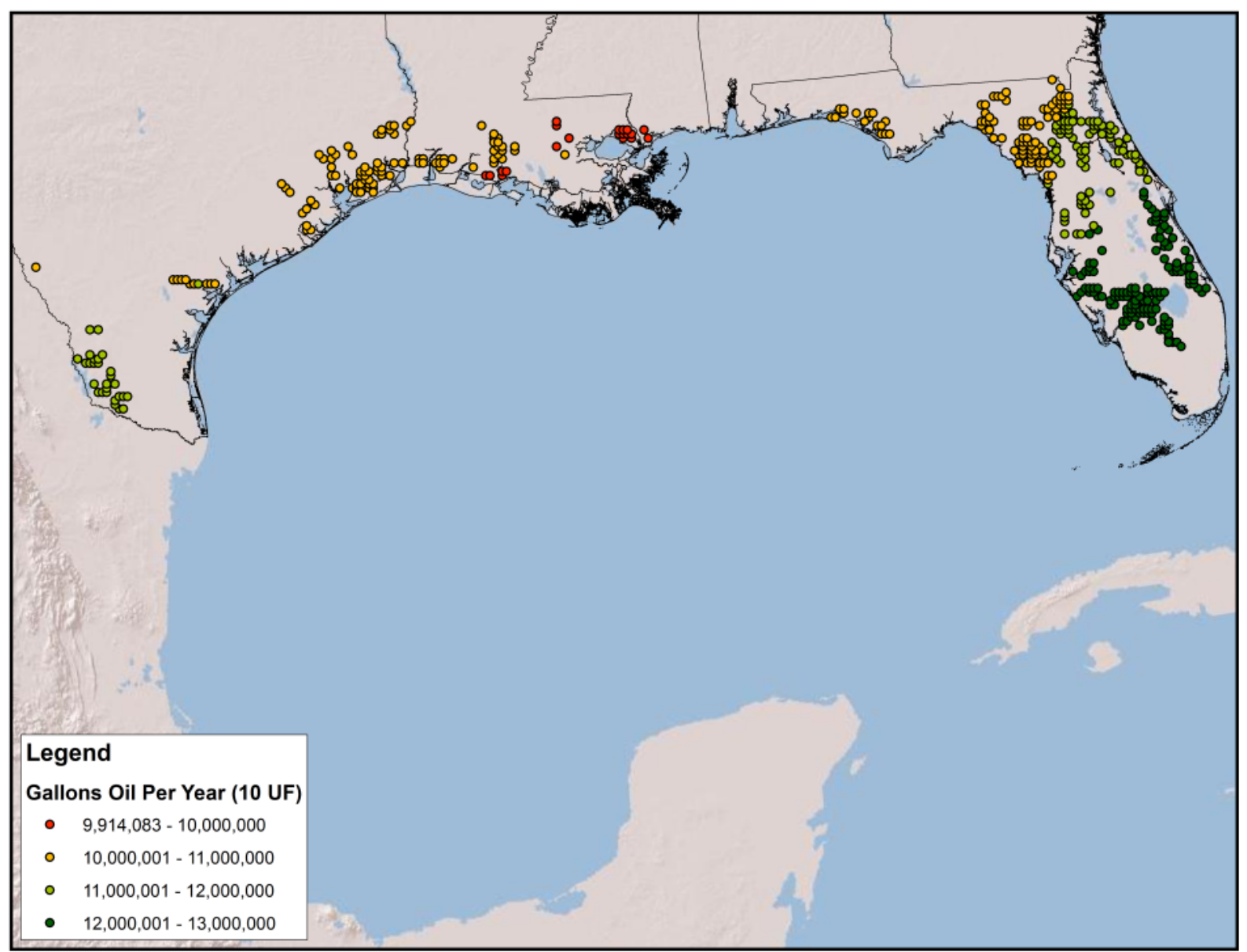

Figure 3.3.1b: Map showing the annual production per 10 unit farms in gallons per year. South Florida has the highest production, but overall the gulf region has high annual productivity. 


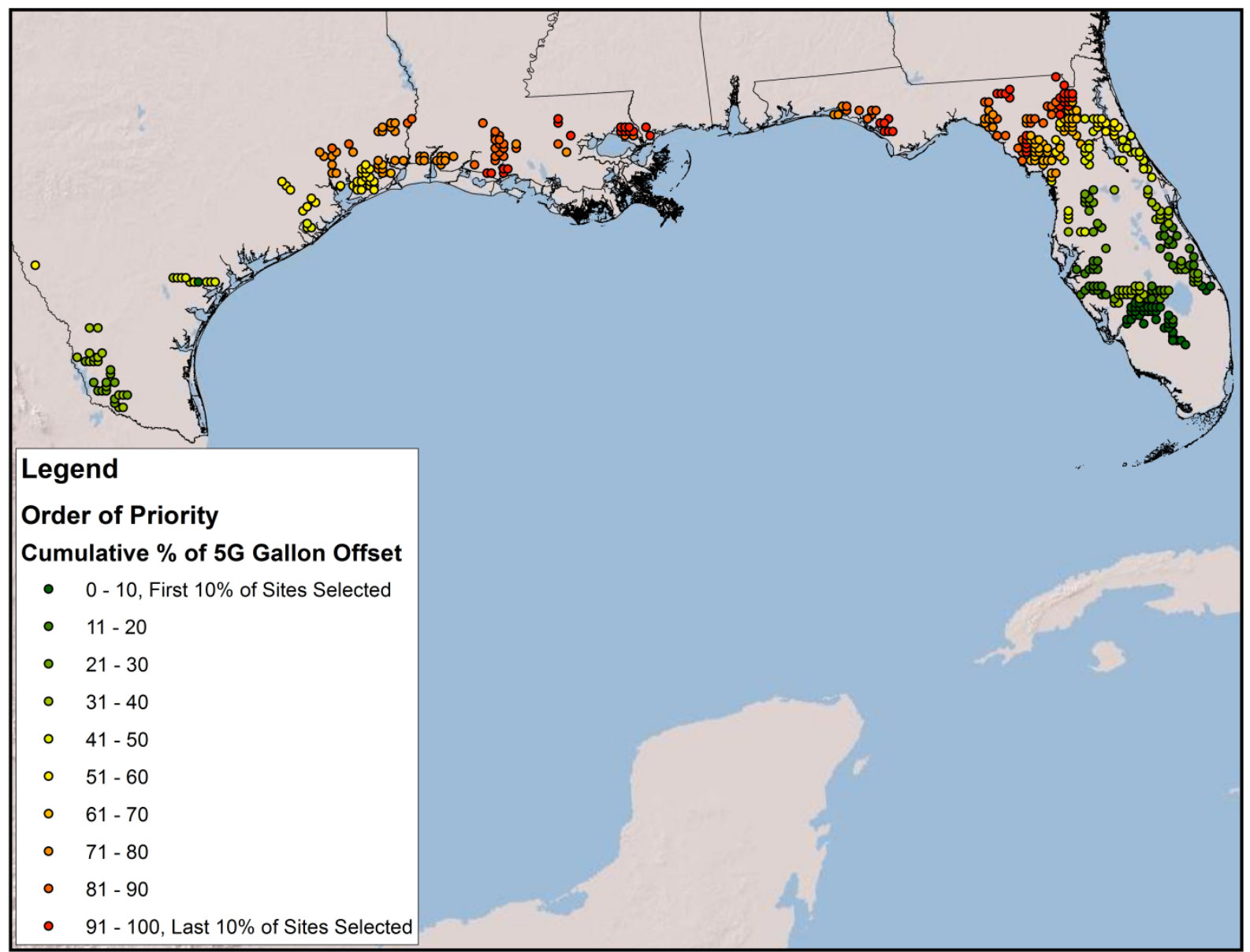

Figure 3.3.1c: Cumulative site prioritization in $10 \%$ intervals based on production, lipid transport, and freshwater pumping cost. Despite the elevated lipid transport costs, south Florida remains the highest priority due to production rate. South Texas sites are also selected due to production and advantageous position relative to refinery locations.

Mean annual biomass production from the selected sites was estimated at $13.2 \mathrm{~g} / \mathrm{m}^{2}-\mathrm{d}$ (Table 3.3.1a), ranging from $6.2 \mathrm{~g} / \mathrm{m}^{2}-\mathrm{d}$ in the winter (January, February, March) to $16.5 \mathrm{~g} / \mathrm{m}^{2}-\mathrm{d}$ in spring. These values are consistent with large-scale commercial productivities of $10-20 \mathrm{~g} / \mathrm{m}^{2}-\mathrm{d}$ (DOE, 2010). As expected, oil production follows the same seasonal pattern, with a mean annual production rate of 1,120 gallons per acre of pond surface (at 25\% lipid content). This conservative estimate is well below published values for current production of 1,500 gal/ac-year (Mascarelli, 2009) and "best case" estimates of 4,000-5,800 gal/ac-year (Weyer et al., 2010). Laboratory and theoretical maximum values even range up to 15,000 gal/ac-year (Mata et al., 2010; Weyer et al., 2010). Water demand, and water use efficiency, follow a similar seasonal pattern, ranging from 96 liters of water per liter of oil in the winter, to 287 in the spring, with an annual mean of 195 liters of water per liter of oil. 
Table 3.3.1a: Mean Biomass, Oil Production, and Water Demand for Selected Sites

\begin{tabular}{|l|c|c|c|c|c|}
\hline & Annual & Winter & Spring & Summer & Fall \\
\hline Biomass $\left(\mathrm{g} / \mathrm{m}^{2} / \mathrm{d}\right)$ & 13.2 & 6.2 & 16.5 & 15.8 & 14.1 \\
\hline Oil (BGY) & 5.0 & 0.6 & 1.6 & 1.5 & 1.3 \\
\hline Water Demand (BGY) & 974.4 & 55.9 & 452.7 & 351.8 & 113.9 \\
\hline G Water per G Oil & 195.0 & 96.2 & 286.9 & 233.0 & 85.8 \\
\hline
\end{tabular}

Note: Annual oil and water are gallons per year, seasonal oil and water are gallon per season (3 month totals).

The BAT growth model first calculates maximum (location and time specific) potential biomass production based on incoming solar radiation. This value is then corrected for the effects of pond water temperature and light intensity. High pond water temperatures cause a slight drop-off in estimated production from spring to summer for some sites. The baseline results represent a "generic" algal strain based on conservative parameter values taken from the literature. In application, one would ideally select an optimal strain for the growing region and climate. For example, peak biomass production shifts from spring to summer with a $1{ }^{\circ} \mathrm{C}$ increase in two growth model input parameters - one that defines the upper end of the optimal pond temperature range and the other, which defines the maximum water temperature before total culture loss. This 1 degree change is likely within the accuracy of the water temperature model and highlights the need for both additional model validation against observational data and better strain specific growth data and associated model refinement. Additional detail is provided in Section 4.

Site selection in this 5 BGY baseline scenario was largely determined by local climate and freshwater availability. Consideration of higher production targets and incorporation of additional resource costs and constraints, including nutrients, alternative water sources, and additional land attributes will result in a more complex and geographically diverse down selection. Consideration of regulatory requirements and local geology and soil conditions may also exclude some sites that are currently selected. For example, karst geology in Florida may remove some high production sites from consideration.

\subsubsection{LCA Results}

LCA results are presented in terms of the well to pump (WTP), pump to wheels (PTW), and well to wheels (WTW) stages. The terminology originates from the original analysis of petroleum fuels. The WTP stage includes all activities related to recovering feedstocks, producing fuels from the feedstocks, and transporting the fuel to a fueling station. For algae, this includes all upstream operations like nutrient manufacturing, plus algae growth, processing to fuel, and delivery of fuel to station. The PTW stage considers fuel combustion in a vehicle. The WTW stage is the sum of WTP and PTW, i.e., is the whole-life of the algae fuel pathway. GHG emissions are reported as grams $\mathrm{CO}_{2}$ equivalent $\left(\mathrm{gCO}_{2} \mathrm{e}\right)$, which considers the global warming potentials of $\mathrm{CO}_{2}$, methane $\left(\mathrm{CH}_{4}\right)$, and nitrous oxide $\left(\mathrm{N}_{2} \mathrm{O}\right)$. Emissions and energy consumption are reported per million BTU (MMBTU) of RD based upon its LHV. 
The WTW GHG emissions are plotted for each season in Figure 3.3.2a. The histograms show the frequency distribution over the ensemble of 446 candidate sites in the 5 BGY scenario. Thus, each curve in the figure (one per season), has 446 entries and differences between the curves reveal seasonal differences in emissions. Winter emissions (black) are much larger than emissions in the other seasons: Most sites produce fuels with WTW GHG winter emissions exceeding those of low-sulfur (LS) diesel (LS diesel WTW emissions are 101,000 $\left.\mathrm{gCO}_{2} \mathrm{e} / \mathrm{MMBTU}\right)$. Figure 3.3.2b shows emissions from non-winter seasons in more detail. Spring (red) has the lowest emissions, but summer (green) is similar enough to average the two periods together. The fall distribution shows two weak peaks separated at roughly 68,000 $\mathrm{gCO}_{2} \mathrm{e} / \mathrm{MMBTU}$.

It may not be appropriate to average the fall data with the spring and summer, given the breadth of the fall distribution. Figure 3.3.2c shows the frequency distribution obtained when spring, summer, and fall are averaged at each site (red) and when just spring and summer are averaged (green). Including the higher peak from fall shifts, the seasonal average upward by 1,360 $\mathrm{gCO}_{2} \mathrm{e} / \mathrm{MMBTU}$. The best treatment would be to eliminate sites with high fall emissions because operating just spring and summer would make the site uneconomical. For sake of simplicity, the analysis presented here will average in the fall data, recognizing that in doing so, it may be overestimating the total fuel capability in the scenario.

To explore the issue further, the candidate sites can be grouped by their fall emissions, pooling together sites with lower fall emissions and sites with higher fall emissions. Low and high is defined by $68,000 \mathrm{gCO}_{2} \mathrm{e} / \mathrm{MMBTU}$, the boundary between the two weak peaks in the fall data. Figure 3.3.2d displays the geographic distribution of the two sub-samples and shows that the lower emissions occur in more southern portions of Florida. Further analysis (not shown) confirmed that fall emissions decreased as the site location moved south in Florida. Although the bimodal nature of the fall distribution may not be statistically significant, the geographic relationship is likely robust.

The remainder of the LCA analysis will exclude winter and it will be assumed there are no operations and no emissions during that period. Each site will be represented by the average over the site spring, summer, and fall emissions and energy consumption.

Figure 3.3.2e displays the geographic distribution of the WTW GHG emissions averaged over spring through fall, as described. PTW emissions is equal to the energy density of the fuel and is always equal to 77,503 $\mathrm{gCO}_{2} \mathrm{e} / \mathrm{MMBTU}$ for RD. WTP emissions are computed from the difference between WTW and PTW and, thus, precisely follow the geographical distribution in Figure 3.3.2e.

Since the emissions are a direct result of energy consumption, the geographical distribution of energy consumption in its various forms (fossil, petroleum, and total) will follow the same geographic distribution. Therefore, the remainder of the analysis will integrate over the geographical distribution by averaging over the ensemble of 446 site-specific data, each of which was obtained via seasonal averaging. Error bars will display the minimum and maximum of each quantity encountered in the ensemble. Figure 3.3.2f displays the results for fossil energy, petroleum energy, total energy (including renewable energy), and GHG emissions on a life-cycle basis. The values for algal RD are summarized in Table 3.3.2a. The uncertainty for petroleum is low, because petroleum consumption arises almost entirely from transportation. The variation in distance between refineries and sites in the 5 BGY ensemble is small compared to the 
transportation distance from refinery to terminal and station; hence, the small uncertainty displayed in the table.

Table 3.3.2a: WTW Results for RD Production in the 5 BGY Scenario Averaged Over Spring, Summer, and Fall

\begin{tabular}{|l|c|c|}
\hline WTW Quantity & Result & Units \\
\hline Fossil energy consumption & $0.68 \pm 0.02$ & BTU / BTU-RD \\
\hline Petroleum energy consumption & $0.106 \pm 0.002$ & BTU / BTU-RD \\
\hline Total energy consumption, including renewable & $3.4 \pm 0.03$ & BTU / BTU-RD \\
\hline GHG emissions (without winter) & $67,400 \pm 2,000$ & $\mathrm{gCO}_{2} \mathrm{e} / \mathrm{MMBTU}-\mathrm{RD}$ \\
\hline
\end{tabular}

Errors correspond to maxima and minima over the ensemble of sites. The total energy row includes renewable energy in the algal biomass, much of which is used on-site for power generation. If winter is included, the GHG emissions change from $67,400 \mathrm{gCO}_{2} \mathrm{e} / \mathrm{MMBTU}$ to $82,400 \mathrm{gCO}_{2} \mathrm{e} / \mathrm{MMBTU}$.

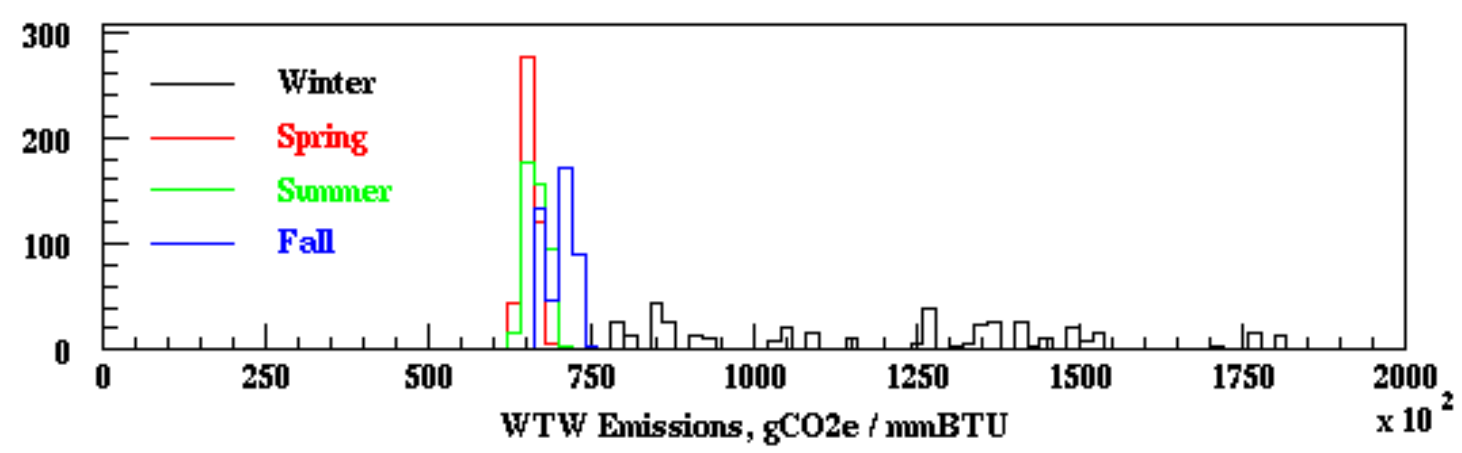

Figure 3.3.2a: Distribution of WTW GHG emissions in the 5 BGY scenario. Each of the four histograms has 446 entries corresponding to the 446 sites in the 5 BGY scenario. Differences between the histograms indicate seasonal differences in emissions. Winter emissions (black) are substantially higher. Note that petroleum diesel emissions are 101,000 gCO2e/MMBTU.

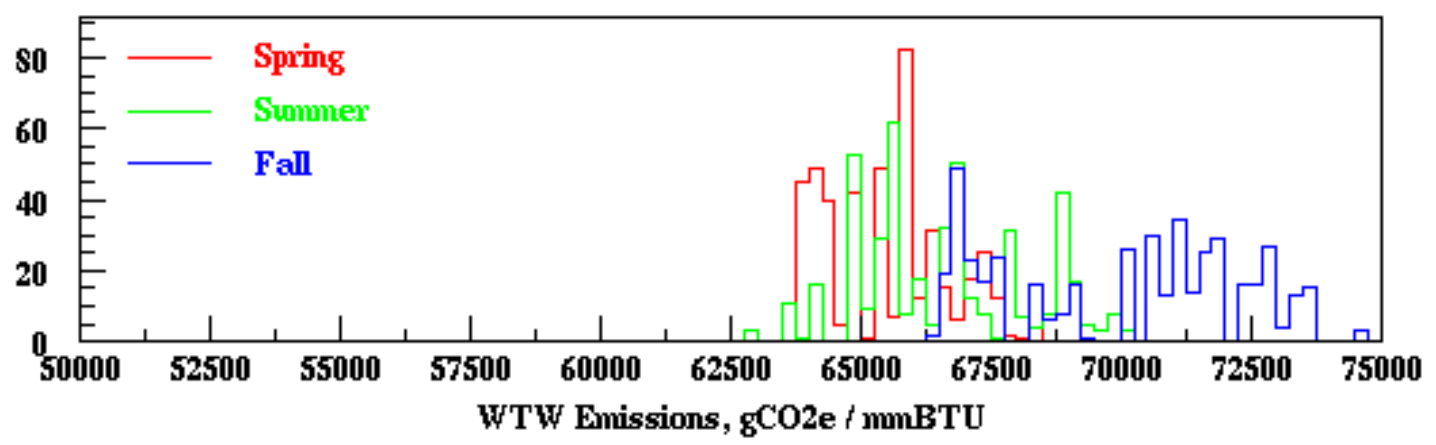

Figure 3.3.2b: Expanded view of Figure 3.3.2a for spring, summer, and fall. Spring and summer are similar enough to lump, but fall emissions are higher. 
Results

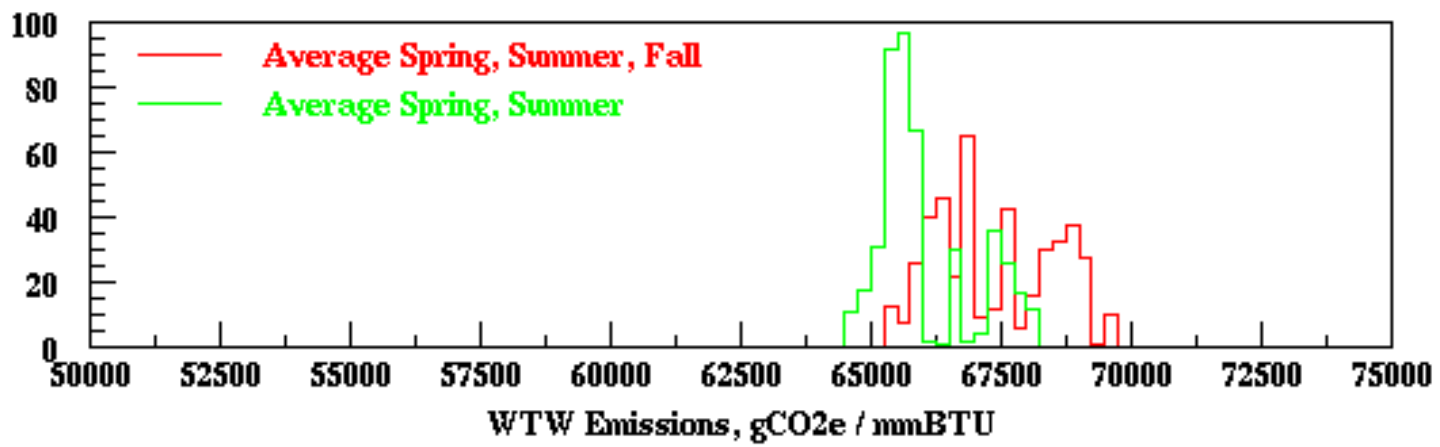

Figure 3.3.2c: Site distribution of WTW GHG emissions after averaging over spring, summer, and fall (red) or averaging over spring and summer (green). Including fall in the average shifts the distribution slightly upward.

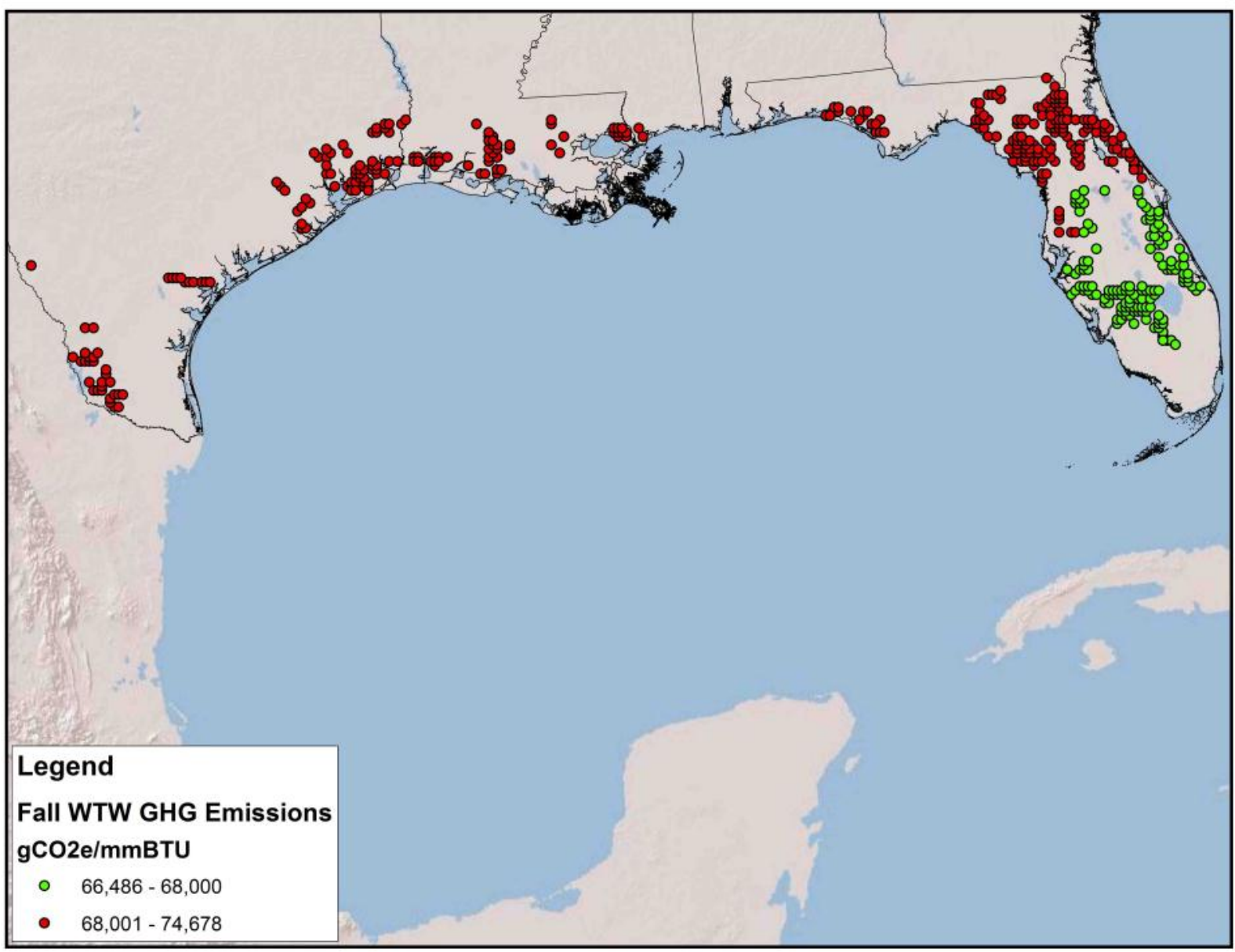

Figure 3.3.2d: The geographic distribution of sites with fall GHG emissions exceeding (red) or below (green) $68,000 \mathrm{gCO}_{2} \mathrm{e} / \mathrm{mmBTU}$ (red). The 68,000 threshold separates the two weak peaks in Figure 3.3.2b. Fall emissions decrease moving south on the Florida peninsula. 


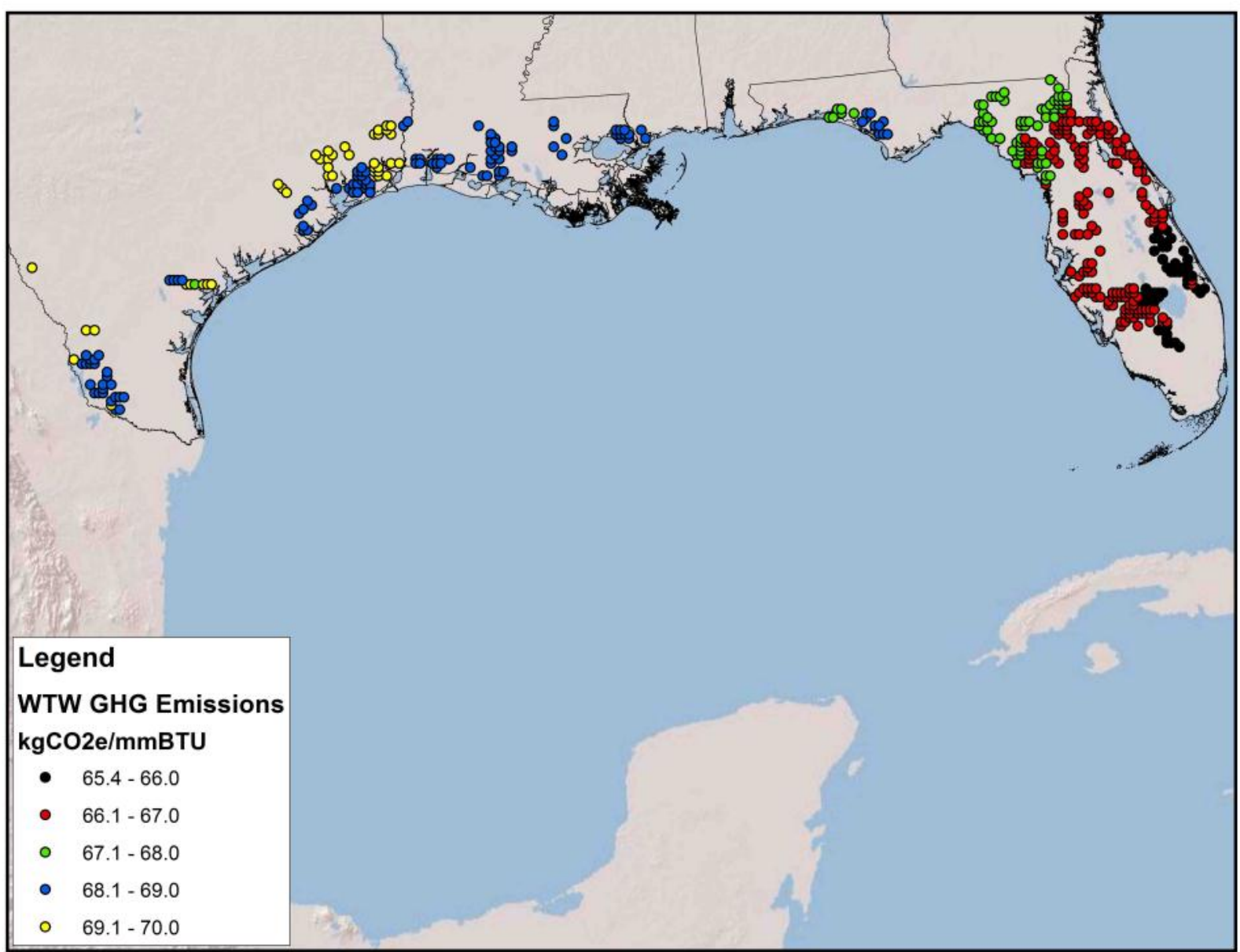

Figure 3.3.2e: WTW GHG emissions as a function of location after averaging spring, summer, and fall. An alternative scenario, Section 4.1 , reduces these numbers substantially. 

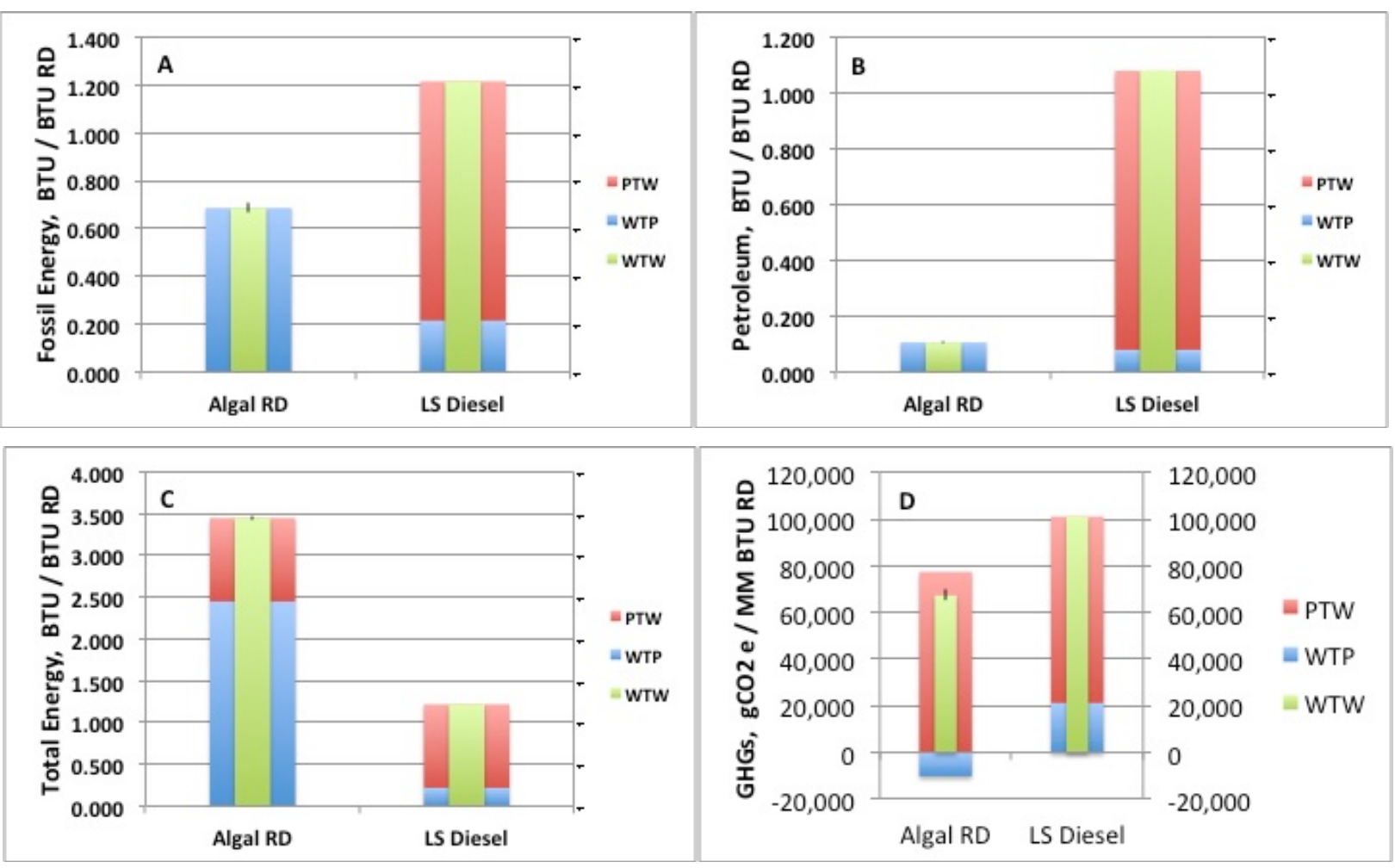

Figure 3.3.2f: WTW LCA results for (A) fossil energy, (B) petroleum energy , (C) total energy including renewable, and (D) GHG emissions for algal renewable diesel in the 5 BGY scenario. Error bars correspond to maxima and minima over the ensemble of sites.

\subsubsection{TEA Results}

The TEA analysis of the 5 BGY screening analysis was similar to the LCA in approach, but the manual nature of the Aspen-based process simulations interfaced with Excel-based costing makes it impractical to run each of the 446 sites individually. Consequently, the sites were grouped into "clusters" according to geographic proximity to reduce the cases to a manageable number, while maintaining reasonable distinctions in water consumption and seasonal variability between each group cluster. The unit farms were grouped as shown below in Figure 3.3.3a, and the average productivity and water consumption (by season) for each unit farm in the group was used as the representative basis for each grouped site in the Aspen models. The average productivity and water values for representative "groups 1-8" are shown in Table 3.3.3a. 


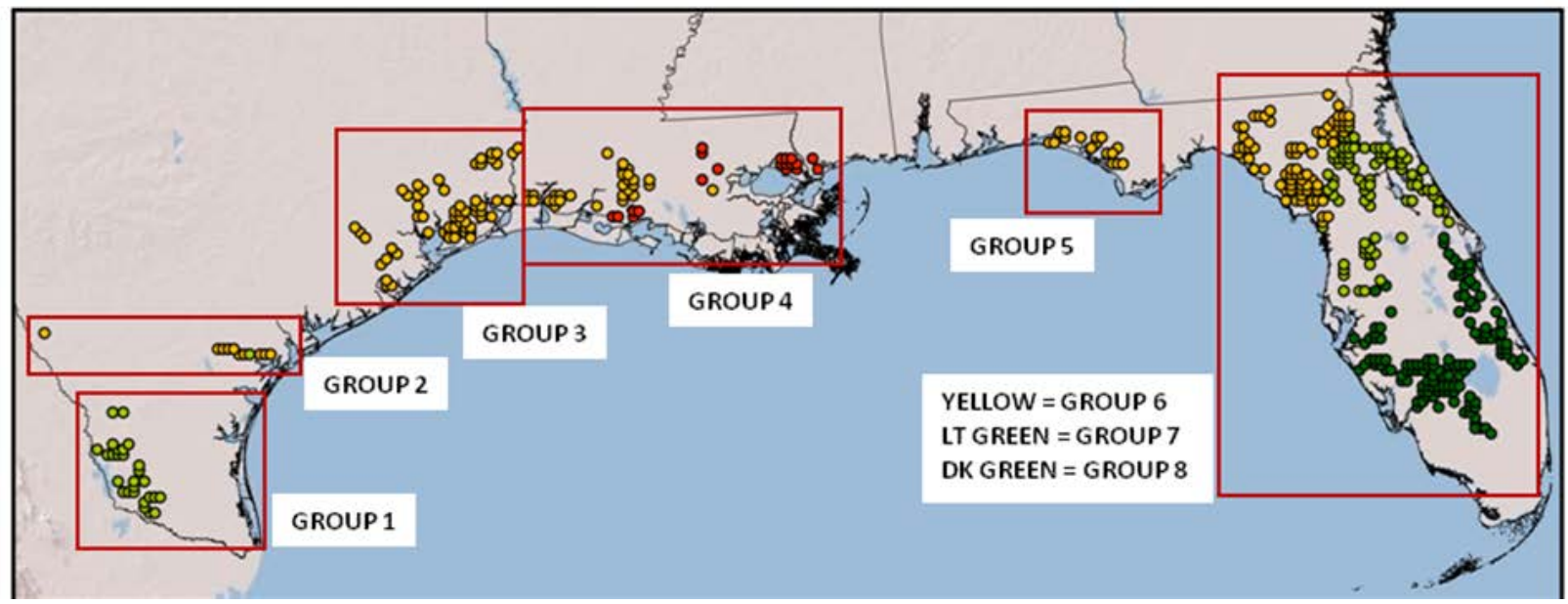

Figure 3.3.3a: Grouping of RA 5 BGY unit farms into representative sites for TEA modeling.

Table 3.3.3a: Average Productivity and Water Consumption Per Season for Each Site Group Maximum productivity (design case) for each site emphasized in bold.

\begin{tabular}{|c|c|c|c|c|c|c|c|c|c|}
\hline $\begin{array}{c}\text { Site } \\
\text { Group }\end{array}$ & $\begin{array}{c}\text { \# of Sites } \\
\text { in Group }\end{array}$ & \multicolumn{4}{|c|}{ Productivity, g/m²/day } & \multicolumn{3}{c|}{$\begin{array}{c}\text { Net Water Loss (Evaporation- } \\
\text { Precipitation), cm/day }\end{array}$} \\
\hline & & Summer & Fall & Winter & Spring & Summer & Fall & Winter & Spring \\
\hline 1 & 27 & 16.6 & 14.0 & 5.5 & 16.5 & 0.5 & 0.16 & 0.09 & 0.37 \\
\hline 2 & 11 & 15.8 & 13.6 & 5.1 & 16.2 & 0.36 & 0.12 & 0.03 & 0.21 \\
\hline 3 & 60 & 14.8 & 13.2 & 4.3 & 15.8 & 0.17 & 0.05 & 0.002 & 0.06 \\
\hline 4 & 49 & 16.5 & 12.6 & 2.8 & 15.0 & 0.04 & 0.01 & 0.001 & 0.02 \\
\hline 5 & 16 & 16.0 & 12.9 & 3.4 & 15.9 & 0.03 & 0.004 & 0.001 & 0.04 \\
\hline 6 & 77 & 16.3 & 13.5 & 4.5 & 16.2 & 0.04 & 0.01 & 0.003 & 0.08 \\
\hline 7 & 82 & 16.1 & 14.4 & 6.5 & 16.9 & 0.05 & 0.01 & 0.01 & 0.11 \\
\hline 8 & 124 & 15.4 & 15.4 & 10.0 & $\mathbf{1 7 . 6}$ & 0.03 & 0.01 & 0.02 & 0.15 \\
\hline Average & & \multicolumn{3}{|c|}{13.2} & & & 0.06 & \\
\hline
\end{tabular}

${ }^{1}$ Overall year-average of all unit farms in 5 BGY screening

While the LCA approach described above is concerned primarily with operating variables (yields, material input/output inventories, etc.) which scale with seasonal fluctuations, the TEA must include considerations for capital and other fixed expenses in the facility that inherently do not scale with varying throughputs. Consequently, the TEA analysis is conducted by setting the capital and fixed operating costs according to the season with maximum productivity (and thus throughput) for each of the eight site groupings shown in Table 3.3.3a, while allowing the variable operating costs and product revenues to fluctuate by season. The maximum seasonal productivity thereby sets the design case, while the installed equipment capacity remains partially under-utilized for the remainder of the year. As shown in Table 3.3.3a, the design case for some site groupings is set during the spring season, while for others it is set during the 
summer. Finally, the variable operating costs and fuel yields determined in Aspen for the three remaining seasons are scaled according to season length to determine total annual costs and yields for each site group. As in the previous TEA model, all cost results are presented here in 2007-dollars.

The TEA results for the 5 BGY scenario are presented in several ways. First, the costs associated with season-dependency (e.g., running seasonal models as described above and taking the weighted average cost results of the eight site groupings) is compared against a single yearaverage model, utilizing the overall average productivity and water loss values shown on the last row of Table 3.3.3a. This addresses the question raised during the Workshop as to how seasonal variability affects the TEA results relative to the previous approach assuming steady state, yearaverage values. As shown in Figure 3.3.3b, the season-dependent approach was shown to increase oil and diesel selling prices by nearly $\$ 1 /$ gal relative to the simpler year-average basis. Based on the RA output for the 5 BGY scenario, the year-average approach yielded an algal oil selling price of $\$ 16.64 /$ gal and diesel selling price of $\$ 18.63 /$ gal, while the season-dependent approach yielded a price of $\$ 17.47 /$ gal and $\$ 19.60 /$ gal respectively. While seasonal variability was shown to increase the cost perceptibly, the drop in productivity from $25 \mathrm{~g} / \mathrm{m}^{2} /$ day to an average of $13.2 \mathrm{~g} / \mathrm{m}^{2} /$ day is responsible for a much larger cost increase of nearly $\$ 6.50 / \mathrm{gal}$, relative to the adjusted process baseline of $\$ 12.15 /$ gal diesel shown in Figure 3.1b. Changes in water consumption based on the $5 \mathrm{BGY}$ scenario do not account for an appreciable cost impact, as shown later in the sensitivity analysis. A detailed breakdown of individual capital and operating cost contributions to the $\$ 18.63$ /gal year-average case is shown in Figure 3.3.3c, with specific costs shown in Figure 3.3.3d (see Appendix C for further cost details). These cost allocations reiterate that algal biofuel economics are largely driven by capital costs (constituting roughly $70 \%$ of the diesel selling price) relative to operating costs, a point that has been stated previously (Davis 2011). This is particularly true at the low average productivity of 13.2 $\mathrm{g} / \mathrm{m}^{2} /$ day, where pond and liner costs constitute nearly $60 \%$ of total installed capital expenses due to inefficient utilization of these costly capital expenditures. Similarly, fixed operating costs, which largely scale with capital costs, constitute the majority of the operating expenses (roughly $60 \%$ ). As productivity increases, the relative cost contributions of ponds, liners, and fixed operating costs decrease relative to other cost allocations. It should also be noted that the pond cost presented in Figures 3.3.3c and 3.3.3d cannot be compared directly to the cost presented in the Davis 2011 publication prior to harmonization, due to differing pond pricing estimates as noted above. 
Results

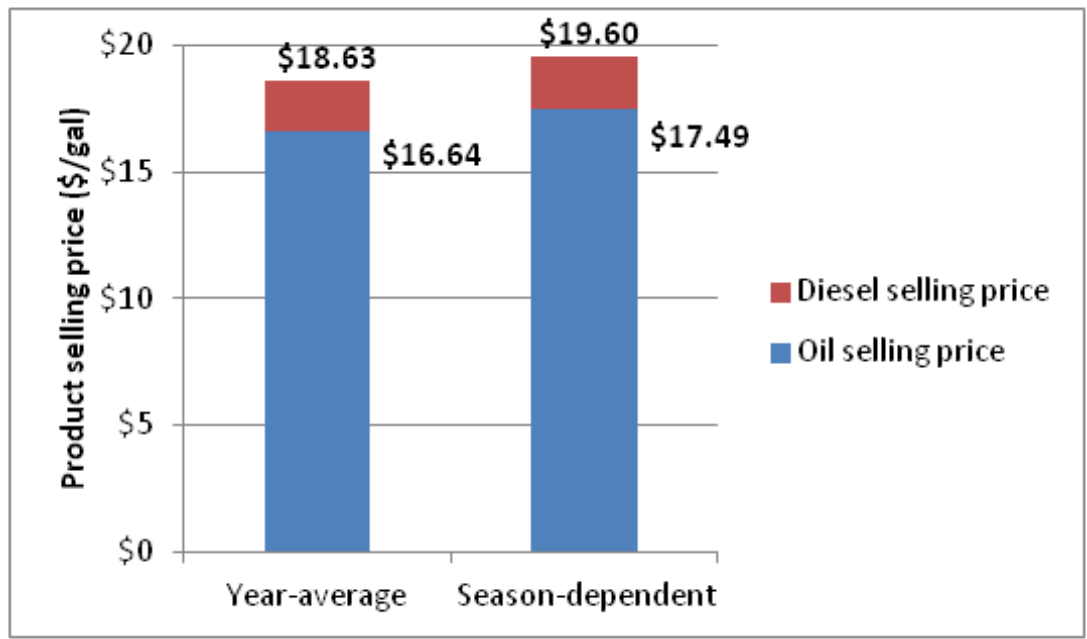

Figure 3.3.3b: Year-average and season-dependent cost results based on 5 BGY scenario.

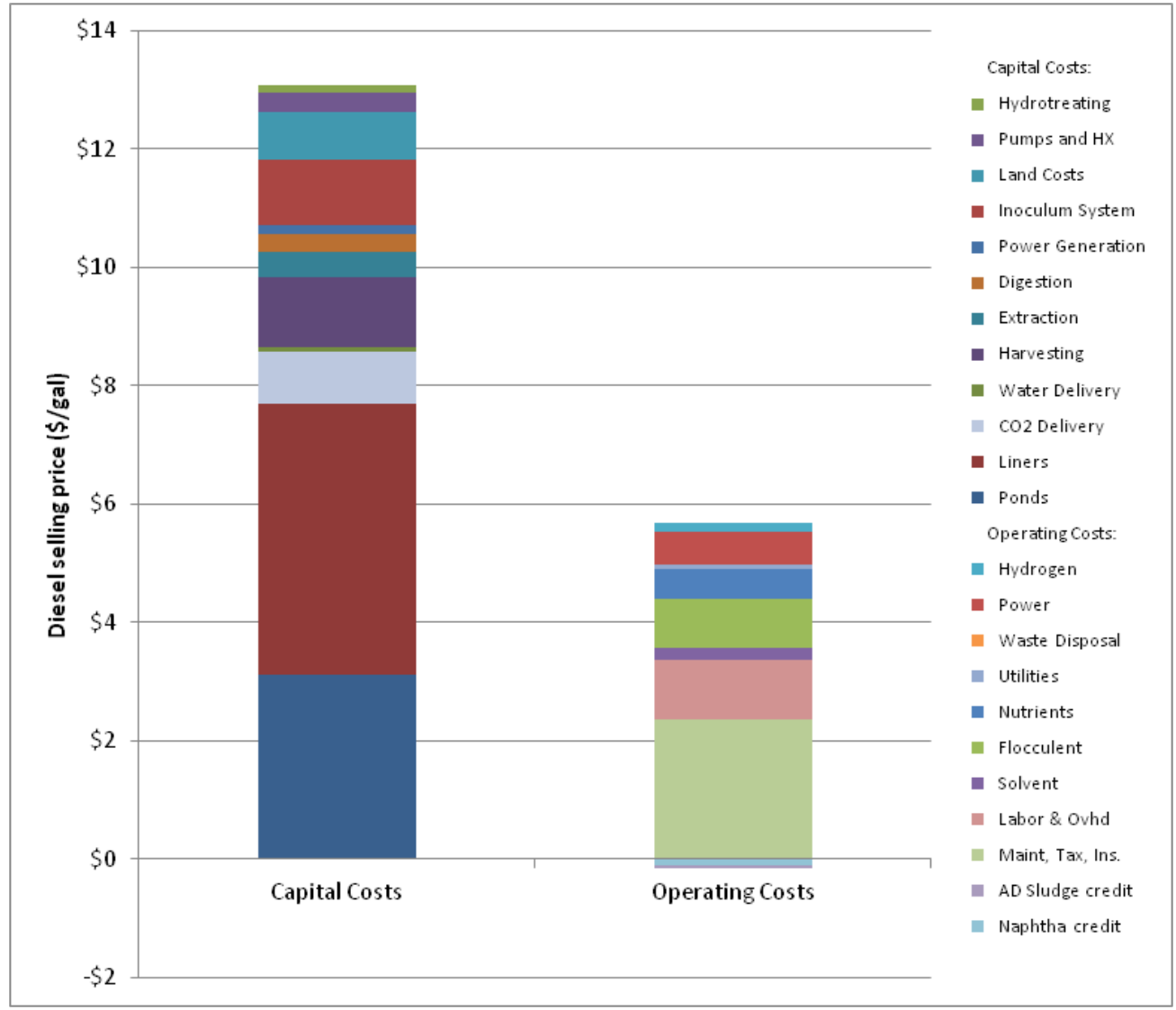

Figure 3.3.3c: Capital and operating cost contributions to the $\$ 18.63 /$ gal diesel price associated with the year-average output of the 5 BGY scenario. 


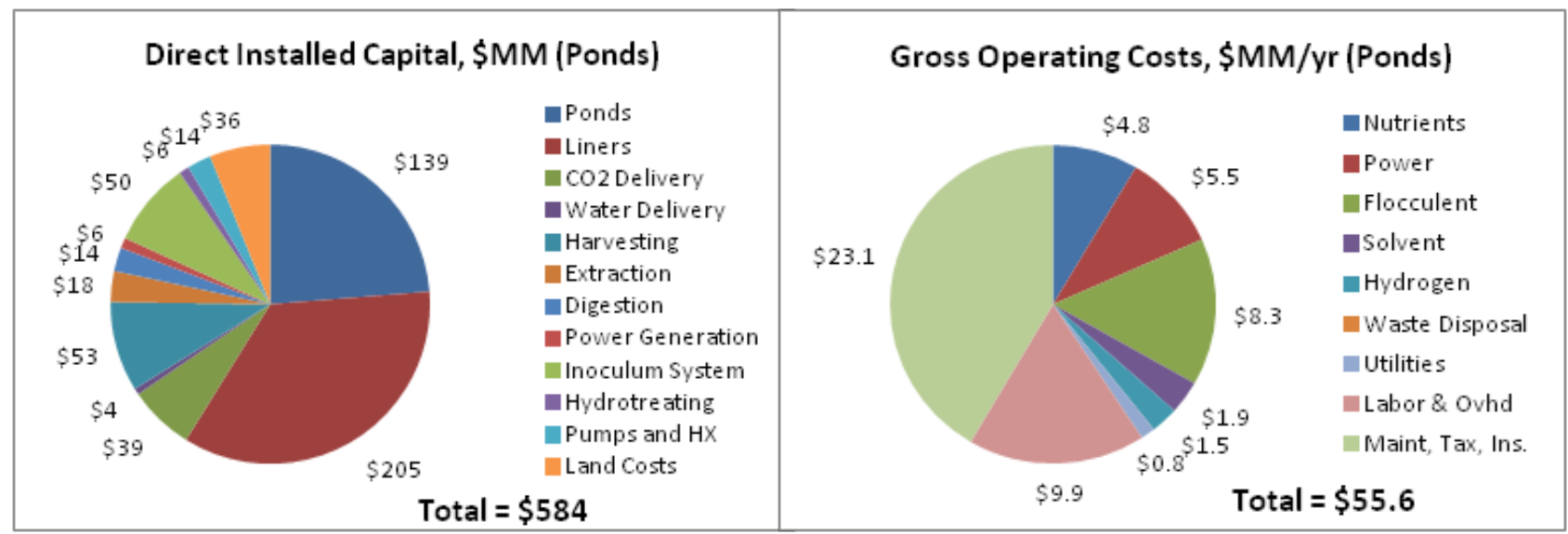

Figure 3.3.3d: Capital and operating expenses associated with the year-average output of the 5 BGY scenario (\$18.63/gal diesel).

Given the importance of seasonal variability on the overall cost results, the more rigorous season-dependent modeling basis will be used for the remainder of the TEA discussion. The cost results for each site grouping, as well as associated seasonal productivity ranges, are shown in Figure 3.3.3e. In addition to the obvious trend of higher prices at lower average productivity, Figure 3.3.3e also highlights another important result — namely that costs also decrease as seasonal variability decreases. A primary example is shown when comparing Site Group 4 with Site Groups 3 and 5, where although Group 4 has nearly the same year-average productivity as Groups 3 and 5 (and in fact a higher maximum-season productivity), it still shows a marked price increase over Group 3 or 5 due to a larger variation between maximum and minimum productivity, and thus overall less efficient utilization of the installed equipment capacity. This is further demonstrated in Group 8, which shows considerably lower seasonal variation along with the highest average productivity, resulting in a cost more than $\$ 3 /$ gal lower than the highest cost at Group 4. 


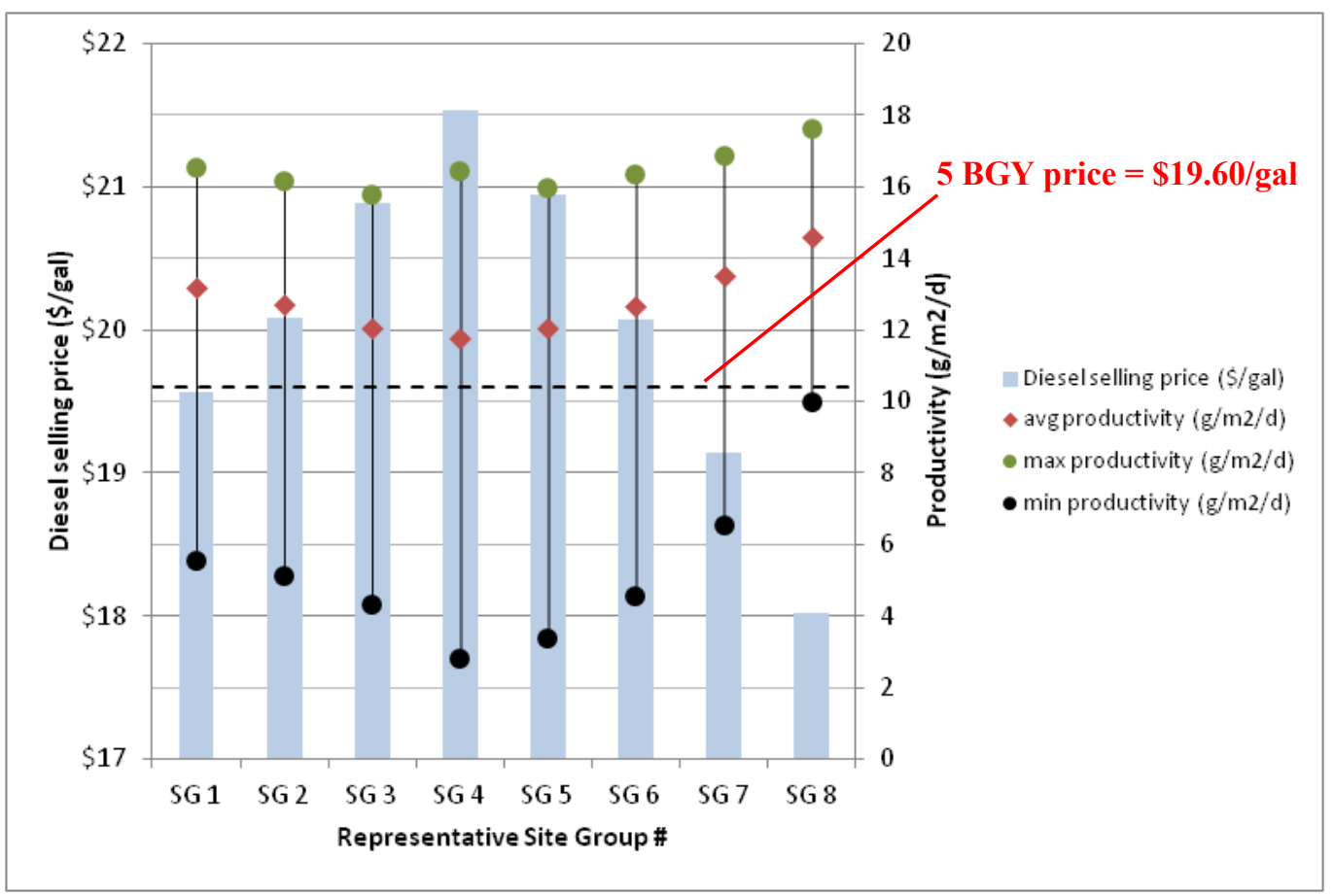

Figure 3.3.3e: Diesel selling price and seasonal productivity range for each representative site group. Reference line $=$ weighted average price for site groups 1-8 (5 BGY price).

Finally, given the very low productivity and high LCA penalty observed for most winter cases, the models were run for a winter shut-down scenario to evaluate the economic impact of ceasing operations between December-February. As shown in Figure 3.3.3f, it was found to be more beneficial to keep the facility running in all cases, with a price premium for winter shut-down ranging from $\$ 1.09-\$ 3.18 /$ gal diesel across the representative site groups. The weighted average for all sites in the $5 \mathrm{BGY}$ scenario was $\$ 19.60 /$ gal for year-round operation or $\$ 21.73 /$ gal for winter shut-down, representing an overall average price premium of $\$ 2.13 /$ gal for shutting the facility down in the winter. Therefore, even at low winter productivities of $3-6 \mathrm{~g} / \mathrm{m}^{2} /$ day, there is a fairly strong economic incentive to keep the facility running as long as the ponds do not freeze. This is due to the fact that variable operating cost (by definition the only costs which can vary throughout the production cycle) represent a relatively small fraction of total contributions to the product selling price at roughly $11 \%$. The small savings associated with removing this portion of the overall cost does not outweigh the larger amount of revenue lost during a winter shut-down. As such, the most beneficial basis for the 5 BGY scenario from a TEA standpoint is year-round operation, with a product selling price of \$17.49/gal algal oil, or \$19.60/gal diesel after harmonization. Again, this price is strictly intended to approximate today's economic baseline and is strongly dependent on a number of parameters as discussed below in the sensitivity analysis. 
Results

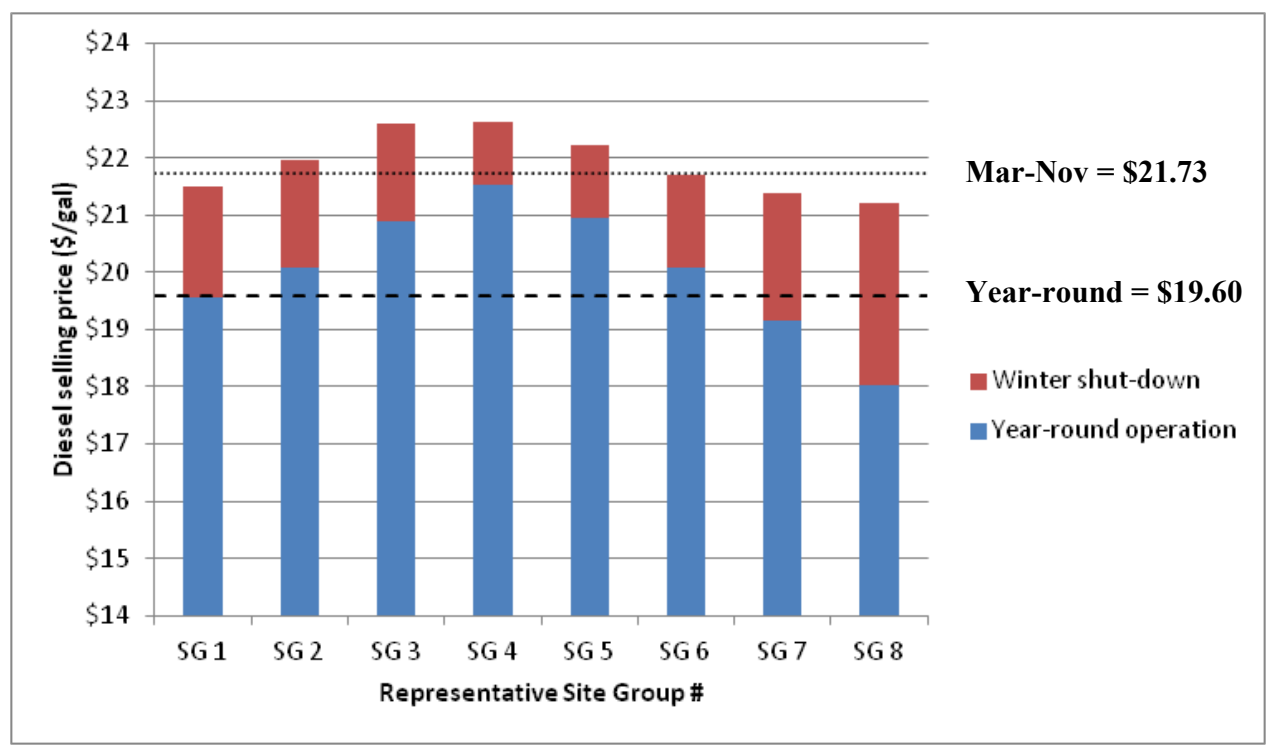

Figure 3.3.3f: Diesel selling price for year-round versus winter shut-down operating modes for the 5 BGY scenario. 
Discussion

\section{Discussion}

The RA screening analysis was intended to identify a collection of sites with the combined potential to produce $5 \mathrm{BGY}$ of fuel output. As a practical matter, the RA work was required as an input to the TEA and LCA analyses and was necessarily based on an early definition of the TEA and LCA harmonization. The RA model used local hourly meteorological data for a 365 day operating year (100\% operating factor), but subsequent TEA and LCA analysis imposed different operational constraints, e.g., 330 day/year operation in TEA and winter shut-down in LCA. As a result, there are a few remaining differences between the final TEA, LCA, and RA treatments, that ultimately cause the net RD production to fall below $5 \mathrm{BGY}$; nevertheless, the RA definition did ensure that a large enough scale was analyzed that we could not (inadvertently) choose "best of the best" sites that would give atypical or non-representative results. This was the real objective. Future harmonization iterations will refine the consistency between the models.

While the harmonization effort was a success both in terms of soliciting feedback to improve the models, as well as accomplishing the goal of harmonization itself, a number of large uncertainties remain in the harmonized models. Many of these uncertainties arise from insufficient public data for algal productivity, lipid content, and process unit performance (harvesting efficiency, extraction efficiency, operating downtime due to pond crashes or strain robustness, nutrient recycle potential, etc.). Productivity and lipid content for scaled-up, sustainable performance in an outdoor environment were very uncertain, yet exhibited tremendous influence over LCA and TEA results, particularly at lower lipid and productivity levels. The steep slopes in the productivity and lipid scans at lower values-Figure 3.1c and Figure 3.1d-mean that small changes in these parameters lead to large volatility in price, energy consumption, and emissions when the mean operating point lies in the steep slope portion of the curves. The current productivity value associated with the RA modeling output falls just in this range, causing LCA to reject the winter season and TEA to suffer over-sizing through much of the year. Moving the average operating point up to a stable region (small slope) can have large effects on the TEA and LCA results. This identifies where research can have a large effect for even modest increases in performance. For example, improving productivity to $20 \mathrm{~g} / \mathrm{m}^{2} / \mathrm{d}$ and improving TAG fraction to $30 \mathrm{wt} \%$, would improve system stability substantially. It is important to note that these values are examples for the current model and will change if the energy consumption or capital investment required per yield of product changes.

Since the productivity assumption affects the results so strongly, the RA productivity calculations were reexamined through sensitivity analysis, with regard to pond water temperature and light saturation (Figure 4a). The RA growth model first calculates maximum potential biomass production based on incoming solar radiation (location and time specific). This value is then corrected for the effects of pond water temperature and light intensity (saturation), through multipliers that range from 0 to 1 . In the sensitivity analysis, mean annual biomass production increased from $13.2 \mathrm{~g} / \mathrm{m}^{2}$-d to $19.1 \mathrm{~g} / \mathrm{m}^{2}$-d, with mean summer biomass production reaching 25 $\mathrm{g} / \mathrm{m}^{2}-\mathrm{d}$. In that case, $2.4 \%$ of the available solar energy was converted into biomass, still within the $1 \%-3 \%$ range of limited observations. Details of the sensitivity analysis are presented below. 
Discussion

The correction for water temperature in the growth model utilizes a piecewise linear function where:

- $\mathrm{T} 1$ is the minimum water temperature for zero productivity $\left({ }^{\circ} \mathrm{C}\right)$

- $\quad \mathrm{T} 2$ is the lower water temperature for optimal productivity $\left({ }^{\circ} \mathrm{C}\right)$

- $\mathrm{T} 3$ is the upper water temperature for optimal productivity $\left({ }^{\circ} \mathrm{C}\right)$

- $\mathrm{T} 4$ is the maximum water temperature at total culture loss $\left({ }^{\circ} \mathrm{C}\right)$.

The optimal pond water temperature for growing microalgae varies by strain and is the subject of continuing research. The literature suggests that optimal temperatures are generally between $20^{\circ} \mathrm{C}$ and $35^{\circ} \mathrm{C}$ (Chisti, 2007; Sheehan et al., 1998). Many microalgae can easily tolerate temperatures as much as $15^{\circ} \mathrm{C}$ lower than their optimal, but exceeding the optimal temperature by $2^{\circ} \mathrm{C}-4^{\circ} \mathrm{C}$ can cause total culture loss (Mata et al., 2010). To provide a conservative baseline estimate, we set the following temperatures:

- $\mathrm{T} 1=10^{\circ} \mathrm{C}$

- $\mathrm{T} 2=20^{\circ} \mathrm{C}$

- $\mathrm{T} 3=30^{\circ} \mathrm{C}$

- $\mathrm{T} 4=35^{\circ} \mathrm{C}$.

The multiplier for light utilization efficiency is modeled using the Bush equation (Huesemann et al., 2009) based on the intensity of incoming solar radiation and a light saturation constant (Ls). The light saturation constant for many strains ranges between 150 and 200 millimoles $(\mathrm{mmol}) / \mathrm{m}^{2} / \mathrm{s}$ (Chisti, 2007; Huesemann et al., 2009). To provide a conservative baseline assessment, we set Ls $=150 \mathrm{mmol} / \mathrm{m}^{2} / \mathrm{s}$.

The baseline results (CASE A in Figure 4a) represent a "generic" algal strain based on conservative parameter values taken from the literature. In application, one would ideally select an optimal strain for the growing region and climate. We explored additional parameter values within the common literature ranges noted above to examine how much the productivity estimate may change. For example, a $1^{\circ} \mathrm{C}$ increase in $\mathrm{T} 3$ and $\mathrm{T} 4$ shifts the peak biomass production from spring to summer (CASE B in Figure $4 \mathrm{a}$ ). This $1^{\circ}$ change is likely within the accuracy of the water temperature model and highlights the need for both addition model validation against observational data and better strain specific growth data and associated model refinement. Additional increases of $\mathrm{T} 3$ and $\mathrm{T} 4$ by $2^{\circ}$ and $4^{\circ}$ over baseline (cases $\mathrm{C}$ and $\mathrm{D}$, respectively, in Figure 4a) improve summer biomass production. Winter, spring, and fall production is increased by reducing $\mathrm{T} 1$ to $5{ }^{\circ} \mathrm{C}$, while keeping $\mathrm{T} 2$, T3, and $\mathrm{T} 4$ at $20^{\circ} \mathrm{C}, 34^{\circ} \mathrm{C}$, and $39{ }^{\circ} \mathrm{C}$, respectively (CASE E in Figure 4a). A significant increase in production over CASE E results from increasing the light saturation constant from 150 to $200 \mathrm{mmol} \mathrm{m}^{-2} \mathrm{~s}^{-1}$ (CASE F in Figure 4a). 


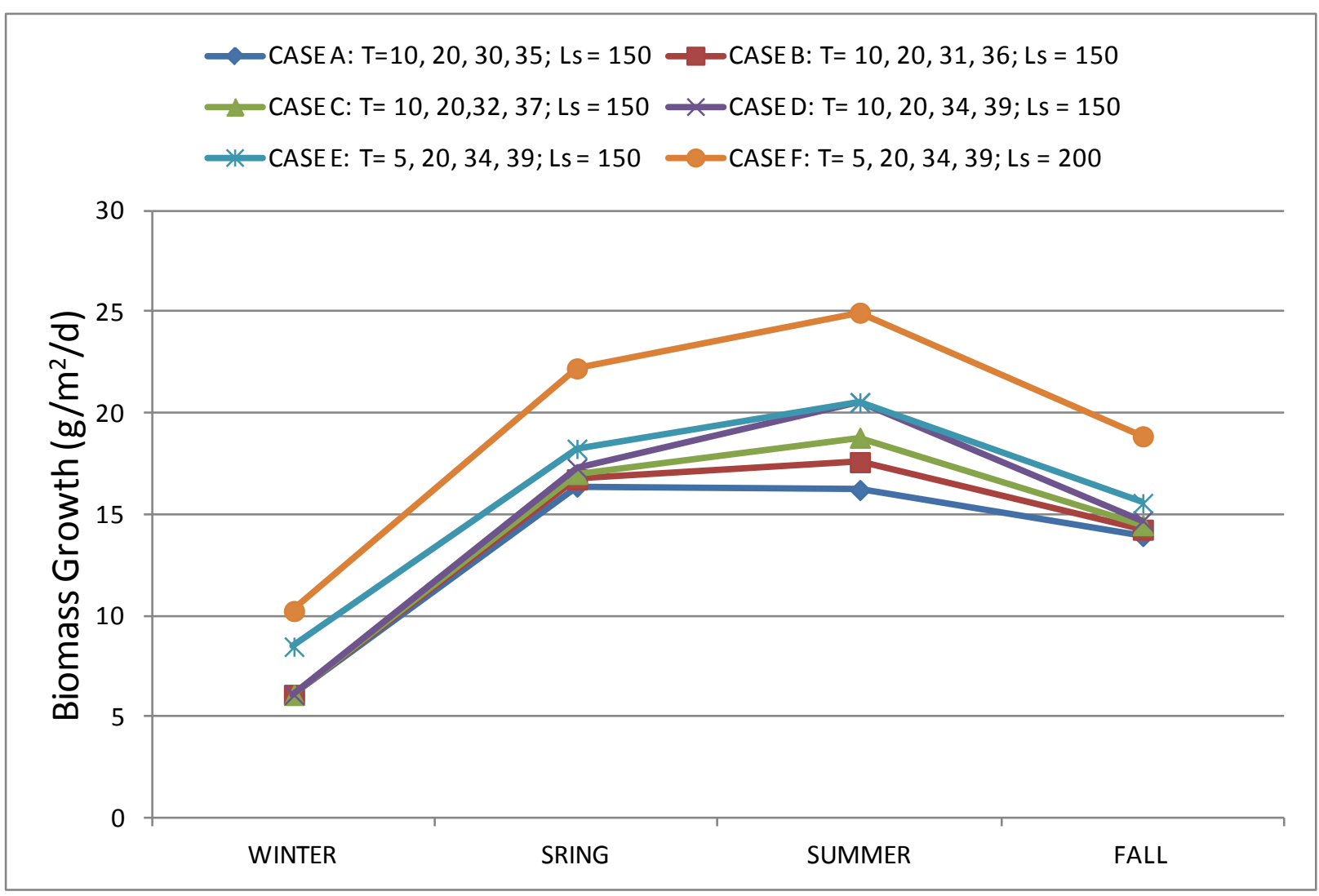

Figure 4a: Seasonal biomass productivity for selected water temperature and solar intensity model input parameter sets. For each case, parameter values are given for T1, T2, T3, T4, and Ls. For example, CASE A values are $\mathrm{T} 1=10^{\circ} \mathrm{C}, \mathrm{T} 2=20^{\circ} \mathrm{C}, \mathrm{T} 3=30^{\circ} \mathrm{C}, \mathrm{T} 4=35^{\circ} \mathrm{C}$, with an $\mathrm{Ls}$ of $150 \mathrm{mmol} / \mathrm{m}^{2} / \mathrm{s}$.

Beyond productivity and lipid content variations, the sensitivities of other process variables are equally important to quantify. Figure $4 \mathrm{~b}$ shows the cost sensitivity of a number of process variables in the TEA model. The first parameter with a high degree of uncertainty and high cost impact is the assumed extraction efficiency. As noted previously, the base assumption of $85 \%$ extraction efficiency is derived from $90 \%$ cell disruption efficiency in the homogenizer (GEA 2012; Milledge 2011; Greenwell 2009), plus 5\% loss of extracted oil via entrainment in the water phase after phase separation. However, there are very few other data sources to support largescale extraction efficiency, particularly on a wet process as stipulated here. When the extraction efficiency is increased to $100 \%$, the diesel selling price decreases by $\$ 2.80 / \mathrm{gal}$, and when decreased to $60 \%$, the cost increases by $\$ 8.30 /$ gal. This is not due to the extraction cost itself (as evidenced by the much lower sensitivity to varying extraction cost), but rather to the high cost of ponds and liners, whose expense in growing algal biomass goes to waste if the lipids are not recovered.

The analysis shows that liners add significant capital costs. For reasons described above, a plastic liner was added to the baseline scenario, which added $\mathbf{\$ 5 . 5 0 / g a l}$ to the diesel selling price in the 5 BGY scenario. Thus, if the ponds did not in fact require a plastic liner, the 5 BGY price would decrease to roughly $\$ 13.90 /$ gal. As shown in Figure 3.3.3c, adding a liner more than doubles the pond cost, which is in line with other studies (Lundquist 2011). Liners provide advantages such as reducing the uncertainties that arise from leakage potential (both a water consumption and 
contamination issue) and circulation costs due to the roughness of unlined ponds. However, a liner is not a technical requirement for pond operability if the soil characteristics are satisfactory, making this a highly contentious assumption. Due to the large added costs, we seek to identify viable alternatives to a plastic liner. Natural materials seemingly have the potential to be cost effective, but even clay-rich natural soils will leak due to soil structure, roots, and worm burrows, etc. While local soils may have sufficient clay to be used as a lining material, they will also require significant reworking (compaction, etc.) to serve as reliable barriers to infiltration. Cost estimates from landfills suggest the installation of a 1 foot clay liner is equivalent in cost to an HDPE geoliner (note: the pond costs assumed in the present TEA analysis, based on Lundquist 2011, include soil working and other site preparation costs to negate the need for liners). Therefore, this parameter will be a local issue, dependent both on local regulatory policies and local soil characteristics. The regulatory framework for lining requirements has yet to be developed for algal ponds, so currently the best analog is sanitary landfills. Envisioned requirements could range from a HDPE plastic plus clay liner (to provide additional leakage protection) to a thin clay liner. Another potential issue is liner replacement, where a 40-mil HDPE liner may require replacement within the 30-year facility lifetime, depending on environmental variables; in this case, the baseline cost would increase by a similar $\$ 5.50 / \mathrm{gal}$. Realistic assessment of liner costs remains a significant issue for research.

The next sensitivity parameter is the assumed operating factor. Again, for the baseline 5 BGY scenario, the assumption of 330 operating days/year was left unchanged from the previous TEA model. This is intended to cover pond crashes and other maintenance applied sparingly throughout the year. If the factor were increased to 365 days/year (improbable even for $n^{\text {th }}$-plant operation), the diesel price would decrease roughly $\$ 1.60 /$ gal, but if the factor were decreased to 250 days/year (due to pond freezes, increased pond crashes and re-inoculation, etc.), the price would increase by $\$ 5.30 /$ gal. This reiterates the importance of a robust algal strain, as well as locating the facility in locations where freezing is minimal. The remaining parameters are largely self-explanatory; however, it is worth noting the low cost sensitivity to water consumption that continues to be observed in the TEA model where varying the evaporative water losses by an order of magnitude has a trivial cost impact. Of course, this does not address the obvious sustainability issues inherent in water usage. The higher cost sensitivity associated with adding a water blowdown stream back to the model is due to losses in algal biomass that ensue from taking a slipstream of the recycle material. The final point worth noting is the sensitivity to nutrient recycle. From a cost standpoint, nutrient recycle is only one of several benefits gained with the use of AD for spent biomass utilization, in addition to significant heat and power production and CHP flue gas recycle. The nutrient costs alone were found to be considerable, but not as highly impactful to the overall cost results as a number of other key variables, as evidenced by the mediocre cost sensitivity to nutrient recycle variations in Figure 4b. Such a result would be similarly applicable to biomass composition (e.g., $\mathrm{C} / \mathrm{N}$ and N/P ratios); while composition can be highly variable and dependent on the point at which harvesting occurs, from a cost standpoint such variations in biomass nutrient demands would mirror the sensitivity to nutrient recycle variations presented here, which do not exhibit an overwhelmingly high economic impact relative to other uncertainties (particularly when AD and nutrient recycle are employed). 


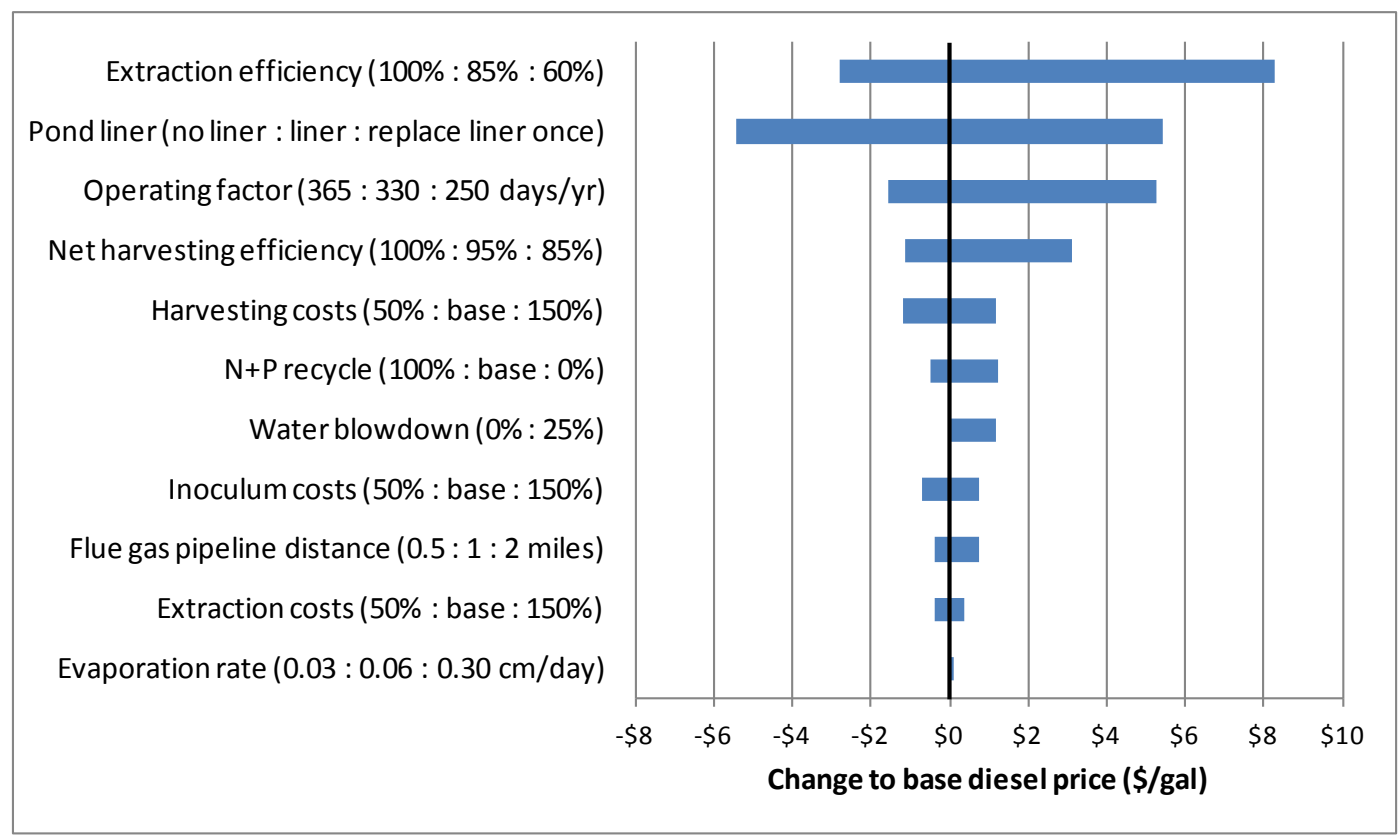

Figure 4b: Cost sensitivity tornado plot for process changes, excluding lipid content and algal productivity variations. Base diesel selling price $=\$ 19.60 /$ gal for 5 BGY scenario.

A final note should also be emphasized regarding selling price versus cost of production; at times these terms are used interchangeably, wrongfully so, as they have very different meanings. All cost figures presented here are representative of minimum product selling price (MSP), including profit at a $10 \%$ internal rate of return. In contrast, the breakeven cost of production (COP), which merely covers the cost of all capital and operating expenses, would be $\mathbf{\$ 8 . 5 2 / g a l}$ algal oil or $\$ \mathbf{\$ 9 . 8 5} /$ gal diesel for the $5 \mathrm{BGY}$ year-round scenario of $\$ 17.49$ and $\$ 19.60 /$ gal MSP for algal oil and diesel, respectively. Such a large difference between COP and MSP is due to the capitalintensive nature of the process, which requires a large return on capital investment.

The LCA and TEA have contrary pressures during winter. Fuel costs are minimized by operating during the winter while GHG emissions are unacceptably high, often exceeding emissions from petroleum diesel. The detailed harmonization analysis and spatially explicit RA (including seasonal) were required to reveal this relationship. An alternative possibility to improve both the TEA and LCA results associated with winter production could be to switch production modes toward targeting alternative products, or co-products, during anticipated periods of low productivity, such as during winter months. This alternative scenario is outside the scope of the current harmonization exercise, but could be a beneficial area for future analysis.

\subsection{Alternative Scenarios}

The baseline harmonized scenario reflects a conservative analysis. This section explores implications for a few changes in system configuration and performance. In doing so, we quantify performance improvements associated with the changes and illustrate how the baseline model serves as a metric for assessing technology changes. Similar analyses will be done with process data emerging from DOE and industrial R\&D programs.

Where possible, changes in the model were motivated by emerging technology. LCA, TEA, and RA results do not have identical drivers. For example, reducing pond mixing (paddlewheel) 
power affects LCA strongly, but is not a major cost driver. Similarly, removing pond liners strongly affects TEA results, but does not affect emissions strongly. Therefore, the variables studied in the LCA, TEA, and RA sections below do not always coincide.

There is significant uncertainty in the biophysics of microalgae growth, particularly processes associated with the conversion of incoming solar radiation to biomass and determining these conversions for many different algal strains. Mean annual biofuel (RD) yield for sites contributing to the $5 \mathrm{BGY}$ target is $1,120 \mathrm{gal} / \mathrm{ac} / \mathrm{year}$. As noted previously, numerous algal strains have been shown to produce $20 \%-50 \%$ of their dry weight biomass as lipids, resulting in oil yields of 1,000-6,000 gal/ac/year (Mascarelli, 2009; DOE, 2010). Hence, this baseline scenario is conservative relative to published experimental yields and is especially so in terms of potential technological improvements.

We explore the impact on the 5 BGY downselect of doubling and tripling productivity from the baseline scenario, to an average of 2,240 and 3,360 gal/ac/year of RD. This could be the result of increased biomass production and/or increased lipid content. The magnitude of these changes would likely vary spatially due to the non-linear influence of solar intensity and water temperature on biomass growth. However, for our initial investigation, we assumed a simple doubling or tripling of productivity at each site.

Doubling productivity eliminates sites in the central Gulf Coast and production is clustered in southeast Texas and Florida (Figure 4.1a). The required land area is reduced by $53 \%$ to an area equivalent to $0.13 \%$ of the CONUS land area (Table $4.1 \mathrm{a}$ ). Water demand is reduced by onethird to a volume equivalent to $2.2 \%$ of the U.S. consumptive water requirement of irrigated agriculture. Water per unit of biofuel is reduced by $30 \%$ to 139 gal water per gal biofuel. Note that such a scenario would place the LCA and TEA results near the "intermediate" biomass production and/or lipid content curves presented in Figures 3.1c-d, resulting in a fundamental shift in the established baseline costs and GHG profiles for the harmonized results.

Tripling productivity reduces the required number of production sites significantly, with most remaining sites located in southeast Texas and Florida (Figure 4.1a). The required land area is reduced to an area equivalent to $0.09 \%$ of the CONUS land area. Water demand is reduced $52 \%$ from the baseline to a volume equivalent to $1.6 \%$ of the U.S. consumptive water requirement of irrigated agriculture. Water per unit of biofuel is reduced to 102 gal water per gal biofuel.

Table 4a: Land and Water Demand Associated With Increased Productivity

\begin{tabular}{|c|c|c|c|}
\hline & \multicolumn{3}{|c|}{ Increase in Productivity } \\
\hline & Baseline & $2 x$ & $3 x$ \\
\hline Percent of CONUS Land ${ }^{1}$ & 0.2822 & 0.1316 & 0.0861 \\
\hline Percent of U.S. Irrigation & 3.26 & 2.16 & 1.56 \\
\hline Water/Oil (gal/gal) & 195 & 139 & 102 \\
\hline
\end{tabular}

${ }^{1}$ Based on CONUS land area of 7,663,941.70 $\mathrm{km}^{2}$ 

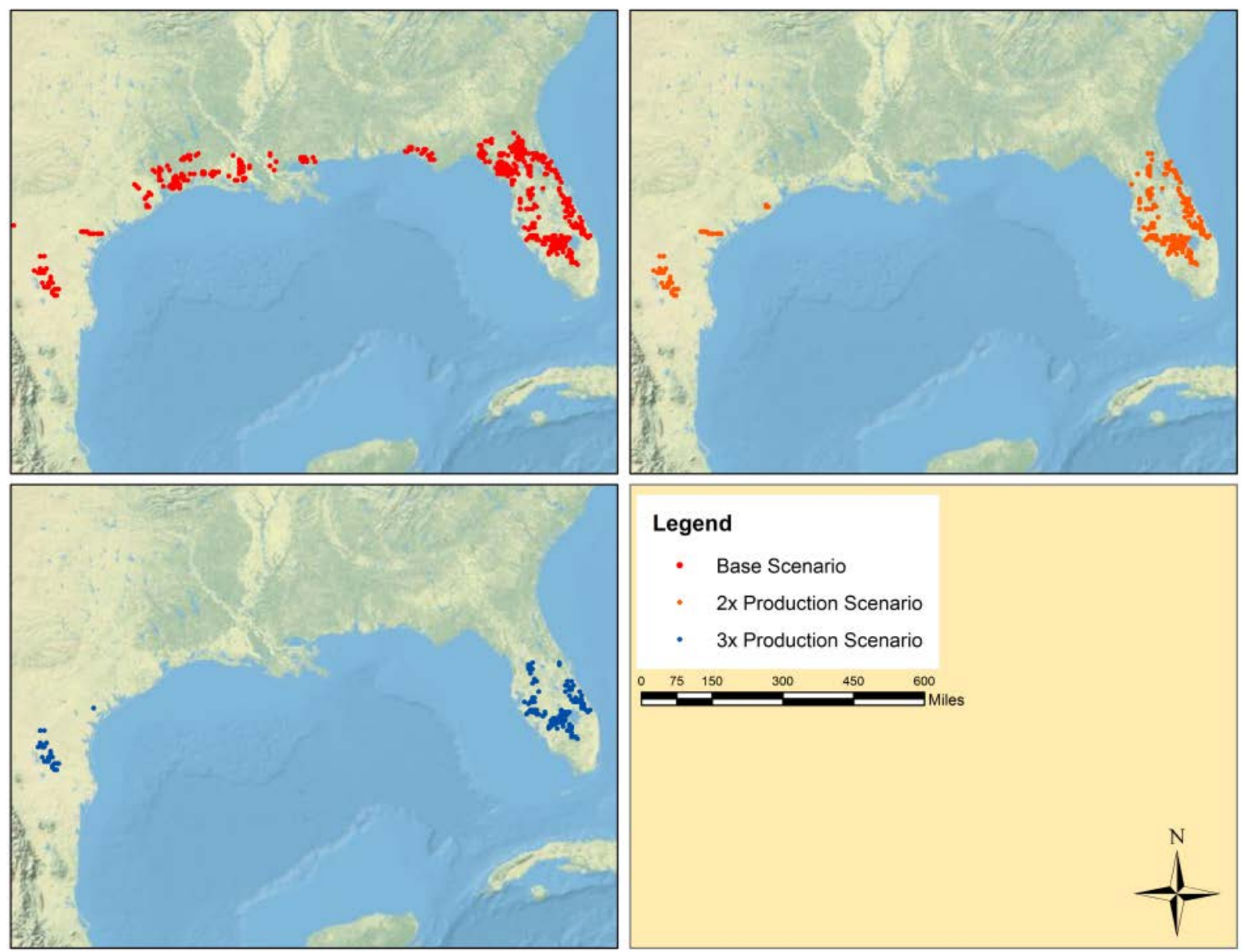

Figure 4.1a: Locations of unit farms required to meet the 5 BGY biofuel production target under: (a) the baseline scenario (upper left), (b) a doubling of production at each site (upper right), and (c), a tripling of production at each site (lower left).

Four changes were explored for LCA implications, namely:

1) Reducing fugitive methane emissions from $2 \%$ of the biogas volume to $0.2 \%$

2) Replacing $\mathrm{AD}$ with catalytic hydrothermal gasification

3) Discarding the flue-gas generated on-site, rather than recycling it

4) Reducing the paddlewheel power consumption

The fugitive methane emissions included in the LCA analysis are intended to illustrate the consequences for operating digesters with losses like those reported in two audits (Flesch et al., 2011; Liebetrau et al., 2010) and as commonly assumed in biogas modeling (Borjesson and Berglund, 2006; Moller et al., 2009). By contrast, the natural gas processing industry has much lower emissions, below $0.2 \%$, so we considered a scenario with $0.2 \%$ fugitive methane emissions.

Catalytic hydrothermal gasification is a catalytic wet process that reduces carbon and nitrogen in organic materials to methane and ammonia. It is compact, fast, and hermetic, while AD requires large volumes and long residence times. It is plausible that this technology will have $0.2 \%$ or 
lower fugitive emission rate. Data from one developer (Genifuels 2011) indicated both nitrogen and phosphorus recovery over $95 \%$. We consider a scenario with catalytic hydrothermal gasification instead of AD. The scenario assumes $90 \%$ recovery for both nitrogen and phosphorus.

The baseline harmonized scenario returned flue-gas from the CHP system to the culture to minimize $\mathrm{CO}_{2}$ demand. The flue-gas $\mathrm{CO}_{2}$ concentration is low on site- $8 \mathrm{wt} \%$ - and the flue gas is hot. The low concentration requires large volumes of flue gas to be sparged into the pond and the elevated temperature reduces blower efficiency. A better design would purify the $\mathrm{CO}_{2}$ from the flue-gas stream, but this requires tradeoffs between heat balance and power balance in the system that were not considered. We evaluated an alternative scenario in which the flue-gas is not returned to the culture to avoid blower energy demand.

Pond mixing, which keeps the algae in suspension during growth, accounts for much of the process power demand. Waterwheel Factory, Inc. in Franklin, North Carolina, is working with a number of algae production developers and has developed alternative patented and patent pending paddlewheel designs and configurations (Waterwheel 2012). Waterwheel engineers computed power requirements for their design for a 667-foot long raceway with 60-foot wide channels $(0.7 \mathrm{ha})$, the largest they have found practicable. At $25 \mathrm{~cm} / \mathrm{s}$ mixing speeds, their computations predict $13 \mathrm{KWh} / \mathrm{ha} / \mathrm{d}$ and $7 \mathrm{KWh} / \mathrm{ha} / \mathrm{d}$ for two possible configurations. These results are to be compared with the $45 \mathrm{KWh} / \mathrm{ha} / \mathrm{d}$ assumed in the baseline harmonized model. The computations were tested by experiments at Waterwheel Factory, Inc. test ponds using a Leeson 1/4 horsepower, 3 phase 230 Volt AC motor connected to an IPTS 100:1 gear ratio worm gear box and an AC Tech / Lenze SMVector Variable Frequency Drive. These were connected to a 96 inch long Waterwheel Factory Helix/Scissor wheel, in a water depth of approximately $1 \mathrm{ft}$ $(30 \mathrm{~cm})$. They were measured using a general instruments FW450 flow meter at 16 data points across the width of the pond at both forward and reverse channel points ( 8 each). Based on these data, we examine a scenario in which the baseline mixing power is reduced from $45 \mathrm{KWh} / \mathrm{ha} / \mathrm{d}$ to $13 \mathrm{KWh} / \mathrm{ha} / \mathrm{d}$.

Figure $4.1 \mathrm{~b}$ explores the GHG implications of these changes when applied cumulatively. Each curve adds another change to those above it, e.g., the scenario studied in the bottom curve labeled, "reduced mixing power" also has no $\mathrm{CO}_{2}$ recycling, has $\mathrm{CHG}$ instead of $\mathrm{AD}$, and has reduced fugitive methane emissions. Productivity was assumed to be $12.5 \mathrm{~g} / \mathrm{m}^{2} / \mathrm{d}$. The baseline scenario fails to achieve $50 \%$ reduction in GHG emissions relative to the 101,000 $\mathrm{gCO}_{2} \mathrm{e} / \mathrm{mmBTU}$ emissions from petroleum diesel regardless of the algal lipid fraction. When the changes described above are applied, the final system satisfies the 50\% goal for all lipid fractions considered. This demonstrates that, for LCA, productivity and lipid fraction requirements change significantly as process energy demand changes.

Figure 4.1c considers the final system, with all modifications above applied, by scanning over both lipid fraction and productivity just as was done in Figure 3.1c for the baseline system. When the lipid fraction is low, more biomass is used for power generation. The convergence of the curves below $20 \mathrm{wt} \%$ lipid fraction reflects cases in which the on-site power production completely meets process needs. GHG emissions rise beyond that lipid fraction because the renewable energy in the biomass remnants falls, forcing use of grid power. In the productivity plot, the emissions become independent of productivity once the productivity level is high enough that the rate of biomass remnant production after lipid extraction corresponds to the onsite power demand. 
Discussion

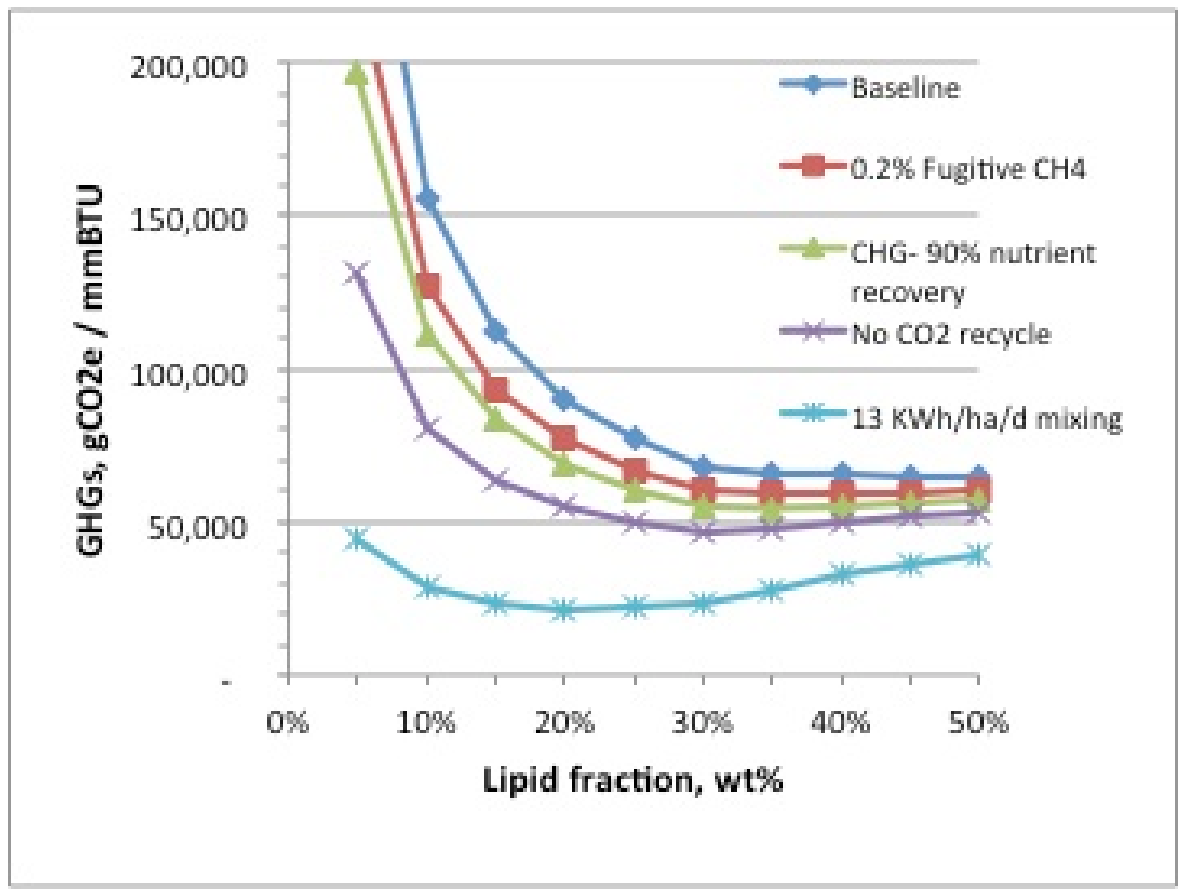

Figure 4.1b: Life-cycle GHG emissions for four alternative scenarios. The four changes defining the scenarios are applied cumulatively. The legend text is described in the text. Productivity was assumed to be $12.5 \mathrm{~g} / \mathrm{m}^{2} / \mathrm{d}$ for comparison with Figure 3.1c. The baseline curve, defined by the baseline analysis, serves as a metric for process changes. Note: Petroleum LS diesel fuel emissions are 101,000 $\mathrm{gCO}_{2} \mathrm{e} /$ $M M B T U$ of $R D$. Although lipid fraction and productivity are not independent variables, the plots display the system sensitivity to both parameters.

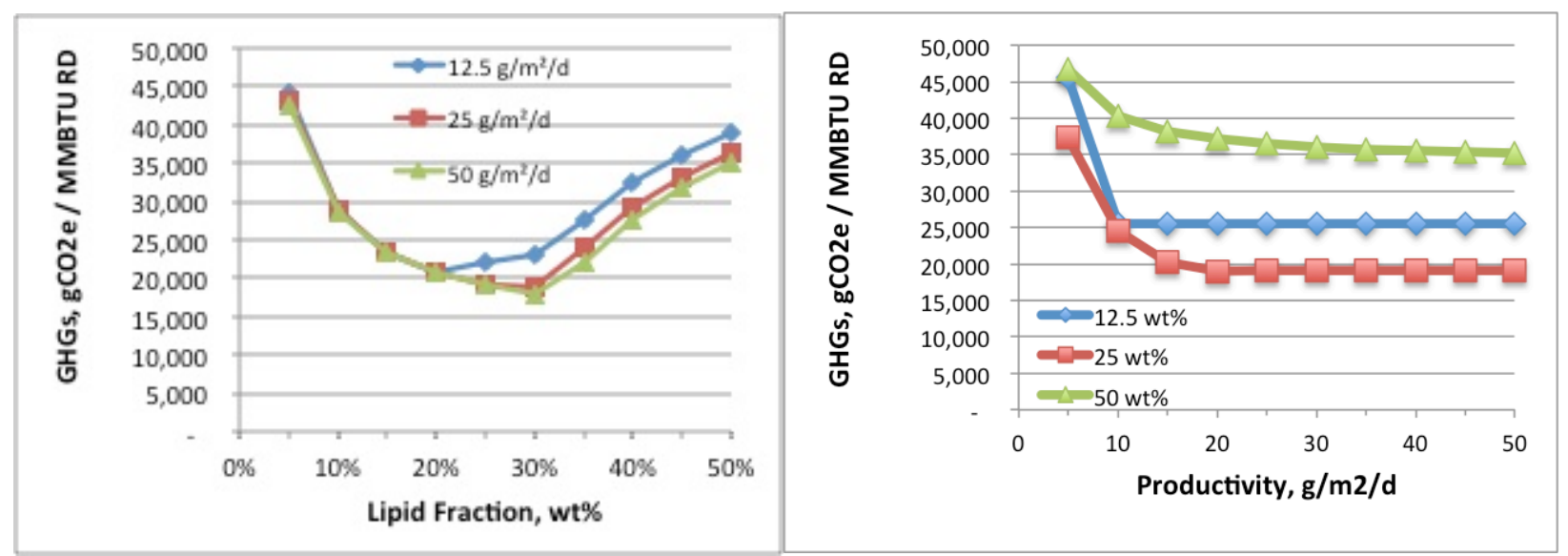

Figure 4.1c: Life-cycle GHG emissions as a function of lipid fraction and productivity when several emission-reducing options are considered. Although lipid fraction and productivity are not independent variables, the plots display the system sensitivity to both parameters. 
A number of improvements were also explored for TEA implications. The driving issues noted above for LCA such as fugitive methane emissions, nutrient recycling, and power consumption are not the main drivers behind TEA. Rather, TEA is more strongly correlated with capital costs associated with algal cultivation and processing. The improvements investigated for TEA include:

1) Reduce harvesting and extraction costs to acknowledge developing technologies for these operations

2) Reduce pond and liner costs associated with either a simpler design or less rigorous site development requirements

3) Replace anaerobic digestion with a dried algal residue byproduct for animal or fish feed

4) Remove the requirement for pond liners.

The first area for TEA improvement is to reduce harvesting and extraction costs. Current costs are derived largely from wastewater technologies given the emphasis on a baseline, near-term model. However, standard wastewater operations do not prove to be as cost-efficient as required for algal oil production. While there are a large number of novel technologies currently being developed for these operations, process and cost data for such technologies is even more scarce than for the baseline processes. Nonetheless it is still useful to consider generic cost reductions to understand how realistic improvements in the harvesting and extraction units can translate into overall economic benefits. First, capital cost for the primary settling operation was revised to cost the settling units based on agricultural practices, according to discussions from the Workshop. Rather than above-ground settlers made of steel and concrete as utilized in municipal and industrial waste water treatment, the simpler tanks are in-ground with plastic-lined walls and a concrete floor. Based on preliminary costing data provided from a developer, the agriculturebased settler tank reduced capital cost by more than $50 \%$ relative to the original settler units, or roughly $50 \%$ for the combined dewatering operations. Next, flocculant operating cost was also removed. This could be provided by a switch from flocculation to a number of alternatives, with one potential option being electrocoagulation (EC). Based on preliminary costing estimates, EC dewatering could potentially present a similar cost as the simple agricultural settler tanks, but with drastically reduced operating cost and higher concentration factors up to $15 \%$ solids (Vandamme 2011). Thus, the implementation of EC dewatering could plausibly provide for a $50 \%$ capital cost reduction for the harvesting step and simultaneous elimination of flocculation requirements. Finally, extraction costs were also reduced by $50 \%$. This was deemed reasonable given the capital-intensive nature of the current process (primarily due to the cost for homogenizers). The assumed 50\% reduction in harvesting and extraction costs was verified to be a reasonable goal by a number of Workshop participants.

As noted above, the primary cost drivers in the harmonized TEA model are for ponds and pond liners. Thus, these are critical items to improve upon to realize economic viability. However, this may be a challenging endeavor as the ponds are already quite minimal and simplistic by design (Lundquist 2011). Therefore, a full 50\% reduction in costs, as assumed for harvesting and extraction, may not be as easily achievable for pond costs. Instead, a $30 \%$ cost reduction is assumed to be achievable, either by relaxing the land grading and excavation requirements, or through a fundamental re-design of the pond system. One example of the latter approach is the patented pond and liner design developed by Phyco Biosciences, which utilizes a simple trenchtype pond with a low-cost mechanical installation system for liners. The company claims 
publicly that this system achieves a " $30+\%$ reduction in capital costs" relative to traditional raceway ponds (Phyco 2012).

Next, the use of AD for processing the spent algal biomass was replaced by selling the algal residue into the animal or fish feed market. This is a popular alternative to AD for purposes of economic analysis, but was not used for the baseline due to an uncertain product selling price, as well as the loss of LCA benefits that would be incurred by switching from AD. Indeed, the NAABB consortium presented a target in the 2011 DOE Algae Peer Review for lipid extracted algae (LEA) to be sold for a credit based on a feed value from " $\$ 250-\$ 1,000 /$ ton" (Olivares 2011). The upper end of this range may be applicable to a fish feed market, but would be well beyond animal feed prices when compared to distiller's dried grains with solubles (DDGS) from corn dry-milling at a typical value of $\$ 100-\$ 150 /$ ton (DOE 2010). In addition to a wide price range, economic uncertainty for an animal/fish feed scenario is further compounded by process limitations that this approach would place on upstream operations. For example, this scenario would preclude the use of alum or other inorganic flocculants during flocculation dewatering; the present analysis assumes the use of chitosan as a flocculant due to its biodegradability in anaerobic digestion. This assumption might plausibly mitigate toxicity concerns in an animal/fish feed scenario as well, although this would require feeding trials to validate. In any case, LEA for animal or fish feed markets are not anticipated to become saturated at scales envisioned for algal biofuels, relative to alternatives such as higher-value specialty chemical or nutraceutical markets. For the LEA feed scenario, a base price of \$350/metric ton was applied, given feedback from Workshop participants regarding such a scenario. To produce the LEA feed material, the AD and power production systems were removed and replaced with a natural gas-heated drum dryer to dry the LEA material to $12 \mathrm{wt} \%$ moisture.

Finally, after improving the primary costs noted above, the liner costs were removed entirely to reiterate the drastic impact that this addition has on overall economics. As noted above, liners were added to the baseline scenario given feedback from the Workshop as well as the requirement for many sites to include liners within the harmonized 5 BGY scenario. However, liners are not necessary if soil conditions and local regulations allow. While excluding plastic liners would likely constrain the total number of potential locations for algal biofuel production to a smaller subset of sites, it would substantially improve economic viability and is therefore important to consider in the context of cost reduction potential.

Figure 4.1d explores the TEA implications of these changes when applied cumulatively in sequence. Similar to Figure $4.1 \mathrm{~b}$, productivity was assumed to be $12.5 \mathrm{~g} / \mathrm{m}^{2} /$ day, close to the overall $5 \mathrm{BGY}$ average of $13.2 \mathrm{~g} / \mathrm{m}^{2} /$ day. After implementing the various improvements, costs were found to improve by $25 \%-35 \%$ while still including liners, or by $45 \%-55 \%$ after removing liners entirely. Additionally, it was found that the assumed value of $\$ 350 /$ tonne for LEA feed results in a diesel price quite similar to that achieved via $\mathrm{AD}$ of algal residues (particularly at higher lipid content where residual biomass decreases). Thus, for LEA feed to become competitive with $\mathrm{AD}$ and enable additional cost improvements, a value greater than $\$ 350 /$ tonne would be required. In any case, the LCA of emissions depends upon the energy recycled from the AD biogas. Unless another form of renewable energy were used on-site, selling the LEA rather than producing biogas would jeopardize the emission reduction objective. As a result, it may be better to pursue lipid fraction or productivity improvements rather than selling the LEA.

As shown in Figures $4.1 \mathrm{~b}$ and $4.1 \mathrm{~d}$, the asymptotic limits to cost and LCA profiles show great potential for improvement to a lower state. This behavior reflects the convention of expressing 


\section{Discussion}

cost and emissions on a product basis, i.e., per volume of fuel. Since productivity and lipid fraction define the fuel yield, changes in them change the normalization basis, producing, in part, the behavior shown in the figures just cited. The limiting values in those figures, obtained at larger productivities and lipid fractions, are determined by the technology of the system. At low productivity and low lipid fraction, the fixed costs for capital and energy are born by limited product volume with poor results. At large productivity and large lipid fraction, the asymptote likely reflects the costs that scale with yield, so that the only way to improve cost or emissions is to change the underlying technology.

Figure 4.1e considers the final TEA model system, with all above cost modifications applied, by scanning over lipid fraction for three productivity curves, as was done in Figure $3.1 \mathrm{~d}$ for the baseline system. The figure suggests that under the assumed improvements described here (including the removal of liners), costs approach a revised asymptote of roughly $\$ 3 /$ gal for high growth (50 g/m²/day), \$4/gal for medium growth $\left(25 \mathrm{~g} / \mathrm{m}^{2} /\right.$ day), and $\$ 6 /$ gal for baseline growth $\left(12.5 \mathrm{~g} / \mathrm{m}^{2} /\right.$ day $)$. This ultimately suggests that to achieve economic viability, aggressive improvements to cell biology (growth rate and lipids) and system engineering (reducing unit costs while improving process performance) will be required together, while also either excluding liners or greatly reducing liner price. Costs could be further reduced below the asymptotic values shown in Figure 4.1e primarily by reducing pond cost further beyond 30\%, or realizing a higher value for the algal residue material above $\$ 350 /$ tonne.

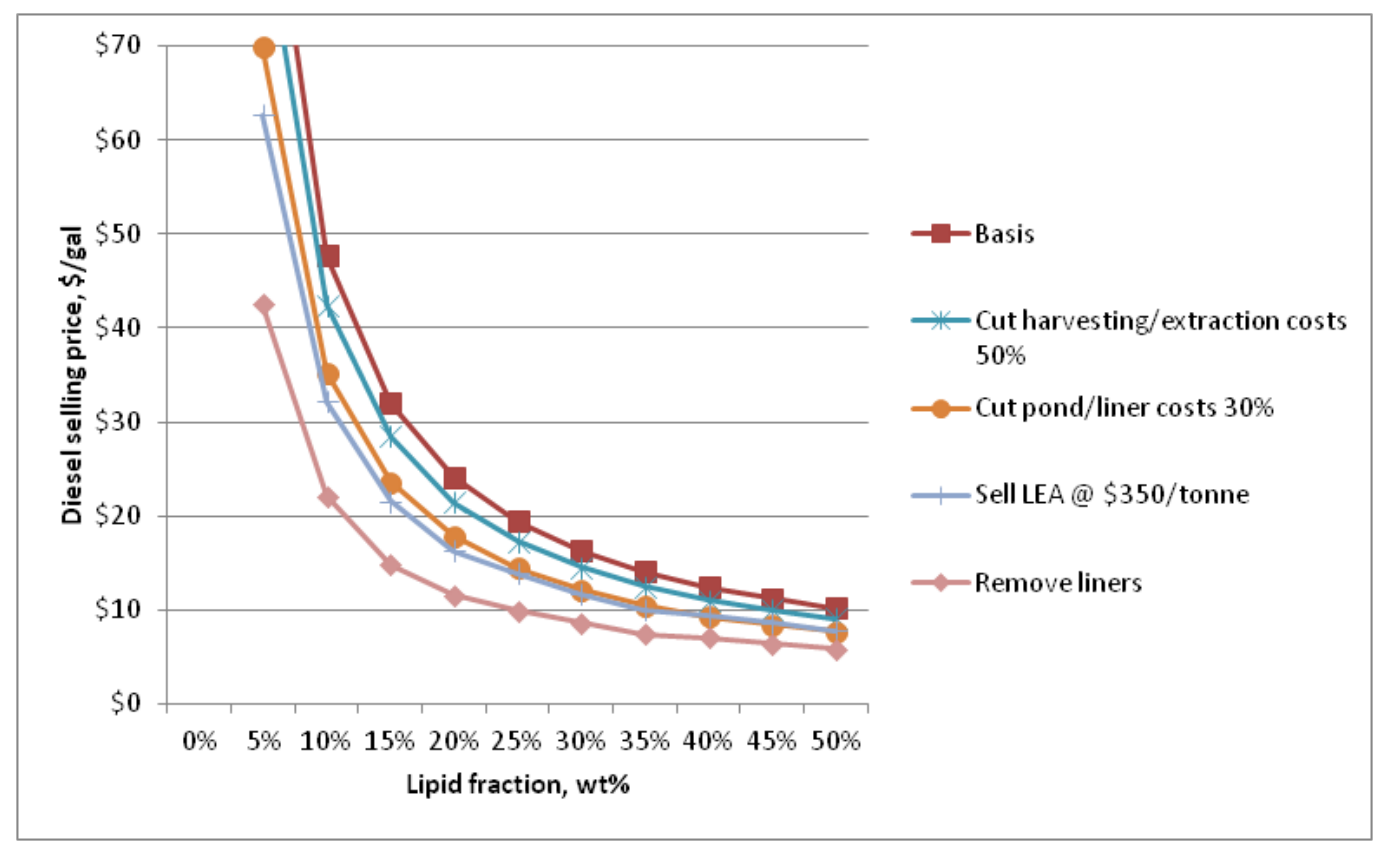

Figure 4.1d: Diesel selling price for four alternative scenarios. The four changes defining the scenarios are applied cumulatively. The legend text is described in the text. Productivity was assumed to be $12.5 \mathrm{~g} / \mathrm{m}^{2} / \mathrm{d}$ for comparison with Figure $3.1 \mathrm{~d}$. 
Discussion

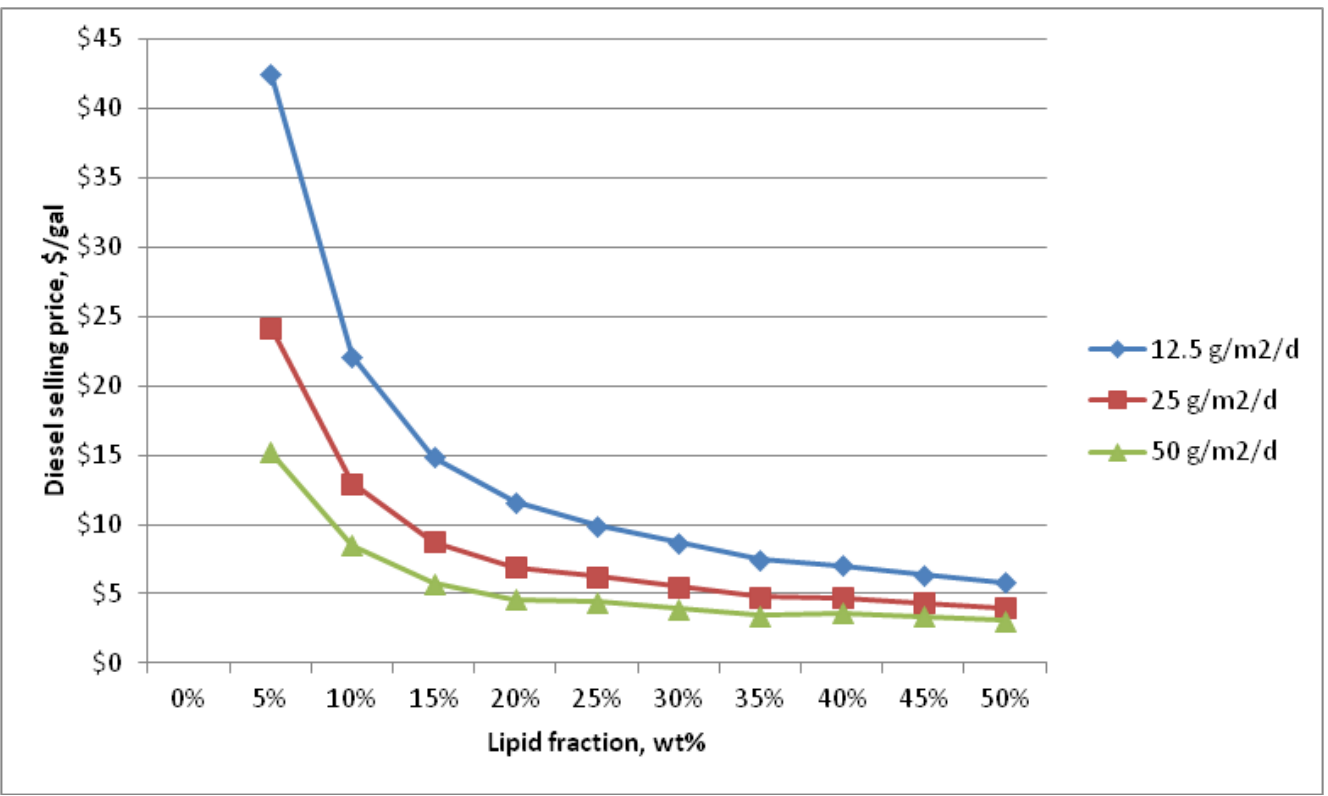

Figure 4.1e: Diesel selling price as a function of lipid fraction when several cost-reducing options are considered. All productivity curves are based on lowest-cost curve in Figure 4.1d. Although lipid fraction and productivity are not independent variables, the plots display the system sensitivity to both parameters.

\subsection{Applying the Baseline}

Given the multitude of alternative novel operations currently under development to improve economics and performance, this section explains how to estimate cost, energy consumption, and emissions when other unit operations are substituted for those utilized in the baseline definition.

\subsubsection{TEA}

Table 4.2a presents the total rolled-up (burdened) cost allocation for each process step and its associated unit-level capital cost translated to a common functional unit, to enable the reader to substitute their own alternate technologies. To maximize transparency and usefulness of the cost items as presented in Figures 3.3.3c-d, all "facility-level" costs such as power, utilities, labor/overhead, and maintenance/insurance are allocated to their respective individual unit operations, thereby presenting the true burdened cost contribution for each major unit step. Again, associated costing and financial assumptions are presented in Section 3.1, Appendix B.2, and Davis 2011. As shown in the table below, the ponds for biomass growth take on the greatest single cost burden after combining all relevant capital expenses (inoculum system, cultivation ponds, and land cost) as well as operating expenses (nutrient costs, power costs for pond mixing, labor, and maintenance).

While the intent of Table 4.2a is to present unit-level cost results in a manner that allows one to swap out any given unit operation with another (via scaling the "capex cost basis" values accordingly) to enable an approximate understanding of what the associated dollar-per-gallon cost impact may be to the baseline price, an important caveat should be noted with such an approach. Namely, installed capital costs are presented as the basis from which to compare alternative operations. This is the most appropriate basis, given that $70 \%$ of the diesel price is associated with capital expenses as noted above. Furthermore, the majority of operating costs are 


\section{Discussion}

fixed costs (maintenance, labor, etc.), which scale in large part with capital expenses as well. However, by substituting one unit operation for another and adjusting capital cost accordingly, the impacts of variable operating costs are not considered; in general this is reasonable given the relatively low contribution of variable costs to overall diesel price, with the most notable exception for the DAF unit where the cost burden comes primarily from flocculant expenses.

Note: As shown in Table 4.2A, hydrotreating contributes a total burdened cost of $\$ 0.83 /$ gal to the diesel selling price in the year-round $\$ 18.63 /$ gal baseline. This includes hydrotreater capital cost, labor, maintenance, variable operating costs for hydrogen and utilities, and co-product credit for naphtha production. In contrast, Figure 3.3.3b shows an algal oil price of $\$ 16.64 /$ gal and diesel price of $\$ 18.63 /$ gal, which could be incorrectly interpreted as suggesting that hydrotreating is responsible for $\$ 2 /$ gal of the diesel price. This is not a correct assumption because the denominator represents two different products, e.g. algal oil at 41.6 MM gal/year versus diesel at 38.7 MM gal/year, as shown in Appendix C for four 4,050-ha facilities. The product selling prices shown in Figure 3.3.3b represent two independent models, one which ends at algal oil production and a second that ends at diesel production. Taking a difference of these two selling prices would not constitute the conversion cost, as it does not utilize the same volumetric basis between the oil and diesel prices.

Table 4.2a: Total Burdened Cost Contributions of Each Major Unit Operation, Associated with the Year-Average Output of the 5 BGY Scenario (\$18.63/gal diesel)

\begin{tabular}{|c|c|c|c|}
\hline Process Area & Unit Operation(s) & $\begin{array}{l}\text { Burdened \$/gal } \\
\text { Contribution }\end{array}$ & Capex Cost ${ }^{1}$ \\
\hline \multirow{3}{*}{ Biomass Production } & $\begin{array}{l}\text { Ponds (inoculation, } \\
\text { cultivation, land cost) }\end{array}$ & $\$ 6.70$ & $\$ 22,500 /$ acre ponds \\
\hline & Liners & $\$ 5.43$ & $\$ 20,500 /$ acre ponds \\
\hline & $\begin{array}{l}\text { Infrastructure }\left(\mathrm{CO}_{2} / \text { water }\right. \\
\text { delivery, minor equipment) }\end{array}$ & $\$ 1.50$ & $\$ 5,700 /$ acre ponds \\
\hline \multirow{3}{*}{$\begin{array}{l}\text { Harvesting and } \\
\text { Dewatering }\end{array}$} & Primary settling & $\$ 1.52$ & $\begin{array}{l}\$ 134,100 / M G D \text { to } \\
\text { primary harvesting }\end{array}$ \\
\hline & DAF & $\$ 1.05$ & $\begin{array}{l}\$ 5,000 / \text { MGD to primary } \\
\text { harvesting }\end{array}$ \\
\hline & Centrifuge & $\$ 0.17$ & $\begin{array}{l}\$ 12,600 / \text { MGD to } \\
\text { primary harvesting }\end{array}$ \\
\hline \multirow{2}{*}{$\begin{array}{l}\text { Extraction and } \\
\text { Fractionation }\end{array}$} & Cell disruption & $\$ 0.51$ & $\begin{array}{l}\$ 25,200 /[\mathrm{dry} \text { ton/day] } \\
\text { algae to extraction }\end{array}$ \\
\hline & Extraction/separation & $\$ 0.36$ & $\begin{array}{l}\$ 7,500 /[\text { dry ton/day] } \\
\text { algae to extraction }\end{array}$ \\
\hline $\begin{array}{l}\text { Spent Biomass } \\
\text { Utilization }\end{array}$ & $A D+C H P$ system & $\$ 0.56$ & $\begin{array}{l}\$ 42,300 /[\text { ton} / \text { day] TS to } \\
\mathrm{AD}\end{array}$ \\
\hline Conversion & Hydrotreating & $\$ 0.83$ & $\$ 190 /[$ gal/day] oil \\
\hline
\end{tabular}

Capex cost basis values represent direct installed costs per given functional unit

\subsubsection{LCA}

LCA results for alternative scenarios can be analyzed by downloading the Greenhouse Gases, Regulated Emissions, and Energy Use in Transportation Model, better known as GREET, and working with the Algae Process Description (APD) tool. APD is described in Frank 2011b. In brief, APD contains an inventory of algae relevant processes with rolled up energy consumption 
at each step. Drop-down menus allow the analyst to choose different process options, including "Custom." A new process can be studied by determining its energy and material consumption per unit of product from the operation and then entering those values in APD. A button on the "Copy to GREET" worksheet causes the model to be copied to GREET where LCA results are computed. Some parameters are in GREET, e.g., CHP parameters and parameters for co-product treatment. When "Copy to GREET" is clicked, APD will configure the bio-oil worksheet to use algae as the bio-oil feedstock. The "Results" worksheet lists results under "CIDI Vehicle: Algaebased RDII 100," which lists results separately for each life cycle stage (feedstock production, fuel production, vehicle operation, and total). The results there are per vehicle mile, while the results in this study were per MMBTU of fuel. The per mile results can be converted to the MMBTU RD basis by dividing the GREET results by the total energy per mile for vehicle operation listed on the "Results" worksheet (4090 BTU/mile in this version) and multiplying by $10^{6}$. The sum of feedstock and fuel production gives the WTP value. The vehicle operation value is the PTW result, while the sum is the WTW. 


\section{Conclusions and Research Opportunities}

After a concerted and rigorous effort, the Harmonization Initiative achieved the initial goals that were established for it, namely presenting the original models to a stakeholder audience in a DOE-sponsored workshop, incorporating feedback wherever possible to improve each respective model, and then working collaboratively to establish a single set of assumptions to apply uniformly in the RA, TEA, and LCA algal biofuels models. As a result, an integrated cost, emissions, and resource potential baseline has been created for algae that identifies key knowledge gaps and sensitivity drivers and can serve as a metric for assessing algae technologies. Only by establishing a consistent basis for today's economic, environmental, and resource constraints on algal biofuels can a path forward be established for tracking and assessing performance improvements required for viability.

The baseline study target of 5 BGY represents a significant fraction of the advanced biofuel target. The production sites most appropriate to meet this target with freshwater algae are located in the vicinity of the Gulf of Mexico. It should be noted that these lands are relatively flat, nonagricultural, relatively undeveloped, non-sensitive lands. Mean biomass production ranged from $6.2 \mathrm{~g} / \mathrm{m}^{2}-\mathrm{d}$ in the winter to $16.5 \mathrm{~g} / \mathrm{m}^{2}-\mathrm{d}$ in the spring, resulting in a potential mean annual biofuel yield of 1,120 gallons per acre from the RA model. The baseline study demonstrated that sufficient freshwater is potentially available to meet open pond water demand at the selected sites. The integrated baseline costs, emissions, and resource potential results were highly sensitive to assumptions for algae productivity and lipid fraction at small values of those parameters, but were less sensitive ("diminishing returns") as productivity and lipid fraction increased (Figures 3.1.c-d). Alternative scenarios were considered that reduced power consumption and costs. In those scenarios, the results again were highly sensitive to productivity and lipid fraction at low values, but different (greatly improved) limiting values were obtained (Figures $4.1 \mathrm{~b}-\mathrm{e}$ ). Several key points are to be made.

If an algal production system is operating at a point corresponding to the steep slope for cost or emissions, then small changes in the productivity and lipid fraction will cause large changes in cost and emissions. This occurs because the productivity is sensitive to season and to site meteorology, so seasonal variations in productivity lead to facilities that must accommodate the intense months, yet are oversized for the rest of the year. This increases fuel cost considerably. Nevertheless, TEA modeling shows that it is always economically advantageous to operate the facility, even at low productivities. This is because the savings in reducing variable operating expenses is not enough to offset the loss in revenue if the facility were to shut down operations during the winter months. On the other hand, if power consumption is not reduced, LCA studies indicated that low productivities could result in emissions that would not meet emission reduction targets. For these reasons, site and strain selection must place a high priority on minimizing seasonal fluctuations in productivity, and productivity increases should be pursued. Furthermore, R\&D for facility designs must go beyond considering annually averaged productivity, must develop seasonal cost and emission curves, and must target productivity and lipid fractions that land in a stable portion of those curves to reduce modeling uncertainties.

Focusing on the LCA of energy consumption and GHG emissions, the key consideration is energy balance on site. A scenario with reduced paddlewheel power demand had a large positive effect on the system and produced algal fuel with $80 \%$ fewer emissions than petroleum diesel, even at $12.5 \mathrm{~g} / \mathrm{m}^{2} /$ day for $20 \mathrm{wt} \%$ TAG. Since energy balance on site is a tension between energy consumption and energy production from the lipid-extracted algae, in some cases power 
consumption on site must be reduced to keep higher lipid fractions from increasing emissions. TEA, though, always benefits from increased lipid fractions.

There is significant uncertainty in the energy and nutrient recycling model, including the model for biogas production from algae and the CHP model. For nutrient recycling, if catalytic hydrothermal liquefaction can demonstrate high nutrient recovery at competitive cost, it may also address concerns about fugitive methane emissions that harmed GHG reduction performance. For CHP, reducing facility heat demands, e.g., steam demand for solvent recovery, might allow for bottom cycles to be added that would greatly increase the CHP efficiency. Finally, gas-fired turbines produce flue-gas with low $\mathrm{CO}_{2}$ concentrations and this makes $\mathrm{CO}_{2}$ recycling power intensive if the $\mathrm{CO}_{2}$ concentration is not increased.

The key results from the TEA effort are primarily associated with high capital costs. While there were a number of modifications to the TEA model, the single largest cost impact was the addition of pond liners. Although plastic liners would allow for greater flexibility in site selection and ensure mitigation of pond leakage, their use incurs a cost greater than any other single operation and results in a much more challenging pathway toward achieving economic viability. This has implications for regulatory policies governing the requirement for pond liners, as well as site analysis to place a high priority on locations with satisfactory soil characteristics to negate the need for liners. Furthermore, the capital-intensive nature of the process results in the asymptotic cost curves noted above wherein any further cost reductions would require a fundamental change in process unit designs or substantial co-product credits.

The TEA baseline selling price for algal diesel was found to increase from $\$ 10.66 /$ gal in the original model, to $\$ 12.15 /$ gal, after applying all process changes brought about from harmonization, to $\$ 19.60 /$ gal after reducing the assumed algal productivity from $25 \mathrm{~g} / \mathrm{m}^{2} / \mathrm{day}$ to the site and season-dependent values associated with the 5 BGY screening analysis (averaging $13.2 \mathrm{~g} / \mathrm{m}^{2} /$ day). Scenarios were considered with higher productivity.

The RA productivities were computed with a biophysics model that, while consistent with reported photo-efficiencies, falls at the lower end of the reported range. Increases in the baseline productivity by factors of 2 and 3 would produce proportional increases in oil yield per acre, while remaining within published values (DOE, 2010). The higher-productivity scenarios explored by TEA and LCA are, thus, not by any means ruled out, but supporting data at scale are needed to adopt the higher values as the baseline. Aside from increasing fuel yield by way of biological improvements in algal productivity and/or lipid content, fuel yield also has room for improvement through increasing overall efficiency factors for harvesting, extracting, and converting algal biomass to fuel product. The TEA and LCA models assume $95 \%$ net harvesting efficiency, $85 \%$ net extraction efficiency, and 78-85 wt\% yield of extracted algal lipid to RD product, resulting in 63-69 wt\% net conversion of stored lipids to final RD fuel. However, sensitivity analysis (e.g., Figure 4b) demonstrates that these assumed efficiency factors exhibit a large overall impact on results, with potential for significant improvement in the future. This demonstrates an additional research need to target ways in which to improve this efficiency through better harvesting and extraction operations and targeted hydrotreater RD yields.

The number of production sites required to achieve the baseline 5 BGY target under the two- and three-fold higher production scenarios would be reduced by $53 \%$ and $70 \%$, respectively, while still located in Texas and Florida. Similarly, the water required per gallon of RD would be reduced from 195 to 139 and 102, respectively, and economic viability would be significantly 
enhanced. Furthermore, some algal strains have been shown to produce $20 \%-50 \%$ of their dry weight biomass as lipids, resulting in oil yields of 1,000-6,000 gal/ac/year (Mascarelli, 2009; DOE, 2010), while oil yield for sites contributing to the 5 BGY RA target is only 1,120 gal/ac/year. Hence, this baseline scenario errs towards a conservative output.

To reduce the defining uncertainties in the harmonized models, public experimentally-verified data are needed. It is important that operational data for sustained, large-scale production of algae in outdoor facilities, specifically with regards to algal growth rate, lipid content, algal culture density, and on-stream time over the course of a year be made available to the modeling effort. The Harmonization Initiative also uncovered a number of additional knowledge gaps where further research would improve model optimization. The key knowledge gaps and areas for further analysis are reiterated as follows:

- Obtain experimental data to validate the assumed harvesting and extraction performance and efficiency metrics, or to support switching to alternative operations

- Work with researchers and developers in the field to quantify performance metrics for novel harvesting/extraction operations, to set realistic future process and cost goals

- Further evaluate $\mathrm{CO}_{2}$ transfer and delivery options, including cost and GHG tradeoffs between low-pressure transport of bulk flue gas versus $\mathrm{CO}_{2}$ capture, both for off-site $\mathrm{CO}_{2}$ as well as recycled $\mathrm{CO}_{2}$ from the CHP system

- Include land-use change in the LCA: the current analysis assumed land-use change effects will be small because algae have relatively high productivity compared to other biofuel crops and because marginal land can be used

- Improve lipid characterization to include appropriate polar and neutral components, as the lipid will be lower-quality than currently assumed. Subsequently, refine modeling of energy inputs, costs, and yields for upgrading algal lipids to renewable diesel as appropriate for the heteroatom content of algal lipids

- Develop first-hand cost values for pond and liner systems based on vendor information to enable a detailed cost breakdown of contributing factors, so that costs can be better optimized for projecting future improvements

- Detailed analysis of cost tradeoffs between plastic pond liners and soil working/compaction requirements to allow for sufficient pond operation without liners

- Realistic spatial modeling of recycling processes considering the specific composition of alternative nutrient sources, their availability, and associated acquisition, transport, and waste handling costs

- Development of improved algae growth models that explicitly consider the performance of specific algal strains under varying climatic and environmental conditions, alternative water and nutrient sources, and a range of cultivation strategies

- $\mathrm{CO}_{2}$ : Realistic spatial modeling of alternative $\mathrm{CO}_{2}$ sources considering the specific composition of alternative sources, their availability, and associated acquisition, transport, and pre-processing costs

- Water: Comprehensive cost assessment of alternative water sources including preand/or post-treatment and handling of salt disposal and potential toxics and regulatory constraints on use and handling

- Land: Incorporation of land acquisition costs and constraints, including effects of sitespecific ground conditions on constructions costs and impact of algal industry demand on land availability and cost 


\section{Appendix A: Workshop Participants}

\begin{tabular}{|l|l|}
\hline Name & Affiliation \\
\hline Mark Wigmosta & PNNL \\
\hline Richard Skaggs & PNNL \\
\hline Andre Coleman & PNNL \\
\hline Ryan Davis & NREL \\
\hline Andy Aden & NREL \\
\hline Phil Pienkos & NREL/SABC \\
\hline Ed Frank & ANL \\
\hline Michael Wang & ANL \\
\hline Ignasi Palou Rivera & ANL \\
\hline Paul Blowers & University of Arizona/NAABB \\
\hline Meghan Starbuck & New Mexico State University/NAABB \\
\hline James Richardson & Texas A\&M/NAABB \\
\hline Myriah Johnson & Texas A\&M/NAABB \\
\hline Jim Oyler & Genifuel/NAABB \\
\hline John McGowen & Arizona State University/SABC \\
\hline Milton Sommerfeld & Arizona State University/SABC \\
\hline Scott Cheney & Arizona State University/SABC \\
\hline Thomas Dempster & Arizona State University/SABC \\
\hline Bill Brandt & Arizona State University/LightWorks \\
\hline Mark Huntley & Cornell/Cellana Consortia \\
\hline Alex Arvavanis & Sapphire Energy \\
\hline Nick Meister & AlgaeVentures \\
\hline Ron Pate & SNL \\
\hline Scott James & SNL \\
\hline Deborah Newby & INL \\
\hline Jared Abodeely & INL \\
\hline Jason Quinn & Colorado State University \\
\hline Ian Woertz & California Polytechnic University \\
\hline Daniel Fishman & BCS, Inc. \\
\hline Joyce Yang & U.S. Dept. of Energy \\
\hline Roxanne Dempsey & U.S. Dept. of Energy \\
\hline Christy Sterner & U.S. Dept. of Energy \\
\hline Kristen Johnson & U.S. Dept. of Energy \\
\hline Christine English & CNJV \\
\hline Amy Schwab & NREL Systems Integration \\
\hline Andrew Argo & NREL Systems Integration \\
\hline & \\
\hline
\end{tabular}


Appendix B: Earlier Studies

\section{Appendix B: Earlier Studies}

\section{B.1 Resource Assessment}

PNNL's algal resource assessment work began in FY 2010 with results through March of 2011 presented in Wigmosta et al., (2011) describing a high-resolution national-scale resource and production assessment for algal biofuels produced from open pond facilities. Potential oil production, land resources, and water requirements were estimated using a series of coupled model components developed at a high spatiotemporal scale, based on the dominant physical processes affecting algal growth. Land suitable for open pond microalgae production was identified using topography and existing land cover data. Physics-based biomass growth and pond temperature models were then used with location specific meteorological and topographic data to estimate potential biofuel production and consumptive water demand.

For the land suitability analysis, it was assumed that each open-pond microalgae biofuel facility consists of one hundred 30-cm deep, 4-ha ponds requiring about 405 ha of land for ponds and another 80 ha for operational infrastructure. Additionally, the ponds and associated infrastructure are situated on potentially non-sensitive flat land to avoid conflicts with existing land use and to minimize soil excavation and water pumping costs. Benemann et al. (1982) researched the economic factors in using various sloped land and determined 1\% slope would be an upper limit for suitable slope. A 30-m digital elevation model consisting of 43.3 billion elevation postings was constructed for the conterminous United States and used to identify contiguous areas that meet $\mathrm{a} \leq 1 \%$ slope criterion. From the suitable slope areas, only non-agricultural, undeveloped, or low-density developed, non-sensitive, generally non-competitive land was considered for microalgal culture facilities. Specifically, this excludes open water, urban areas, airports, cultivated cropland and orchards, federal and state protected areas such as national and state parks, wilderness areas, wildlife refuges, wetlands, and other areas that are deemed environmentally sensitive.

This analysis identified 11,588 non-competitive areas (i.e., potential pond facilities) totaling approximately $430,830 \mathrm{~km}^{2}$, or $5.5 \%$ of the conterminous United States, that are potentially suitable for large-scale open pond microalgae production. The resulting analysis concludes the following land cover types from largest to smallest area: $42 \%$ shrub/scrub, $19 \%$ herbaceous, $14 \%$ evergreen forest, $10 \%$ pasture land, $8 \%$ deciduous forest, and $7 \%$ other lands including mixed forest, barren, and low-intensity developed.

A simplified, biophysical, open pond microalgae growth model was used to simulate the conversion of solar energy during photosynthesis to chemical energy storage in the form of oils and other biomass based on site-specific incoming solar radiation and pond water temperature. An unsteady, two-dimensional hydrodynamic and water quality model was used to estimate water temperature and evaporative water loss at the pond facility based on 30 years of hourly meteorological data.

The open pond water temperature and microalgae biomass growth models were applied to the 11,588 potential pond facilities located throughout the conterminous United States. The biomass growth model was run using our best estimate of microalgae efficiencies and lipid contents, as published in current literature. As expected, biomass production varied in time and space with a 30 -year national mean of $8.7 \mathrm{~g} / \mathrm{m}^{2}-\mathrm{d}$. The maximum biomass production of $15.8 \mathrm{~g} / \mathrm{m}^{2}-\mathrm{d}$ is consistent with large-scale commercial productivities of 10-20 g/ $\mathrm{m}^{2}-\mathrm{d}$ (DOE 2010). We 
calculated a national mean annual lipid production rate of 5,775 L/ha-year (4,620 L/ha-year of biofuel, considering the $80 \%$ conversion efficiency).

National patterns of microalgae biofuel production from algae show an expected strong linkage to climate, which in turn is tied to patterns of time, elevation, topography, and latitude (Figure B.1). Evaluating annual patterns at the national scale, the low-elevation southern portions of the United States exhibit the highest production rates ranging from 6,000-8,000 L/ha-year of potential biofuel production. These areas are characterized by relatively warm year-round temperatures and additional hours of solar insolation over more northerly locales. Higher elevation and northern tier locations exhibit the lowest production rates ranging from 2,0004,000 L/ha-year. These areas exhibit a long winter season and a shorter growing season. The total production potential of all $430,830 \mathrm{~km}^{2}$ of suitable (i.e., non-agricultural, non-competitive, non-sensitive) land in the conterminous United States is $220 \mathrm{BL} / \mathrm{year}$, which is equivalent to nearly $48 \%$ of the U.S. petroleum imports required to meet transportation demand during 2008.

The hourly open pond algae growth model is operated so that the water depth in the open pond can fluctuate over a limited range. This way, when precipitation exceeds pond evaporation, the pond can store additional water for later use when hourly evaporation exceeds precipitation. Water demand is defined as the amount of water required to keep the pond water depth from falling below $25 \mathrm{~cm}$. Water demand is greatest in the western United States (Figure B.2), exhibited by higher rates of evaporation, generally ranging from 4-21 ML/ha-year, compared to the eastern United States, which ranges from $<1-4 \mathrm{ML} /$ ha-year.

Irrigated agriculture represents by far the largest consumptive use of freshwater in the United States with $113,135 \mathrm{BL} /$ year in 1995 . If all $430,830 \mathrm{~km}^{2}$ of land potentially available for microalgae production were used, the total freshwater consumptive demand to satisfy evaporative loss would be $312,079 \mathrm{BL} /$ year, which is 2.75 times the amount of water consumed nationally through irrigated agriculture, averaging 1,421 liters of water per liter of oil produced. One approach to minimize both the land and freshwater footprint of biofuel production is to preferentially select available land with the lowest water use per liter of biofuel produced. This favors locations around the Gulf Coast, most of the eastern seaboard, and areas adjacent to the Great Lakes (Figure B.3). While these locations are favorable in their freshwater consumption requirement, considerations must be made for local and regional water availability and demand, now and into the future.

Cumulative biofuel production as a function of cumulative land and water use is presented in Figure B.4. The solid line is based on pond facilities sorted from lowest to highest in water use per liter of biofuel to minimize water use. The dashed line is based on pond facilities sorted from lowest to highest in land use per liter of biofuel to minimize land use. By selecting land to minimize water use (Figure B.4a), the EISA "advanced biofuels" renewable fuel target of 79.5 $\mathrm{BL} /$ year would require about $28,000 \mathrm{BL}$ of consumptive water-use per year, a volume equivalent to $25 \%$ of the water consumed in irrigated agriculture. Compared to the average water use for all suitable land $(1,421 \mathrm{~L}$ water/L oil), this represents a $75 \%$ reduction in water demand to $350 \mathrm{~L}$ of water per L of oil produced and a $67 \%$ reduction in land use. Optimizing to reduce the land footprint (Figure B.4b), regardless of water use, decreases the land area by less than $20 \%$ compared to optimization based on water-use efficiency. However, optimizing to reduce the land footprint increases consumptive water use 3.3, 2.5, and 1.3 times for cumulative biofuel production rates of $50 \mathrm{BL} /$ year, 79.5 BL/year (EISA "advanced biofuels" renewable target), and $250 \mathrm{BL} /$ year, respectively. 
Appendix B: Earlier Studies

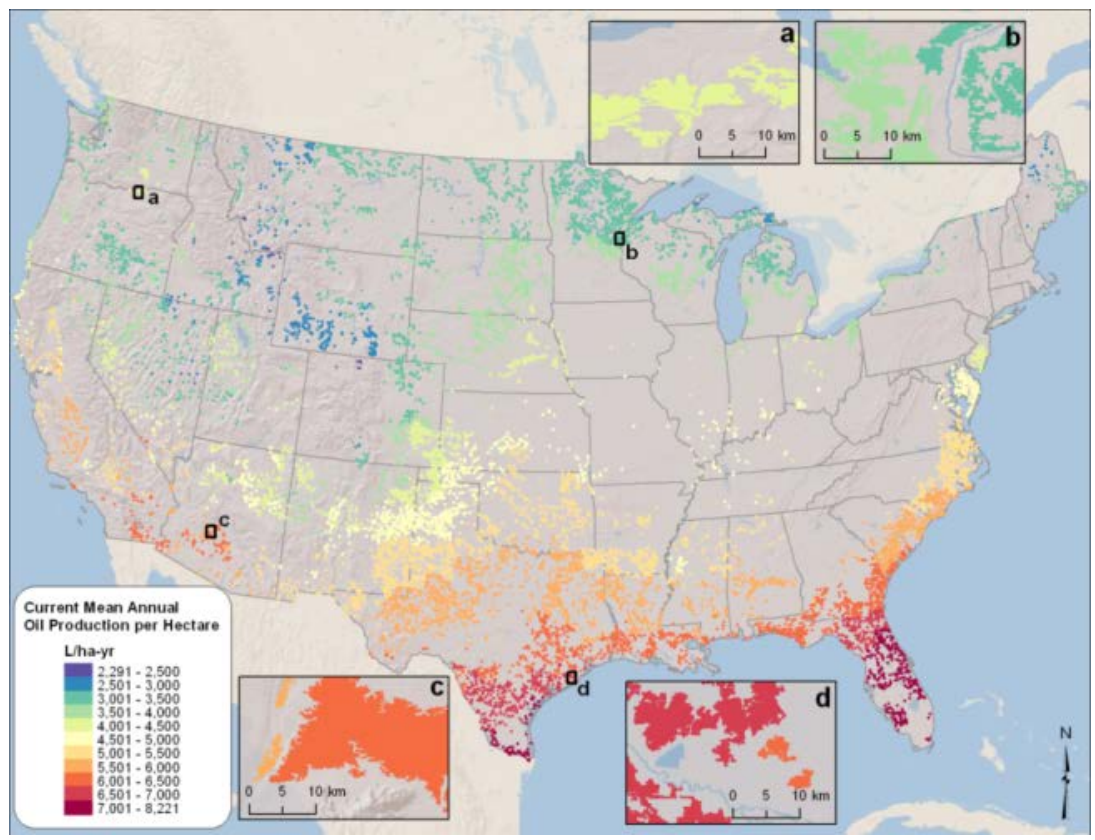

Figure B.1: Mean annual biofuel production (L/ha-year) under current technology plotted at the centroid of each pond facility. (Wigmosta et al., 2011). ${ }^{\mathrm{ii}}$

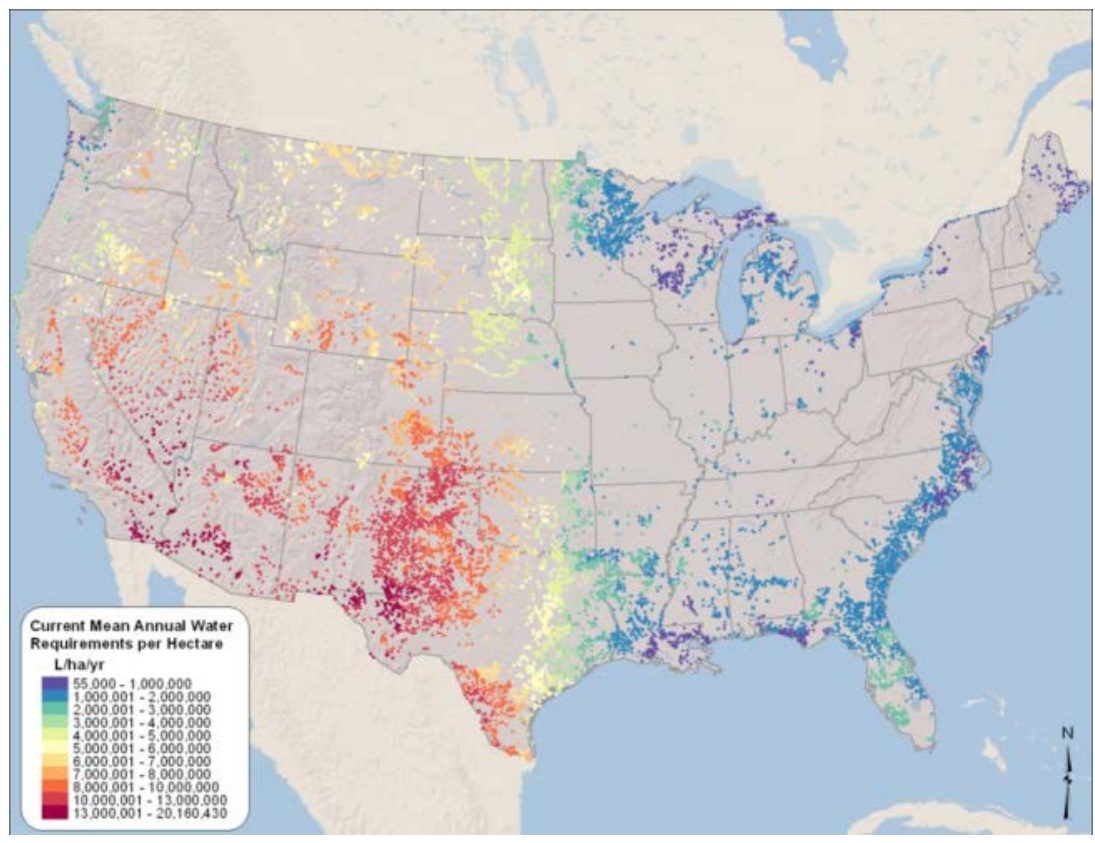

Figure B.2: Mean annual water requirements (L/ha-year) for microalgae biofuels production using current technology plotted at the centroid of each pond facility. (Wigmosta et al., 2011).i" 
Appendix B: Earlier Studies

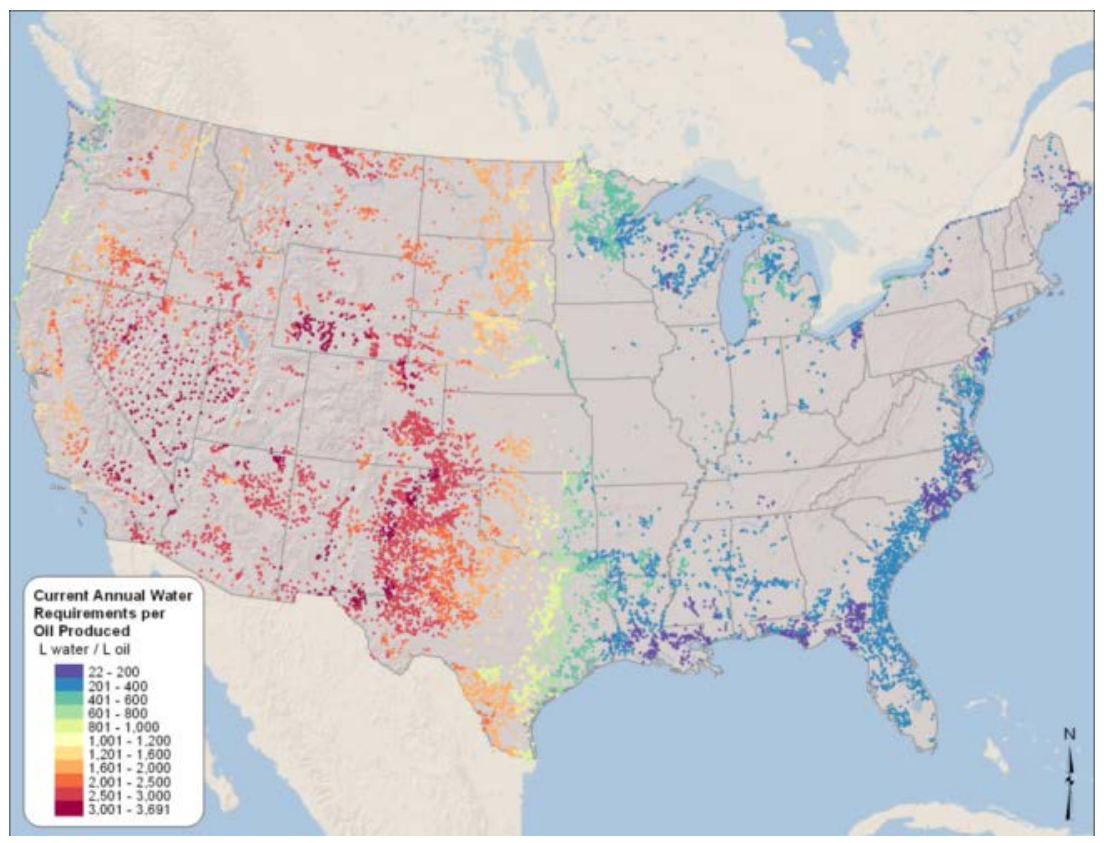

Figure B.3: Mean annual microalgae biofuel water requirements per liter of biofuel produced (L water/L biofuel) plotted at the centroid of each pond facility. (Wigmosta et al., 2011).i 
Appendix B: Earlier Studies
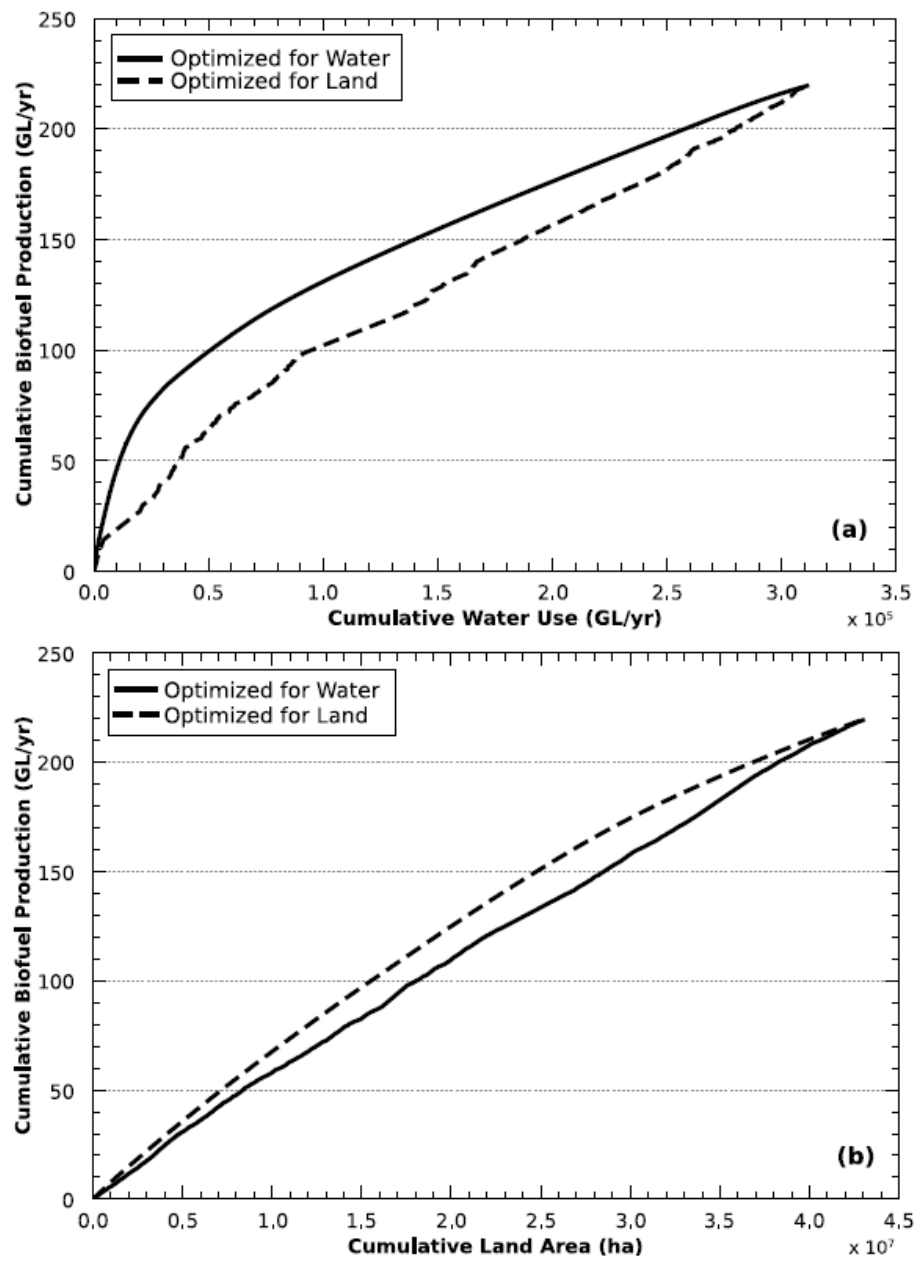

Figure B.4: Annual cumulative biofuel production as a function of cumulative water use (a) and cumulative land use (b). (Wigmosta et al., 2011). "The solid line is based on pond facilities sorted from lowest to highest in water use ( $\mathrm{L}$ water/L biofuel). The dashed line is based on pond facilities sorted from lowest to highest in land use (ha land/L biofuel).

\section{B.2 TEA}

NREL's algae TEA analysis (within the context of the current DOE efforts) began in FY 2010, as an expansion to a preliminary process and cost modeling task undertaken in support of EPA's RFS-2 rulemaking to quantify process inventories and GHG potential for algal biofuels. Since that time, under DOE support it has expanded in scope, rigor, and breadth of understanding, and has been published in two peer-reviewed journals (Davis 2011; Sun 2011) and presented in a number of public forums. It has been well-received in all formats. The FY 2010-2011 TEA analysis, as published in the relevant DOE milestone reports, is summarized on a high level here, with more details available in the publication.

The initial TEA analysis in FY 2010 focused on three cultivation pathways, autotrophic via open ponds, autotrophic via photobioreactors (PBRs), and heterotrophic via fermentation of cellulosic sugars. However, in subsequent analysis the heterotrophic pathway was removed from comparison, as it was decided that it is more appropriate to include such a pathway in the biochemical sugar platform (e.g., producing a fuel from an organism grown on an organic carbon 
substrate). Thus, TEA analysis in FY 2011 focused on the two autotrophic cultivation pathways, leaving "algae" to be defined strictly in the context of photosynthetic growth. In both the initial FY 2010 and updated FY 2011 analyses, the PBR pathway was found to be substantially more costly than the open pond pathway (specific to a tubular PBR configuration), resulting in a fuel selling price roughly twice as high as the open pond basis. For this reason, as well as the fact that the ANL and PNNL models have largely focused thus far exclusively on open pond production, the PBR pathway was not a focus of the Harmonization Workshop and is not included in the present report. This does not mean that PBRs are excluded from future consideration or analysis, but merely that the Harmonization Workshop focused on open ponds for which more data exists and more analysis has been conducted.

To conduct the analysis, rigorous process models were established using Aspen Plus simulation software in order to estimate material and energy balances on a unit-level basis. The resulting process information was then used as inputs to an Excel-based economic model to estimate capital and operating costs for the system, which ultimately allowed for establishing yearly cash flows and product selling prices. All process assumptions were based on what could plausibly be achieved using today's commercially available technology, using publicly available literature for what has been shown to be accomplished, thereby representing a "current technology" benchmark. After making a number of modifications and improvements along the way, the basic process configuration assumed for the most recent (FY 2011) baseline analysis is summarized as follows: algae are grown in open, unlined raceway ponds (priced at $\$ 34,000 /$ ha in 2009-dollars per Lundquist 2011) and are harvested at a rate equal to the growth rate. $\mathrm{CO}_{2}$ is supplied to the ponds in purified form at a delivered cost of $\$ 40 /$ metric ton, which includes cost for carbon capture from flue gas, as well as transportation to the facility. The purified $\mathrm{CO}_{2}$ is fed to the ponds by way of 1-meter deep sumps, which are assumed to achieve $90 \% \mathrm{CO}_{2}$ retention with $10 \%$ outgassing losses. Nitrogen and phosphorous nutrient demands are met using ammonia and DAP, respectively, and are supplied in stoichiometric quantities. Dewatering is achieved in a three-step system, namely bioflocculation (spontaneous settling), DAF, with the use of chitosan as a flocculent, and centrifugation, which ultimately concentrates the biomass from 0.5 to 200 $\mathrm{g} / \mathrm{L}(20 \%$ solids). The overall harvesting efficiency is assumed to be $90 \%$. The algal oil is extracted in a two-step process using high-pressure homogenizers to disrupt and/or lyse the algal cell walls, followed by solvent extraction with butanol. The water and spent biomass material is separated in a disc stack centrifuge and sent to anaerobic digestion, whereby biogas is evolved and burned in a gas turbine to produce power, while a significant portion of the nutrients are fixed in the supernatant and recycled to the ponds. The turbine flue gas is used to raise steam and additional electricity in a CHP cycle and is then recycled to the ponds to reduce fresh $\mathrm{CO}_{2}$ demands. Finally, the butanol solvent is recovered and recycled in a stripping column, and the resulting purified algal oil is subsequently upgraded in a hydrotreater to produce a diesel blendstock with a small naphtha co-product. This process is shown in the schematic below. 
Appendix B: Earlier Studies

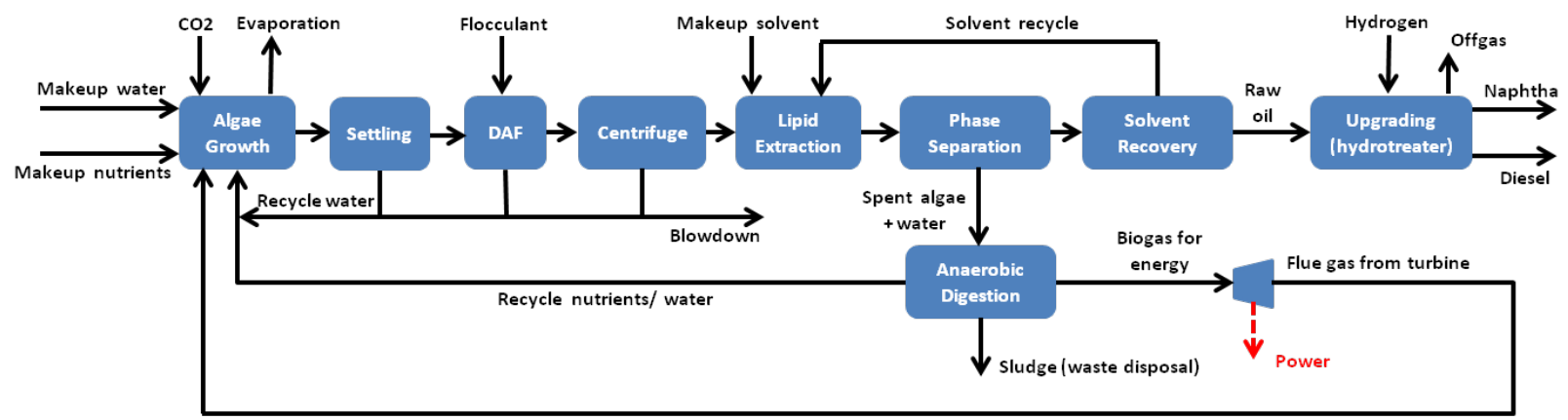

Figure B.5: Schematic of baseline process used in FY 2011 TEA analysis. (Davis et al. 2011).'

The key process and economic assumptions used in conjunction with the modeled process depicted in Figure B.5 are summarized below in Tables B.1-2.

Table B.1: Summary of FY 2011 TEA Baseline Design Assumptions

\begin{tabular}{|l|c|l|}
\hline Parameter & Assumption & Notes \\
\hline $\begin{array}{l}\text { Scale of production, MM gal/year } \\
\text { algal oil }\end{array}$ & 10 & Basis for modeling \\
\hline Algae productivity, g/m²/day & 25 & Achieved today in literature (Griffiths 2011) \\
\hline Algal cell density, g/L & 0.5 & $\begin{array}{l}\text { Steady-state value, typical for open ponds } \\
\text { (Carlsson 2007) }\end{array}$ \\
\hline Lipid content, dry wt\% & $25 \%$ & Achieved today in literature (Griffiths 2011) \\
\hline $\mathrm{CO}_{2}$ consumed, lb/lb algae & 1.9 & $\begin{array}{l}\text { Assumed algae composition (Clarens } \\
2010)\end{array}$ \\
\hline $\mathrm{N}$ demand, dry wt\% of algae & $8.7 \%$ & $\begin{array}{l}\text { Assumed algae composition (Clarens } \\
2010)\end{array}$ \\
\hline $\mathrm{P}$ demand, dry wt\% of algae & $1.3 \%$ & $\begin{array}{l}\text { Assumed algae composition (Clarens } \\
2010)\end{array}$ \\
\hline Operating days/year & 330 & Assumed \\
\hline
\end{tabular}


Appendix B: Earlier Studies

Table B.2: Summary of FY 2011 TEA Financial Assumptions

\begin{tabular}{|c|c|c|}
\hline Parameter & Assumption & Notes \\
\hline Target internal rate of return & $10 \%$ & $\begin{array}{l}\text { Basis for cost } \\
\text { calculations }\end{array}$ \\
\hline Cash flow methodology & Discounted cash flow rate-of-return & \multirow{6}{*}{$\begin{array}{l}\text { Standard NREL } \\
\text { assumption }\end{array}$} \\
\hline Debt : equity ratio & $60 \%$ debt $/ 40 \%$ equity & \\
\hline Loan terms & 10 year, $8 \%$ interest & \\
\hline Tax rate & $35 \%$ & \\
\hline Depreciation schedule & MACRS, 7 year (general) / 20 year (power) & \\
\hline Plant lifetime & 30 years & \\
\hline Power credit & $6.5 \phi / \mathrm{KWh}$ & (EIA 2011) \\
\hline Naphtha credit & $\$ 2.76 / \mathrm{gal}$ & (EIA 2011) \\
\hline \multicolumn{3}{|l|}{ Indirect capital factors: } \\
\hline Site Development & $9 \%$ of ISBL & \multirow{5}{*}{$\begin{array}{l}\text { Standard NREL } \\
\text { assumption }\end{array}$} \\
\hline Warehouse & $4 \%$ of ISBL & \\
\hline Pro-rateable Costs & $10 \%$ of TDC & \\
\hline Field Expenses & $10 \%$ of TDC & \\
\hline Home Office and Construction & $20 \%$ of TDC & \\
\hline Contingency & $30 \%$ of TDC & $\begin{array}{c}\text { Given scale-up } \\
\text { uncertainties }\end{array}$ \\
\hline Other Costs & $10 \%$ of TDC & \multirow{2}{*}{$\begin{array}{l}\text { Standard NREL } \\
\text { assumption }\end{array}$} \\
\hline Working Capital & $5 \%$ of $\mathrm{FCl}$ & \\
\hline
\end{tabular}

Given the assumptions described above, the FY 2011 baseline results for algal oil and diesel selling prices are shown below in Figure B.6. While both the open pond and PBR pathways are shown here, the present discussion focuses exclusively on the open pond pathway, which was

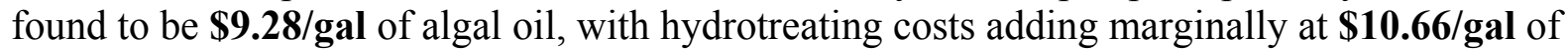
upgraded diesel. It should be noted that all costs presented here represent MSP, including a 10\% internal rate of return, and are indexed to 2007-dollars for consistency with other NREL platforms. 
Appendix B: Earlier Studies

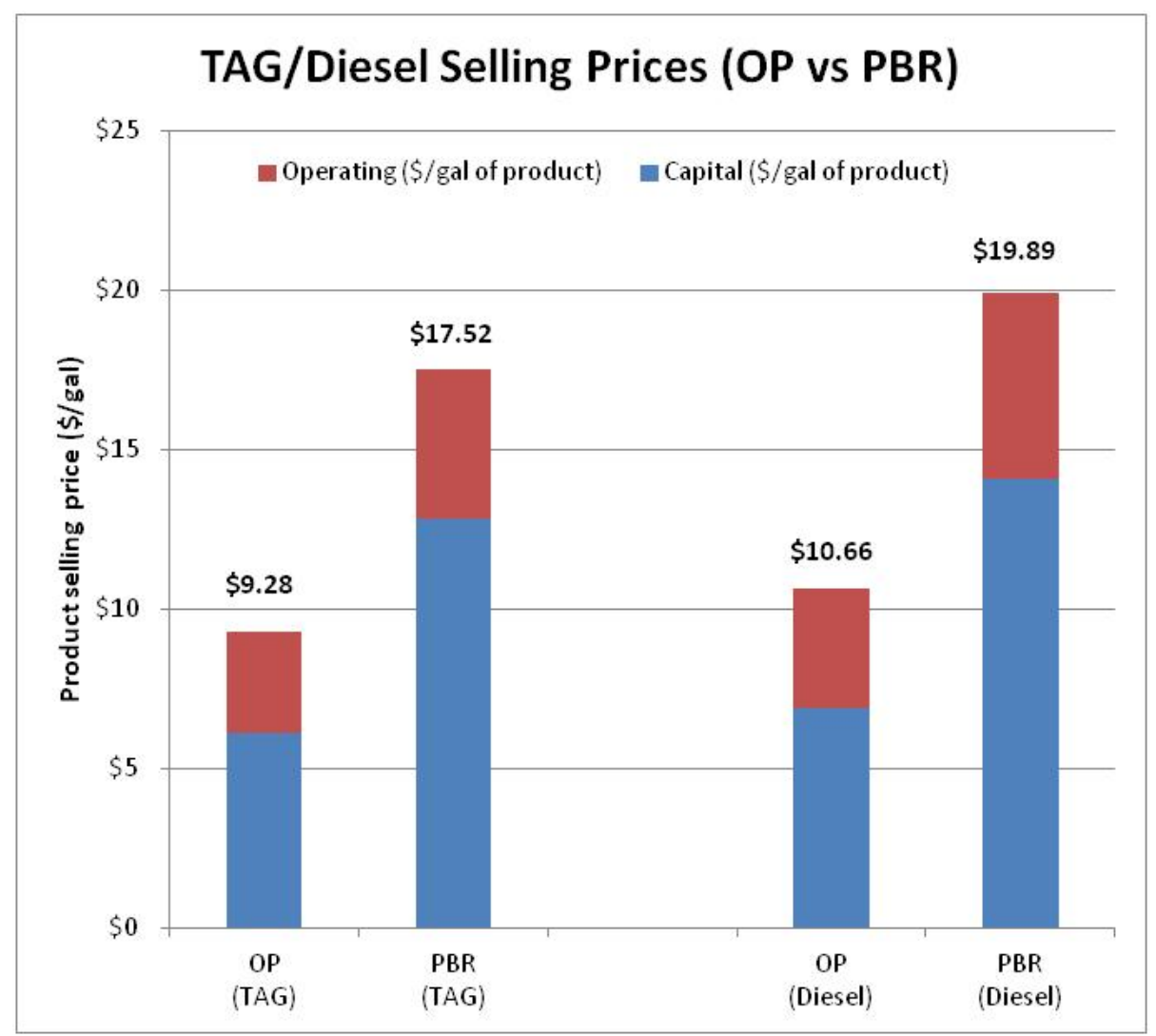

Figure B.6: FY 2011 TEA baseline economics for TAG and diesel production. (OP = open ponds, $\mathrm{PBR}=$ photobioreactors)

In addition to the baseline economic evaluation, a sensitivity analysis was also conducted to understand the largest cost drivers by which to improve economics through targeted $\mathrm{R} \& \mathrm{D}$, as well as to quantify uncertainties in the model. The latter point is particularly important in the context of algal biofuel modeling, which intrinsically carries a high degree of uncertainty in process scale-up due to the nascent stage of the industry. The sensitivity analysis was conducted by establishing tornado plots, in which single input parameters are individually varied across a reasonable range of values. The resulting plot for the open pond pathway is presented below. 


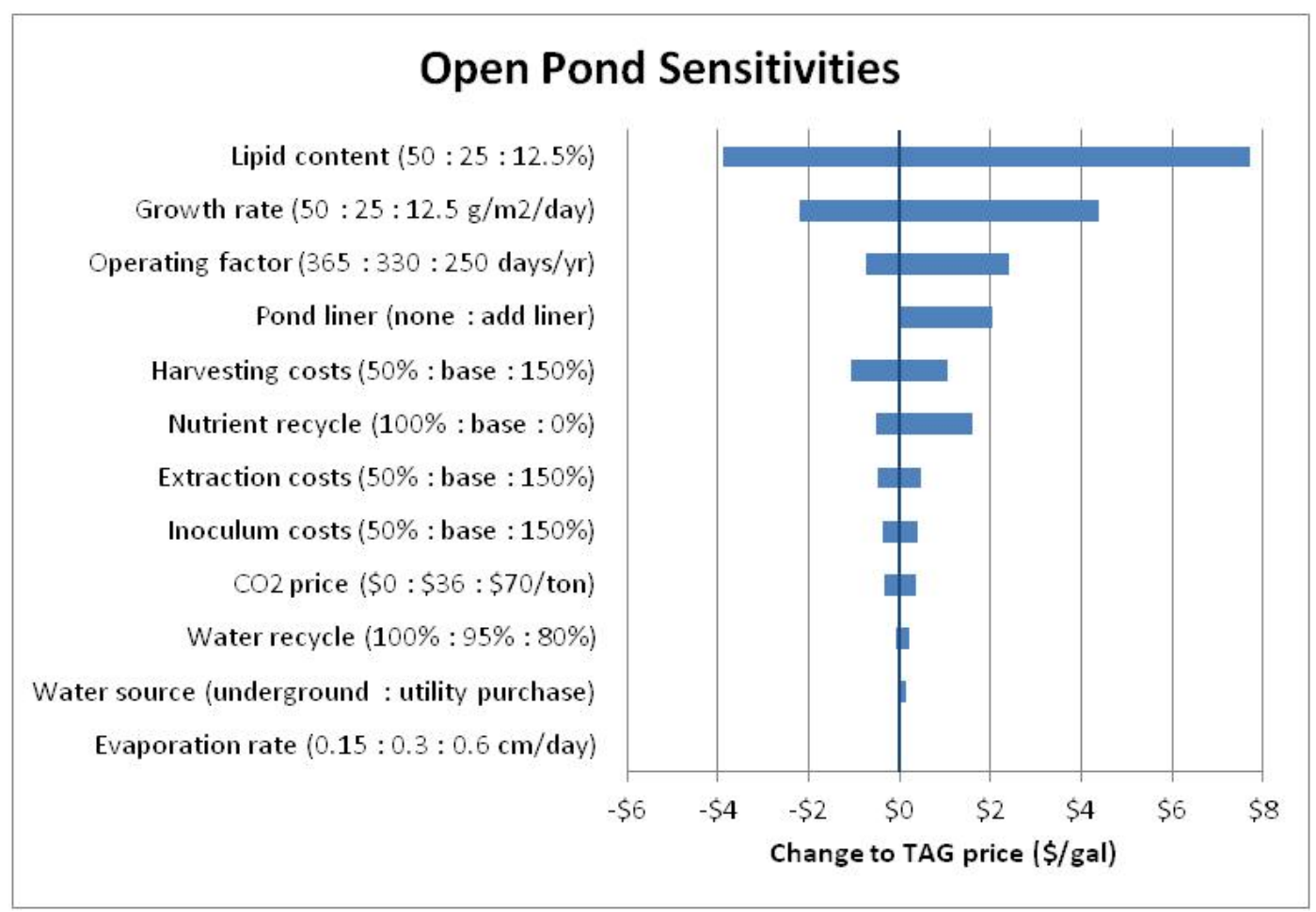

Figure B.7: FY 2011 TEA sensitivity analysis; baseline MSP = \$9.28/gal TAG.

As shown in Figure B.7, the largest cost sensitivities in the FY 2011 TEA model were found to be the algal lipid content and growth rate. Specifically, it was found that a step change in the lipid content results in nearly twice as large of a cost impact as a similar step change in growth rate; this is an important result, given that there is typically a tradeoff between these two parameters making it more economically beneficial in targeting improvements to the lipid content from an R\&D standpoint. Alternatively, even small changes to the lipid content or the growth rate can have very large economic impacts; it is critical to accurately portray these parameters based on real, achievable, and sustainable data under today's state of technology in order to project a reasonable economic baseline. A major goal of the Harmonization Workshop was for the three labs to harmonize the algal productivity parameters and to get buy-in from DOE stakeholders on the harmonized assumptions. Another important sensitivity result to emphasize is the assumption regarding pond liners. While the assumption thus far in the TEA task has been that liners are not required (for example, due to high clay content of the local soil), cursory analysis suggested that adding a liner could increase costs by at least $\$ 2 /$ gal relative to the FY 2011 baseline. Thus, this is an important assumption that will likely be location-specific. The remaining parameters in Figure B.7 are self-explanatory and mostly related to engineering considerations, but it should be noted that several improvements in such parameters could combine into additional significant cost savings.

\section{B.3 LCA}

LCA analysis was performed to determine the net energy consumption and total GHG emissions incurred when producing fuel from algal lipids. LCA quantifies the potential benefits of algal biofuels, compared to petroleum and other transportation fuels, by accounting for operations 
during all stages of fuel production including upstream operations to provide nutrients, other materials, and process fuels. Since algal biofuel production is a nascent technology, the LCA sought to determine key parameters affecting total energy consumption and GHG emissions.

The LCA was conducted using GREET, a model developed at Argonne National Laboratory with support from DOE EERE. It is a publicly available LCA tool with more than 15,000 registered users designed to investigate numerous fuel and vehicle cycles (see Wang 1999a and b and the GREET website at http:/greet.es.anl.gov/main). In the GREET model suite, the fuelcycle model for transportation fuels considers the operations involved in producing and using fuels, while the vehicle-cycle model considers operations involved in manufacturing and decommissioning vehicles, including recycling. GREET is used to compute fossil, petroleum, and total energy use (including renewable energy in biomass), emissions of $\mathrm{GHG}\left(\mathrm{CO}_{2}, \mathrm{CH}_{4}\right.$, and $\mathrm{N}_{2} \mathrm{O}$ ), and emissions of six criteria pollutants: carbon monoxide $(\mathrm{CO})$, volatile organic compounds (VOCs), mono-nitrogen oxides $\left(\mathrm{NO}_{\mathrm{x}}\right)$, sulfur oxides $\left(\mathrm{SO}_{\mathrm{x}}\right)$, particulate matter with a diameter no larger than 10 micrometers $\left(\mathrm{PM}_{10}\right)$, and particulate matter with a diameter no larger than 2.5 micrometers $\left(\mathrm{PM}_{2.5}\right)$.

GREET contains many vehicle/fuel systems. Fuel types include gasoline, diesel, biofuels, hydrogen, natural-gas-based fuels, and electricity. Vehicle technologies include gasoline engines, diesel engines, hybrid electric vehicles with gasoline and diesel engines, plug-in hybrid electric vehicles with gasoline and diesel engines, battery-powered electric vehicles, and fuel cell vehicles. Because of the wide array of fuels and vehicles analyzed under a shared methodological umbrella, shared upstream and downstream emissions, and shared co-product models, GREET provides a framework for consistently examining and comparing life-cycle energy use and emissions of many vehicle/fuel systems.

A detailed report describing the analysis and model (Frank et al., 2011a) is briefly summarized here. The analysis considered operations within the system boundary shown in Figure B.8. Landuse change and infrastructure materials for constructing the facility were not considered. Figure B.9 shows the algae growth and lipid production operations including operations that recover energy and nutrients from the LEA residuals that remain after lipid extraction. Details are further explained in Frank et al., 2011a and in the harmonization discussion, Section 2.2.

There were several main results from this study. The process, as modeled, was energy intensive and required additional electrical power to be imported even after recovering energy from the LEA. The baseline scenario produced 55,400 $\mathrm{gCO}_{2} \mathrm{e} / \mathrm{MMBTU}$ of biodiesel, while a comparable system boundary for LS diesel produced 101,000 $\mathrm{gCO}_{2} \mathrm{e} / \mathrm{MMBTU}$. Although algal BD required less net fossil fuel than LS diesel, it required more fossil fuel during the production stage and when considered on an energy basis, compared to other biofuels. 


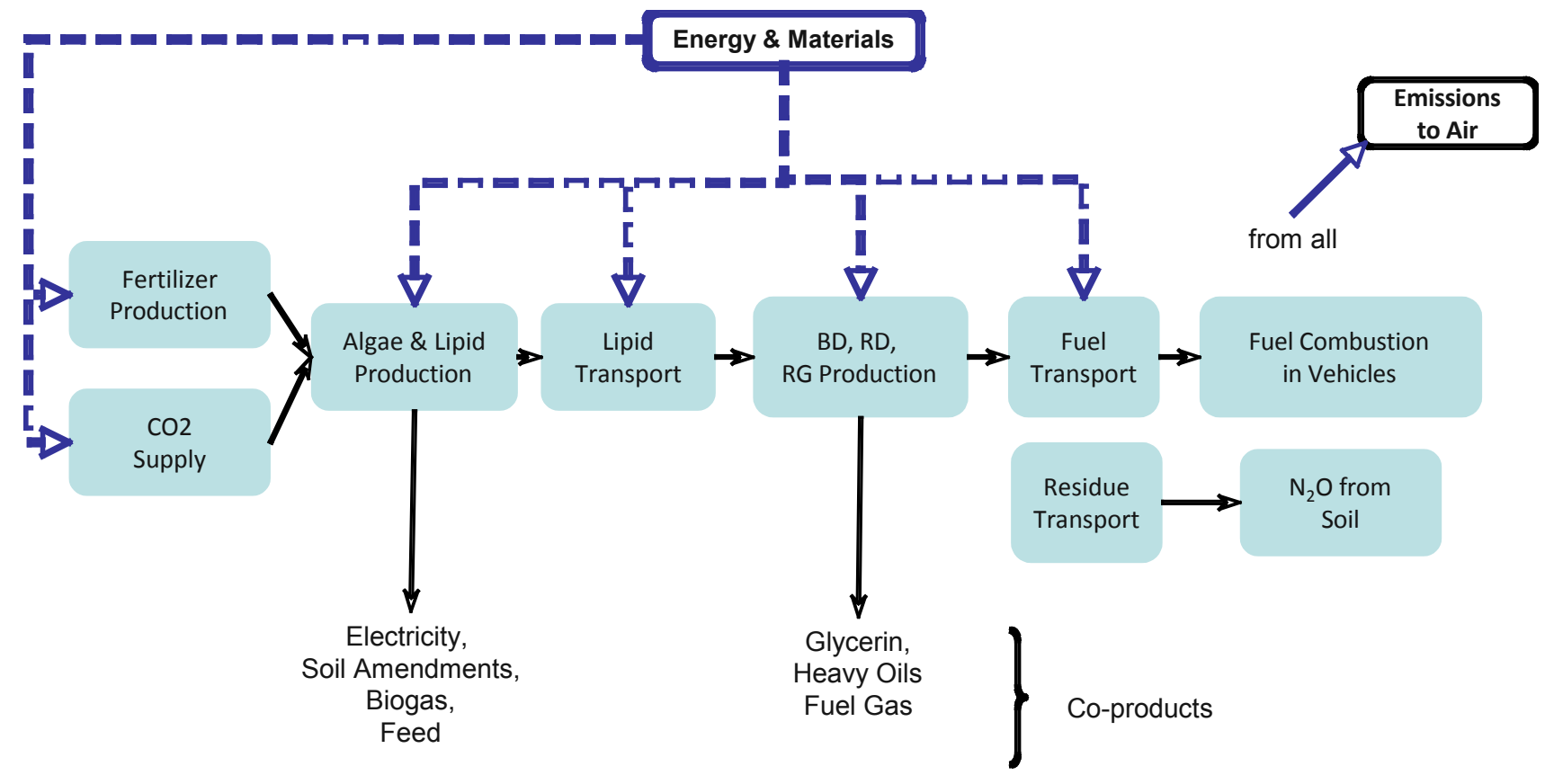

Figure B.8: System boundary defining the LCA.

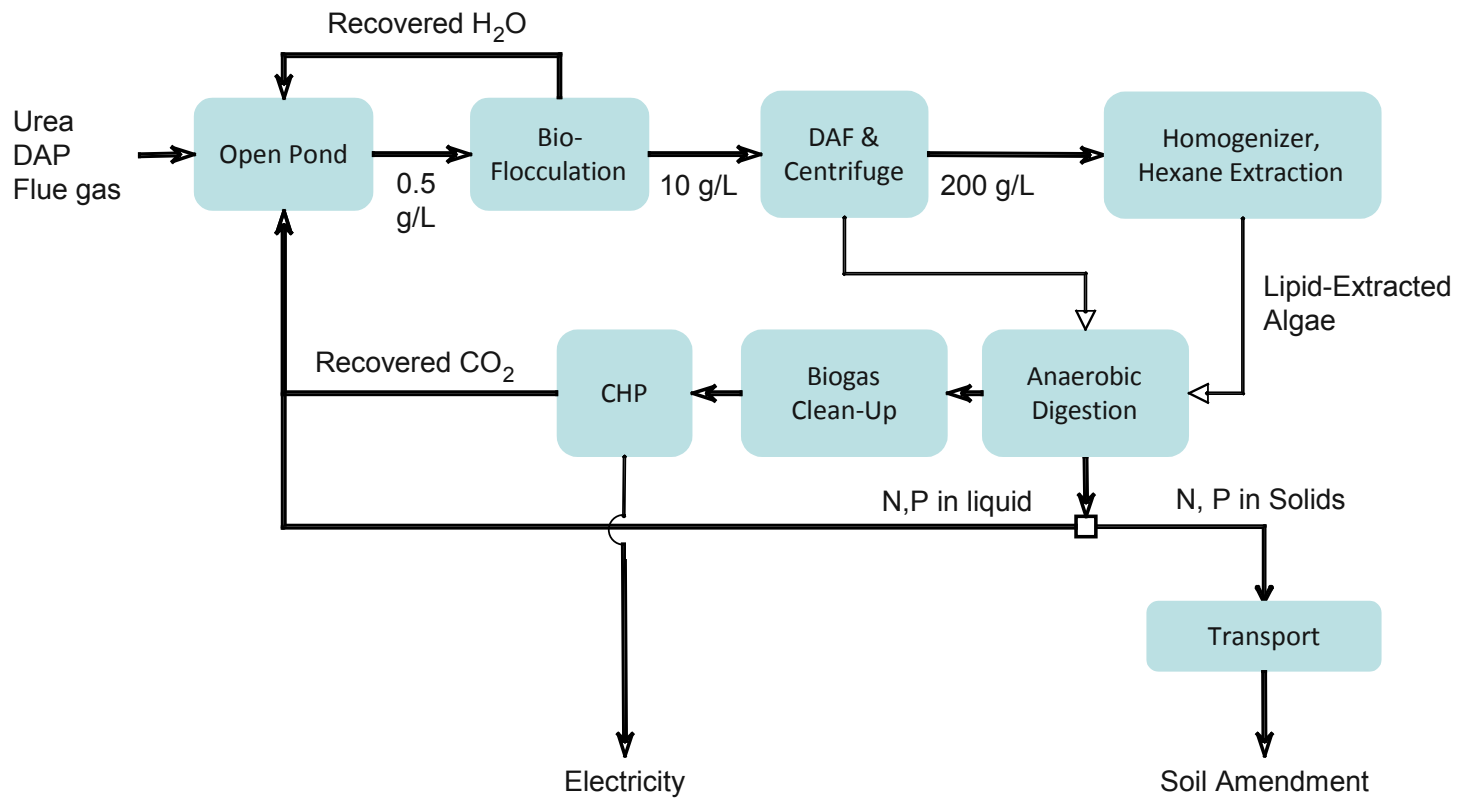

Figure B.9: Schematic of the algae and lipid production model.

The largest uncertainties in the energy recovery model related to the digestibility and methane yield from LEA for which there were few data. Similarly, nutrient recovery was poorly understood both in terms of the recovery rates for nitrogen and phosphorus, as well as whether recovered forms would in fact be useable. In particular, it was merely assumed that the anaerobic 
digester supernatant in which the recovered nitrogen is mineralized would be tolerated by a stable algal culture.

Even though the energy recovery from the LEA failed to meet the net power demand on site, it is still nevertheless a critical step and satisfied $75 \%$ of on-site electrical demand and $100 \%$ of the on-site heat demand. Unfortunately, the biogas production process carried substantial potential for GHG emissions. These emissions were derived from fugitive methane emissions during biogas production and digestate handling plus $\mathrm{N}_{2} \mathrm{O}$ emissions when digestate was applied in fields to displace agricultural fossil-fuel based fertilizers. The fugitive $\mathrm{CH}_{4}$ and direct $\mathrm{N}_{2} \mathrm{O}$ emissions made up $36 \%$ of the total GHG burden for the pathway $\left(23 \%\right.$ from $\mathrm{CH}_{4}$ and $13 \%$ from $\mathrm{N}_{2} \mathrm{O}$ ).

A sensitivity analysis (Figure B.10) showed that, within the production model, lipid fraction, water movement (including pond mixing and culture movement on-site), and power generation parameters (including AD yields and CHP performance) were significant sources of uncertainty. Similarly, the poorly defined lipid extraction process was affecting the results significantly. Note, though, that in Figure 6, the parameters are not compared with equal confidence intervals, because no statistical distributions for the various parameters are known. Some parameters, like dewatering energy, are uncertain because the process is poorly specified at this early time, and others, like lipid fraction and productivity, are uncertain both because the performance is evolving and because there will be an inherent stochastic behavior arising from site-to-site and day-to-day variations in performance intrinsic to the process.

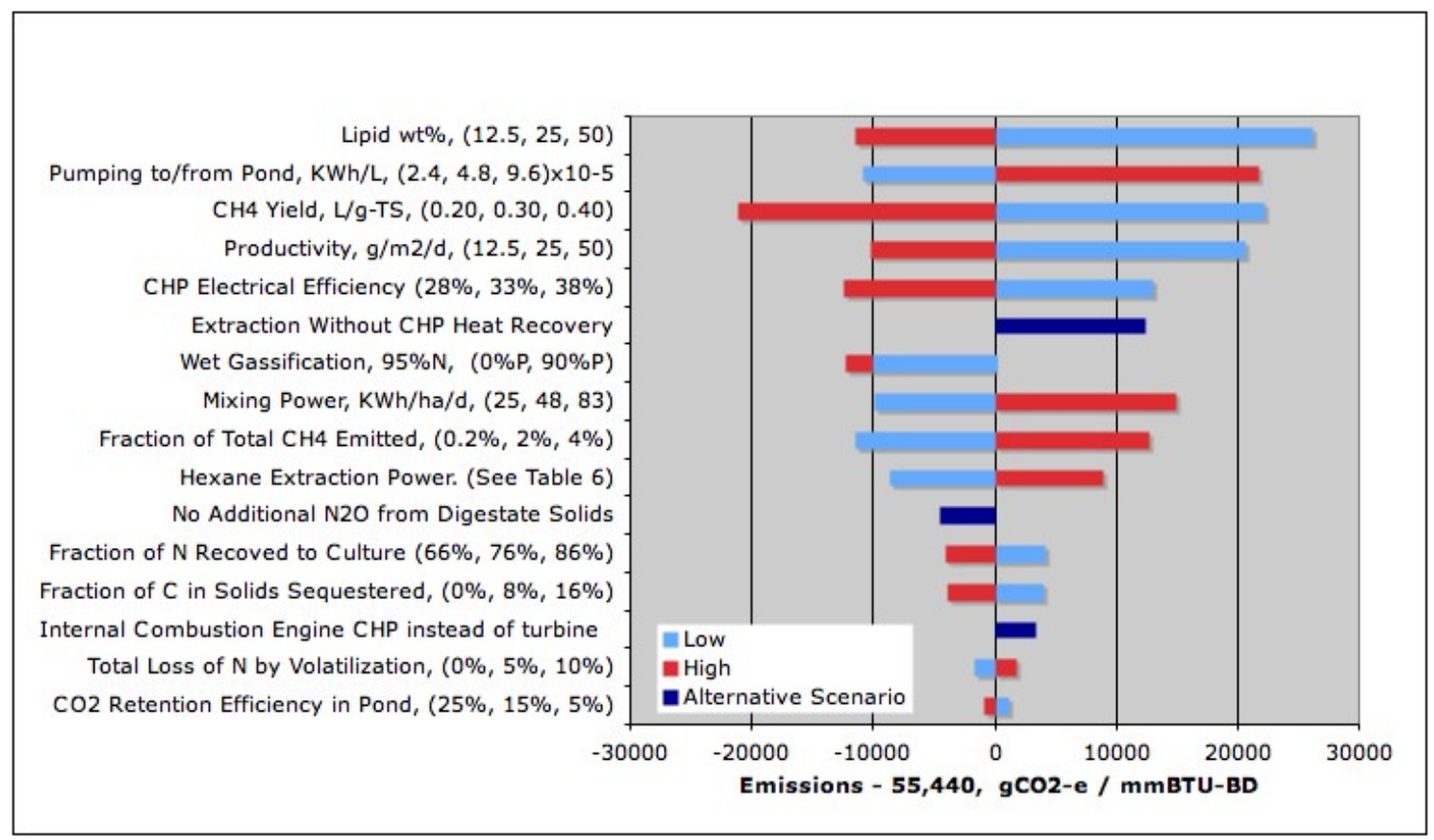

Figure B.10: LCA sensitivity analysis. 
Appendix C: TEA Cost Details for Harmonized Model (5BGY, year-average case)

\section{Appendix C: TEA Cost Details for Harmonized Model (5BGY, year- average case)}

Algal Oil Production

(10.4 MGY oil output)

\begin{tabular}{|lr|}
\hline DIRECT CAPITAL COSTS & Cost (\$MM) \\
\hline Component & $\$ 138.6$ \\
\hline Ponds + paddle wheels & $\$ 205.2$ \\
\hline Pond liners & $\$ 38.7$ \\
\hline Flue gas delivery+distribution & $\$ 3.7$ \\
\hline Water delivery+distribution & $\$ 47.0$ \\
\hline Primary harvesting (settling) & $\$ 1.7$ \\
\hline Secondary harvesting (DAF) & $\$ 4.4$ \\
\hline Tertiary harvesting (centrifuge) & $\$ 14.1$ \\
\hline Cell rupturing & $\$ 4.2$ \\
\hline $\begin{array}{l}\text { Solvent extraction (LLE column, } \\
\text { centrifuge, solvent stripper) }\end{array}$ & $\$ 35.9$ \\
\hline Land Costs & $\$ 14.0$ \\
\hline Anaerobic Digestion & $\$ 6.2$ \\
\hline Gen-Set & $\$ 50.2$ \\
\hline Inoculum production system & $\$ 1.0$ \\
\hline Steam boiler & $\$ 13.2$ \\
\hline Water pumps & $\$ 0.0$ \\
\hline Initial Water Charge & $\$ 542.3$ \\
\hline $\begin{array}{l}\text { TOTAL INSTALLED } \\
\text { DEPRECIABLE CAPITAL }\end{array}$ & $\$ 35.9$ \\
\hline $\begin{array}{l}\text { TOTAL INSTALLED NON- } \\
\text { DEPRECIABLE CAPITAL }\end{array}$ & $\$ 578.2$ \\
\hline TOTAL INSTALLED CAPITAL & \\
\hline
\end{tabular}

\begin{tabular}{|lr|}
\hline INDIRECT CAPITAL COSTS & \\
Component & Cost $\mathbf{( \$ M M )}$ \\
\hline Site Development & $\$ 12.9$ \\
\hline Warehouse & $\$ 4.9$ \\
\hline TOTAL DIRECT COSTS & $\$ 560.0$ \\
\hline Pro-rateable Costs & $\$ 56.0$ \\
\hline Field Expenses & $\$ 56.0$ \\
\hline Home Office and Construction & $\$ 56.0$ \\
\hline Contingency & $\$ 112.0$ \\
\hline Other Costs & $\$ 28.0$ \\
\hline TOTAL INDIRECT COSTS & $\$ 308.0$ \\
\hline & \\
\hline & $\mathbf{2}$ \\
\hline WIXED CAPITAL INVESTMENT & $\$ 43.4$ \\
\hline & \\
\hline TOTAL CAPITAL INVESTMENT \\
\hline
\end{tabular}

RD Production

(41.6 MGY oil feed, 38.7 MGY RD output)

\begin{tabular}{|lr|}
\hline DIRECT CAPITAL COSTS & Cost (\$MM) \\
\hline Component (1) & $\$ 2,169.1$ \\
\hline Direct depreciable capex (raw oil) & $\$ 143.7$ \\
\hline Direct non-depreciable capex (raw oil) & $\$ 23.9$ \\
\hline Diesel hydrotreating plant & \\
& \\
& \\
& \\
& \\
& \\
\hline $\begin{array}{l}\text { TOTAL INSTALLED } \\
\text { DEPRECIABLE CAPITAL }\end{array}$ & \\
\hline $\begin{array}{l}\text { TOTAL INSTALLED NON- } \\
\text { DEPRECIABLE CAPITAL }\end{array}$ & \\
\hline TOTAL INSTALLED CAPITAL & $\$ 143.7$ \\
\hline
\end{tabular}

\begin{tabular}{|lr|}
\hline INDIRECT CAPITAL COSTS & Cost (\$MM) \\
\hline Component (1) & $\$ 53.6$ \\
\hline Site Development & $\$ 19.7$ \\
\hline Warehouse & $\$ 2,266.2$ \\
\hline TOTAL DIRECT COSTS & $\$ 226.6$ \\
\hline Pro-rateable Costs & $\$ 226.6$ \\
\hline Field Expenses & $\$ 226.6$ \\
\hline Home Office and Construction & $\$ 453.2$ \\
\hline Contingency & $\$ 113.3$ \\
\hline Other Costs & $\$ 1,246.4$ \\
\hline TOTAL INDIRECT COSTS \\
\hline \\
\hline FIXED CAPITAL INVESTMENT \\
\hline Working Capital & $\$ \mathbf{3 , 5 1 2 . 7}$ \\
\hline & $\$ 175.6$ \\
\hline TOTAL CAPITAL INVESTMENT & $\$ 3,832.0$ \\
\hline
\end{tabular}

(1) Note, RD production assumes a ratio of 4 algal oil facilities (10.4 MGY oil production each) to one RD facility (41.6 MGY oil feed = 38.7 MGY RD output); thus includes 4x multiple on all "raw oil" costs 
Appendix C: TEA Cost Details for Harmonized Model (5BGY, year-average case)

Algal Oil Production (10.4 MGY oil output)

\begin{tabular}{|lr|}
\hline OPERATING COSTS & $\begin{array}{r}\text { Cost } \\
\text { Component }\end{array}$ \\
\hline Powmer & $\$ 5.5$ \\
\hline Nutrients (N,P) & $\$ 4.8$ \\
\hline Flocculant & $\$ 8.3$ \\
\hline Solvent (extraction) & $\$ 1.9$ \\
\hline Waste disposal & $\$ 0.0$ \\
\hline Utilities (cooling water, steam) & $\$ 0.0$ \\
\hline Labor and overhead & $\$ 8.2$ \\
\hline Maintenance, tax, insurance & $\$ 19.2$ \\
\hline GROSS OPERATING COSTS & $\$ 47.8$ \\
\hline AD sludge (fertilizer co-product credit) & $(\$ 0.5)$ \\
\hline NET OPERATING COSTS & $\$ 47.3$ \\
\hline
\end{tabular}

RD Production

(41.6 MGY oil feed, 38.7 MGY RD output)

\begin{tabular}{|lr|}
\hline OPERATING COSTS & $\begin{array}{r}\text { Cost } \\
\text { Component (1) }\end{array}$ \\
\hline GMM/year)
\end{tabular} \mid $\begin{array}{r}\$ 191.3 \\
\hline \text { Hydrogen }\end{array}$

(1) Note, RD production assumes a ratio of 4 algal oil facilities (10.4 MGY oil production each) to one RD facility (41.6 MGY oil feed $=38.7$ MGY RD output); thus includes $4 x$ multiple on all "raw oil" costs 


\section{References}

Algal Biomass Organization (2011). "Plenary session: an update on the global consortia." Presented at the 2011 Algae Biomass Summit (ABS), October 26, 2011.

Benemann, J.R., and W.J. Oswald, 1996, Systems and Economic Analysis of Microalgae Ponds for Conversion of $\mathrm{CO} 2$ to Biomass, Final Report, Pittsburgh Energy Technology Center.

Borjesson, P. and M. Berglund (2006). "Environmental systems analysis of biogas systems--Part I: Fuel-cycle emissions." Biomass and Bioenergy 30(5): 469-485. Campbell, P. K., T. Beer, et al. (2009).

Campbell, P.K., et al., 2009, Greenhouse Gas Sequestration by Algae-Energy and Greenhouse Gas Life-Cycle Studies.

Carlsson, A. et al. (2007). "Micro- and Macro-Algae: Utility for Industrial Applications." Outputs from the EPOBIO Project, ISBN 978-1-872691-29-9

Clarens, A.F., Resurreccion, E.P., et al. (2010). "Environmental Life Cycle Comparison of Algae to Other Bioenergy Feedstocks." Environmental Science \& Technology 44: 1813-1819.

Chisti, Y. (2007), Biodiesel from microalgae, Biotechnol. Adv., 25, 294-306, doi:10.1016/j.biotechadv.2007.02.001.

Collet, P., A. Helias, et al. (2011). "Life-cycle assessment of microalgae culture coupled to biogas production." Bioresource Technology 102(1): 207-214.

Davis et al. (2010). "Industrial Ecology 2.0" Journal of Industrial Ecology 14, no. 5: 707-726.

Davis, R., A. Aden, et al. (2011). "Techno-economic analysis of autotrophic microalgae for fuel production." Applied Energy 88(10): 3524-3531.

Demorro, C., 2012, OriginOil Announces It Can Produce Algae Fuel in Existing Oil Refineries. Gas2 webmagazine, website http://gas2.org/2012/01/20/originoil-announces-it-canproduce-algae-fuel-in-existing-oil-refineries $<$ last accessed 3/14/2012 $>$

DOE, 2010, National algal biofuels technology roadmap, Rep. DOE/EE-0332, Biomass Program, Off. of Energy Efficiency and Renewable Energy, Washington, D. C.

EIA,(2011. EIA electricity prices and fuel price forecasts, retrieved September 2011, from: http://www.eia.doe.gov/cneaf/electricity/epm/table5 3.html and http://www.eia.doe.gov/oiaf/forecasting.html

EIA, 2012a, Petroleum and Other Liquids- Spot Prices, website http://205.254.135.7/dnav/pet/pet_pri_spt_s1_d.htm $<$ last accessed 3/14/2012>

EIA, 2012b, Electricity- Electric Power Monthly, website http://205.254.135.24/electricity/monthly/epm_table_grapher.cfm?t=epmt_5_3 $<$ last accessed 3/14/2012>

EPA, 2008, Catalog of CHP Technologies.

EPA, 2001, National Pollutant Discharge Elimination System: Regulations Addressing Cooling Water Intake Structures for New Facilities website http://www.epa.gov/fedrgstr/EPAWATER/2001/December/Day-18/w28968.htm $<$ last accessed Jan. 31, 2012> 
Frank, E. D., J. Han, et al. (2011a). Life-Cycle Analysis of Algal Lipid Fuels with the GREET Model. ANL/ESD/11-5, Argonne National Laboratory.

Frank, E. D., J. Han, et al. (2011b). User Manual for Algae Life-Cycle Analysis with GREET: Version 0.0. ANL/ESD/11-7, Argonne National Laboratory.

Flesch, T. K., R. L. Desjardins, et al. (2011). "Fugitive methane emissions from an agricultural biodigester." Biomass and Bioenergy 35(9): 3927-3935.

GEA 2012 retrieved 3/18/12 from http://www.nirosoavi.com/fileadmin/GEA_Niro_Soavi/Global/PDFs/Downloads/Literature_on_our_App lications/Biotech/pb_algae.pdf

Genifuel Corporation. "Genifuel Corporation." Retrieved July, 2011, 2011, from http://www.genifuel.com/

Greenwell, H. C., L. M. L. Laurens, et al. (2009). "Placing microalgae on the biofuels priority list: a review of the technological challenges." Journal of The Royal Society Interface 7(46): 703-726.

Griffiths, M., Harrison, S.T.L. (2009). "Lipid productivity as a key characteristic for choosing algal species for biodiesel production." J Appl Phycol 21: 493-507.

Harris, R. W., M. J. Cullinane, Jr., et al. (1982). Process Design and Cost Estimating Algorithms for the Computer Assisted Procedure for Design and Evaluation of Wastewater Treatment Systems (CAPDET). EPA.

Humbird, D. et al. (2011). "Process Design and Economics for Biochemical Conversion of Lignocellulosic Biomass to Ethanol.” NREL Technical Report, http://www.nrel.gov/docs/fy11osti/47764.pdf

Huesemann, M. H., T. S. Hausmann, R. Bartha, M. Aksoy, J. C. Weissman, and J. R. Benemann (2009), Biomass productivities in wild type and a new pigment mutant of Cyclotella sp. (Diatom), Appl. Biochem. Biotechnol., 157, 507-526, doi:10.1007/s12010-008-8298-9.

Kadam, K. L. (2001). Microalgae Production from Power Plant Flue Gas: Environmental Implications on a Life Cycle Basis. NREL/TP-510-29417, National Renewable Energy Laboratory.

Leung, W.W.F. (1998). Industrial Centrifugation Technology. New York, McGraw-Hill.

Liebetrau, J., J. Clemens, et al. (2010). "Methane emissions from biogas-producing facilities within the agricultural sector." Engineering in Life Sciences 10(6): 595-599.

Lundquist, T.J., I.C. Woertz, et al. (2011). “A Realistic Technology and Engineering Assessment of Algae Biofuel Production.” Energy Biosciences Institute, University of California

Mascarelli, A. L. 2009, Gold rush for algae, Nature, 461, 460-461, doi:10.1038/461460a.

Mata, T. M., A. A. Martins, and N. S. Caetano (2010), Microalgae for biodiesel production and other applications: A review, Renew. Sustain. Energy Rev., 14, 217-232, doi:10.1016/j.rser.2009.07.020.

Milledge, J. J. and S. Heaven (2011). "Disc Stack Centrifugation Separation and Cell Disruption of Microalgae: A Technical Note." Environment and Natural Resources Research 1(1): $17-24$. 
Moller, J., A. Boldrin, et al. (2009). "Anaerobic digestion and digestate use: accounting of greenhouse gases and global warming contribution." Waste Management \& Research 27(8): 813-824.

Nagle, N. and P. Lemke (1989). "Microalgal Fuel Production Processes: Analysis of Lipid Extraction and Conversion Methods." Extract from Bollmeier, W. et al., "Aquatic Species Program Annual Report"; http://www.nrel.gov/docs/legosti/old/3579.pdf

NETL, 2010, Carbon Sequestration Atlas of the United States and Canada - Third Edition (Atlas II), National Energy Technology Laboratory $162 \mathrm{pp}$.

Olivares, J.A., Sayre, R., et al. (2011). "NAABB: Algae R\&D activities peer review." Presented at the DOE Algae Program Peer Review, Annapolis, MD, April 7-8, 2011.

Phyco Biosciences (2012). "Phyco Biosciences Super Trough System.” Retrieved 3/15/2012, from http://www.phyco.net/Technology

Sheehan, J., T. J. Dunahay, J. Benemann, and P. Roessler (1998), A look back at the U.S. Dept. of Energy's Aquatic Species Program: Biodiesel from algae, Rep. TP - 580 - 24190, Natl. Renewable Energy Lab., Golden, Colo.

Stone, N. (1999). "Renovating Leaky Ponds.” Report to the Southern Regional Aquaculture Center. Retrieved 1/18/2012, from https://srac.tamu.edu/index.cfm/event/getFactSheet/whichfactsheet/6/

Sun, A., Davis, R., et al. (2011). "Comparative cost analysis of algal oil production for biofuels." Energy 36: 5169-5179.

Tchobanoglous, G., F. L. Burton, et al. (2003). Wastewater engineering : treatment and reuse. Boston, McGraw-Hill.

Uduman, N., Y. Qi, et al. (2010). "Dewatering of microalgal cultures: a major bottleneck to algae-based fuels." Journal of Renewable and Sustainable Energy 2(012701): 1-15.

USDA (1984). "Basic Information on Irrigation Pumping Costs." Retrieved 1/16/12, 2012, from http://www.nm.nrcs.usda.gov/technical/fotg/section-1/irrigation-guide/irrigationpumping-costs.pdf.

USDA (2012). "Fertilizer use and price." Retrieved 1/25/2012, from http://www.ers.usda.gov/Data/FertilizerUse/

Vandamme, D., S.C.V. Pontes, et al. (2011). "Evaluation of Electro-Coagulation-Flocculation for Harvesting Marine and Freshwater Microalgae." Biotechnology and Bioengineering 108: 2320-2329.

Wang, M.Q., 1999a, The Greenhouse Gases, Regulated Emissions, and Energy Use in Transportation (GREET) Model Version 1.5, Argonne National Laboratory, Argonne, Ill., Aug.

Wang, M.Q., 1999b, GREET 1.5-Transportation Fuel-Cycle Model, Volume 1: Methodology, Development, Use, and Results, ANL/ESD-39, Vol. 1, Argonne National Laboratory, Argonne, Ill., Aug

Wang, L. K. (2007). Biosolids treatment processes. Totowa, N.J, Humana. 
Waterwheel Inc. (2012). Retrieved March 15, 2012, 2012, from http://www.youralgaesolution.com/wclient.html

Weyer, K. M., D. R. Bush, A. Darzins, and B. D. Wilson (2010), Theoretical maximum algal oil production, Bioeng. Res., 3, 204-213, doi:10.1007/ s12155-009-9046-X.

Wigmosta, M. S., A. M. Coleman, R. J. Skaggs, M. H. Huesemann, and L. J. Lane, 2011, National microalgae biofuel production potential and resource demand, Water Resour. Res., 47, W00H04, doi:10.1029/2010WR009966

Williams, P. J. 1. B. and L. M. L. Laurens (2010). "Microalgae as biodiesel \& biomass feedstocks: Review \& analysis of the biochemistry, energetics \& economics." Energy \& Environmental Science 3(5): 554-590.

${ }^{\mathrm{i}}$ Figures 2.1a and B.5 reproduced from Davis et al., Techno-economic analysis of autotrophic microalgae for fuel production, Applied Energy, Volume 88, 3524-3531, 2011. Copyright 2011 Elsevier.

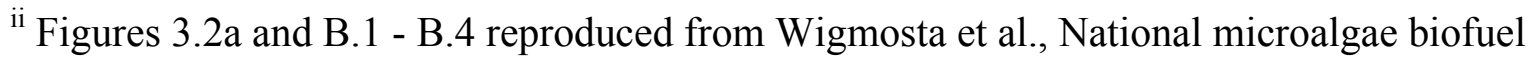
production potential and resource demand, Water Resources Research, Volume 47, W00H04, 2011. Copyright 2011 American Geophysical Union. Reproduced by permission of American Geophysical Union. 